\title{
Modifications of quinolones and fluoroquinolones: hybrid compounds and dual-action molecules
}

\author{
Joanna Fedorowicz ${ }^{1}$ (D) Jarosław Sączewski ${ }^{1}$
}

Received: 1 March 2018 / Accepted: 1 May 2018/Published online: 7 June 2018

(C) The Author(s) 2018

\begin{abstract}
This review is aimed to provide extensive survey of quinolones and fluoroquinolones for a variety of applications ranging from metal complexes and nanoparticle development to hybrid conjugates with therapeutic uses. The review covers the literature from the past 10 years with emphasis placed on new applications and mechanisms of pharmacological action of quinolone derivatives. The following are considered: metal complexes, nanoparticles and nanodrugs, polymers, proteins and peptides, NO donors and analogs, anionic compounds, siderophores, phosphonates, and prodrugs with enhanced lipophilicity, phototherapeutics, fluorescent compounds, triazoles, hybrid drugs, bis-quinolones, and other modifications. This review provides a comprehensive resource, summarizing a broad range of important quinolone applications with great utility as a resource concerning both chemical modifications and also novel hybrid bifunctional therapeutic agents.
\end{abstract}

\section{Graphical abstract}

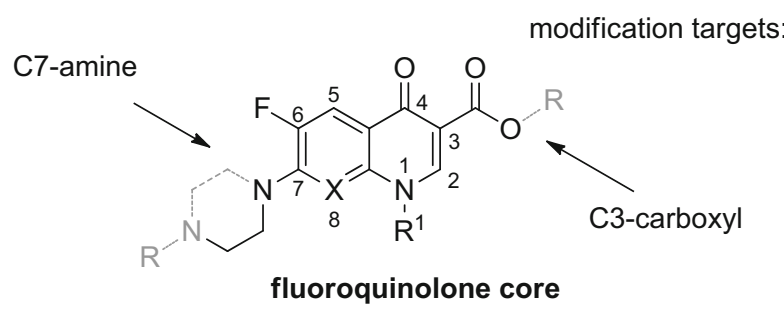

Keywords Antibiotics $\cdot$ Antitumor agents $\cdot$ Antiviral activity $\cdot$ Conjugates $\cdot$ Drug research $\cdot$ Hybrid drugs

\section{Introduction}

Fluoroquinolones (Fig. 1) are broad-spectrum synthetic antibiotics (effective for both Gram-negative and Grampositive bacteria) that play an important role in treatment of serious bacterial infections, especially hospital-acquired infections and others in which resistance to older antibacterial classes is suspected. Since the discovery of nalidixic acid by George Lesher in 1962 [1], over ten thousand analogs

Joanna Fedorowicz

jfedorowicz@gumed.edu.pl

1 Department of Organic Chemistry, Medical University of Gdańsk, Al. Gen. J. Hallera 107, 80-416 Gdańsk, Poland have been synthesized from which four generations of chemotherapeutics with broad spectrum of antibacterial activities have emerged [2]. Fluoroquinolones can enter cells easily via porins and, therefore, are often used to treat intracellular pathogens. Quinolone anti-microbial agents exert their antibacterial action via inhibition of homologous type II topoisomerases, DNA gyrase, and DNA topoisomerase IV [3]. The molecular basis for the quinolone inhibition mechanism has been extensively studied. A crystal structure of moxifloxacin in complex with Acinetobacter baumannii topoisomerase IV shows the wedge-shaped quinolone stacking between base pairs at the DNA cleavage site and binding conserved residues in the DNA cleavage domain through chelation of a noncatalytic magnesium ion [4]. The 
Fig. 1 General structure of fluoroquinolones with atom numeration

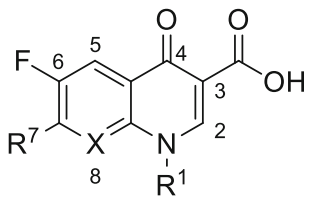

position 7 is considered to be one that directly interacts with DNA gyrase [5-8], or topoisomerase IV. The $\mathrm{R}^{7}$ substituent greatly influences potency, spectrum, and pharmacokinetics. A recent interesting observation is that increased bulkiness of $\mathrm{R}^{7}$ appears to confer protection from the efflux exporter proteins of bacteria, and diminishes the likelihood of bacterial resistance in wild-type bacterial strains [9-11], and increases anti-anaerobic activity.

In recent years, the concept of "dual-action drugs" has been gaining popularity in medicinal chemistry and medicine. Since a single drug is not always able to adequately control the illness, the combination of drugs with different pharmacotherapeutic profile may be needed [12]. Drugs involving the incorporation of two biologically active compounds in a single molecule with the intention of exerting dual drug action have been described [13]. For example, one of the hybrid parts may be incorporated to counterbalance the known side effects associated with the other hybrid part, or to amplify its effects through action on another biological target. In addition, hybrid drugs could be used to avoid fast developing bacterial resistance caused by frequent mutations in bacterial genome.

Interestingly, the fluoroquinolone chemotherapies linked to another antibacterial agent represent the most comprehensively described hybrid compounds. This review deals with the recent literature (2007-2017) concerning custom applications of quinolones and fluoroquinolones, as well as their hybrid conjugates with dual or enhanced action mechanisms.

\section{Metal complexes}

Copper is one of the most important biometals due to its biological role and potential synergetic activity with drugs [14]. $\mathrm{Cu}(\mathrm{II})$ complexes with drugs are much more active in the presence of nitrogen-donor heterocyclic ligands, such as 2,2'-bipyridine, 1,10-phenanthroline, or 2,2'-dipyridylamine [15]. Hernández-Gil and coworkers reported the synthesis of two new ternary complexes of $\mathrm{Cu}$ (II) with ciprofloxacin and 1,10-phenanthroline. The aim of the study was to obtain artificial nucleases capable of cleaving DNA chains. The nucleolytic activity of copper complexes with nitrogendonor heterocyclic ligand was revealed in the presence of $\mathrm{H}_{2} \mathrm{O}_{2}$ and reducing agents [16]. The chemical nuclease activity tests were performed in the presence of ascorbate and have shown that both complexes are efficient in DNA breaking. Mechanistic studies with various radical oxygen scavengers were undertaken and revealed that the cleavage reaction is mediated by hydroxyl radicals, superoxide anion, and singlet oxygen [17].

Chalkidou and coworkers designed a series of $\mathrm{Cu}(\mathrm{II})$ complexes with another quinolone antibiotic-flumequine. This synthetic drug belongs to the first generation of quinolones and is chiral. The complexes were prepared in the absence or the presence of the nitrogen-donor heterocyclic ligands: 2,2'-bipyridylamine (1), 2,2'-bipyridine, pyridine, or 1,10-phenanthroline (Fig. 2). In the resultant complexes, flumequine behaved as a deprotonated bidentate ligand being coordinated to copper via the pyridine oxygen and one carboxylate oxygen. All novel complexes showed higher affinity to bovine and human serum albumin (proteins involved in the transport of metal ions and metal-drug complexes through the blood stream) than free flumequine. Furthermore, the complexes exhibited similar or higher binding constants to calf-thymus DNA than free quinolone with the highest value for the complex with pyridine ligand. The mechanism of DNA binding probably involves intercalation, as inferred on the basis of hypochromic effect observed with UV spectroscopy [18].

Complexes of copper(I) iodide or copper(I) thiocyanate and phosphine derivative of sparfloxacin bearing auxiliary steric hindered diimine ligands (2,9-dimethyl-1,10phenanthroline or 2,2'-biquinoline (2)) were prepared by Komarnicka and coworkers. Phosphine ligand was used to avoid oxidation and hydrolysis reactions by a strong copper-phosphine interaction. The conjugates obtained were tested against CT26 (mouse colon carcinoma) and A549 (human lung adenocarcinoma) cancer cell lines. The cytotoxicity of all compounds was found to be significantly increased $\left(\mathrm{IC}_{50} 6.04 \pm 0.3-42.64 \pm 0.73\right)$ in comparison with free sparfloxacin $\left(\mathrm{IC}_{50} 122.84 \pm 4.21-273.50 \pm 10.63\right)$ and extremely higher than cisplatin $\left(\mathrm{IC}_{50} 222.45 \pm 10.78\right.$ $298.12 \pm 13.09)$ [19].

Neutral sparfloxacin-copper complexes were also utilized by Efthimiadou and coworkers. They prepared conjugates bearing ligands such as 2,2'-bipyridine (3), 1,10phenanthroline, or 2,2'-dipyridylamine in high yields $(65-70 \%)$ by the template reaction of equimolar quantities of the deprotonated sparfloxacin, $\mathrm{CuCl}_{2}$, and the corresponding $\mathrm{N}$-donor ligand. The copper atom in obtained conjugates was five-coordinative and had slightly distorted square pyramidal geometry. Sparfloxacin was bound to $\mathrm{Cu}(\mathrm{II})$ via the pyridone and one carboxylate oxygens. The interactions of complexes with calf-thymus DNA showed that the complexes are able to bind DNA by intercalation mode. Antibacterial activity was tested against Escherichia coli, Pseudomonas aeruginosa, and Staphylococcus aureus. The conjugates were found to be more active than the parent drug against E. coli, but less active against 


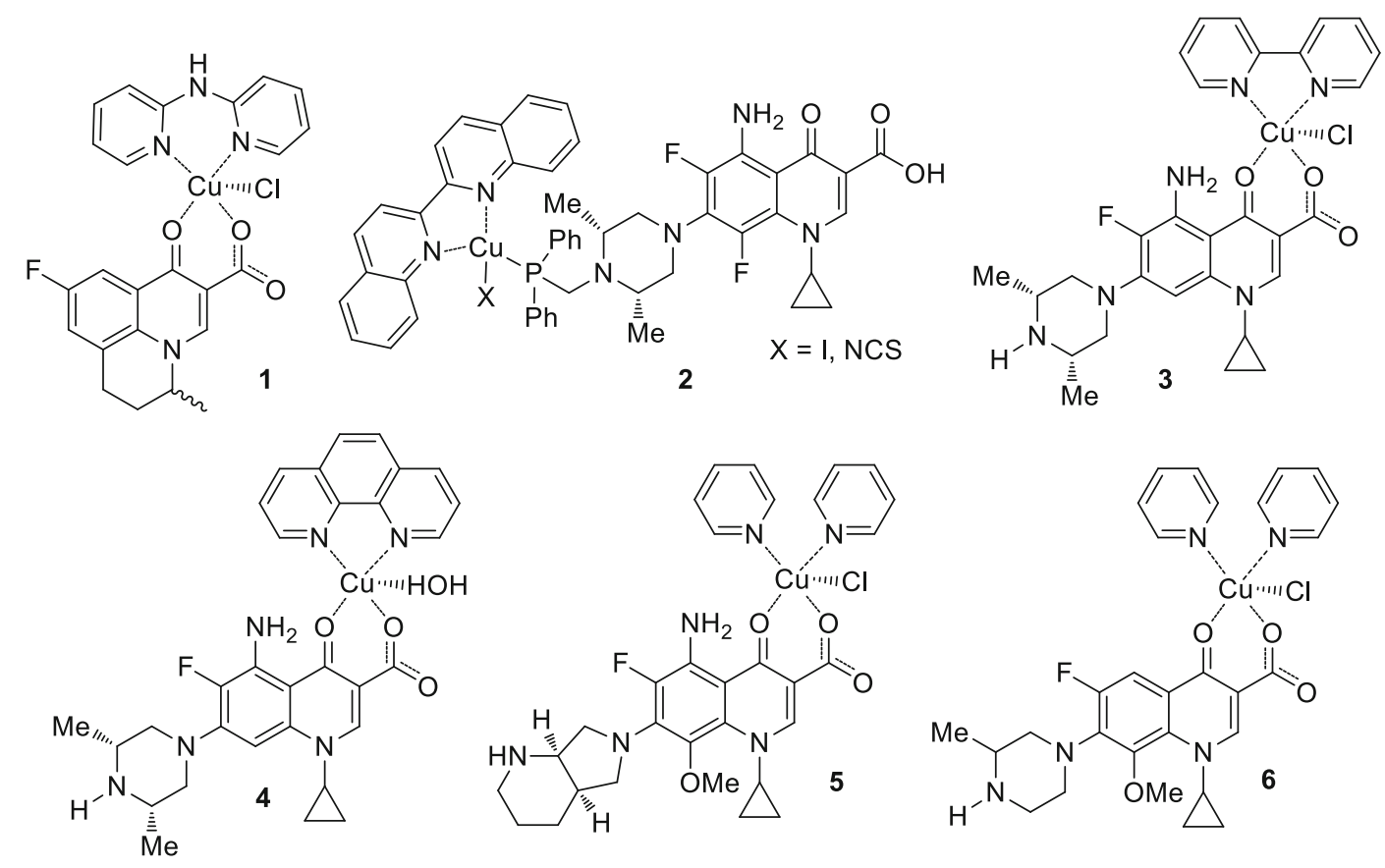

Fig. 2 Structures of flumequine-Cu(II)-2,2'-bipyridylamine (1), sparfloxacin-Cu(I)-2,2'-biquinoline (2), sparfloxacin-Cu(II)-2,2'-bipyridine (3), sparfloxacin-Cu(II)-1,10-phenanthroline (4), moxifloxacin-Cu(II)-bipyridyl (5), and gatifloxacin-Cu(II)-bipyridyl (6) complexes

remaining strains of bacteria with the lowest MIC values obtained for complexes bearing 2,2'-bipyridine and 1,10phenanthroline ligands. These two complexes were tested as potential anticancer agents against human leukemia cell line HL-60 (peripheral blood human promyelocytic leukemia) in MTT assays and showed enhanced cytotoxic properties compared to free sparfloxacin which displayed no cytotoxic effect [20].

Shingnapurkar and coworkers also prepared sparfloxacin-Cu complexes having butterfly motif to expand fluoroquinolone activity on anti-proliferative properties against cancer cells. Fluoroquinolones are able to inhibit DNA topoisomerase in mammalian cells. This enzyme is overexpressed in hormone independent breast cancer cell lines. The complexes of fluoroquinolone and copper alone or with appended ancillary ligands, namely, 2,2'bipyridine, 1,10-phenanthroline (4), and 4,5-diazafluoren-9-one, were synthesized and characterized. The obtained conjugates were tested against BT20 breast cancer cell line II $\alpha$. IC 50 values of novel complexes were four- to tenfold lower than in case of the parent drug indicating that anti-proliferative activity of quinolones may be related to their metal chelating ability. The dimeric compound of sparfloxacin and copper without additional ligands was the most potent molecule in the series [21].

Another research group synthesized moxifloxacin-copper complexes showing antitumor activity against breast cancer cells. They prepared four new conjugates, with or without additional ligands (pyridyl, bipyridyl (5), and phenanthroline), and performed anti-proliferative tests against estrogen-independent MDA-MB-231 and BT-20, as well as hormone-dependent MCF-7 and T47D cancer cell lines. All the conjugates were able to induce activity of caspases-3/7 and apoptosis in breast cancer cells with no toxic effect on MCF-10A, normal breast epithelial cell line. Moxifloxacin alone did not exhibit any anti-proliferative or apoptosis-inducing properties against any of the cell lines examined; however, when complexed with copper, it exhibited divergent cancer cell-specific activity with the strongest effect for phenanthroline adduct [22].

Complexes of copper and moxifloxacin or gatifloxacin bearing bipyridyl or phenanthroline ligands were also prepared by Singh and coworkers and tested in human lung carcinoma cells A-549. The highest cytotoxic activity exhibited complex 6 [gatifloxacin-Cu(II)-bipyridyl]. DNA fragmentation, cell shrinkage, transformation of cells into small membrane-bound vesicles or apoptotic bodies were observed in treated cells. Late apoptosis was perhaps induced by chromatin condensation. The metal complexes enhanced the apoptotic effect of the parent quinolone drugs, which may be useful for designing more effective drugs against lung cancer [23].

Technetium- $99 \mathrm{~m}$ is a radionuclide which serves as imaging agent because of its high biological stability [24], while rhenium is its non-radioactive analog possessing cytotoxic properties in some complexes [25]. Kydonaki and coworkers synthesized tricarbonyl complexes of $\operatorname{Re}(\mathrm{I})$ and ${ }^{99 \mathrm{~m}} \mathrm{Tc}$ with oxolinic acid or enrofloxacin in the 
Scheme 1



presence of methanol (7a), triphenylphosphine (7b), or imidazole (7c) as coligands (Scheme 1). The resultant conjugates were neutral, air-stable, and DMSO-soluble, but insoluble in water and most organic solvents. The deprotonated quinolone ligands were bound bidentately to $\operatorname{Re}(\mathrm{I})$ ion through the pyridone oxygen and one carboxylate oxygen. Interaction with calf-thymus DNA was investigated by UV spectroscopy and affinity to bovine and human serum albumin was evaluated by fluorescence emission spectroscopy. Mode of interaction with nucleic acids was identified as intercalation and the highest DNAbinding constant was achieved for Re-enrofloxacinmethanol complex 7a. The affinity to bovine and human serum albumin was similar or higher than that of free quinolones. Topoisomerase II $\alpha$ inhibition experiments revealed that Re-enrofloxacin-imidazole complex displays ability to inhibit the enzyme at the concentration of $100 \mu \mathrm{M}$. This result suggests that metal coordination has a considerable impact on the activity of quinolones. The radiotracer complex of technetium, enrofloxacin, and imidazole was investigated in cellular uptake and biodistribution studies. The complex was able to enter K-562 human erythroleukemia cells and had been distributed in cellular compartments such as nuclei, mitochondria, and cytosol, with the highest accumulation in mitochondria. Notably, fast clearance from blood and muscle was observed after injection of the tracer conjugate in healthy mice, which indicate suitable pharmacokinetic profile for further evaluation as imaging agent [26].

\section{Nanoparticles and nanodrugs}

Biopolymer encapsulation of drug to form micro- and nanoparticles can be used as a drug delivery tool to change bioavailability, modify pharmacokinetics, target the drug, and redirect the antibiotic to tissues or organs, where infection occurs. Fluoroquinolones exhibit high affinity for binding $\mathrm{Mg}^{2+}$, which causes a depletion of the ion in bones and articular cartilage. The concentration of ofloxacin (fluoroquinolone widely used in hospitals) in the articular cartilage is three times higher than the corresponding concentration in plasma [27]. Lee and coworkers formed microparticles of albumin and hypromellose acetate succinate (HPMCAS) containing ofloxacin achieved by the spray dry method. Albumin was chosen, because it is biocompatible, biodegradable, and non-toxic natural protein component of blood [28]. HPMCAS is a hydrophilic cellulose derivative bearing succinyl groups and acts as entering coating agent. The obtained particles' morphology was spherical with a smooth surface. Particle size $(0.1-7 \mu \mathrm{m})$ depended on ofloxacin concentration. Ofloxacin nanospheres were administrated to $\mathrm{BALB} / \mathrm{c}$ mice and good distribution was maintained. The release of ofloxacin was more sustained than ofloxacin in solution in all organs tested (spleen, brain, liver, and lung). This particle formulation is more favorable for treatment of diseases that affect the liver and brain, because the release from the particles was extended there by 24 and $48 \mathrm{~h}$, respectively, and dosing regimens would be improved by less frequent dosing [29].

A different approach was used by Marslin and coworkers [30]. They used nanoparticles made of two different polymers, namely, poly(D,L-lactic-co-glycolic acid (PLGA) and methoxy poly(ethylene glycol)-bpoly(lactic-co-glycolic acid) (mPEG-PLGA), to improve the efficiency of ofloxacin delivery at the site of action and inhibition of its extrusion. Since polyethylene glycol (PEG) is commonly used for drug conjugation and has the ability to bind DNA [31] and block drug efflux pump [32], the hypothesis was that mPEG-PLGA will improve antibacterial activity. The copolymer methoxy poly(ethylene glycol)-b-poly(lactic-co-glycolic acid) (mPEG-PLGA) was prepared by ring-opening polymerization of PLGA and mPEG in the presence of stannous octanoate as a catalyst. Ofloxacin encapsulated mPEG-PLGA and PLGA nanoparticles wa prepared by the emulsion solvent evaporation method. The nanoparticles exhibited a smooth 
spherical shape and were heterogeneous in their size; no aggregation or adhesion was observed. The obtained nanoparticles were tested on clinically important human pathogenic strains (E. coli, P. aeruginosa, Proteus vulgaris, Salmonella typhimurium, Klebsiella pneumoniae, and $S$. aureus) and markedly improved bacterial uptake and bacteriocidal activity compared to free ofloxacin. The ofloxacin-mPEG-PLGA nanoparticles displayed higher antibacterial activity, efficient bacterial uptake, sustained release, and strict control of bacterial growth. PEGylation increased bacterial membrane permeability, allowing the accumulation of mPEG-PLGA nanoparticles inside the cells to a greater extent than PLGA nanoparticles. The nanoformulation also delayed the development of bacterial resistance in comparison with the free drug [30].

Pure nanodrugs (PNDs) are forms of carrier-free therapeutic agents, i.e., nanoparticles, which are composed entirely of pure drug molecules [33]. Xie and coworkers designed propeller-shaped ciprofloxacin and norfloxacin PNDs which could form nanosized aggregates. The aim of the study was to obtain compounds that can be used as both therapeutic drugs and imaging agents by aggregation-induced emission (AIE) technique. The emission of AIEactive luminogens is poor in solution and increases upon their aggregation in response to restricted molecular motions. Such nanoaggregates are frequently obtained using propeller-shaped molecules [34]. The drug derivatives were synthesized from fluoroquinolone, perfluoroaryl azide, and an aldehyde in acetone solution (Scheme 2). Compounds $\mathbf{8 a - 8 d}$ and $\mathbf{8 g}$ behaved as AIE-active luminogens showing fluorescent properties with the quantum yield up to $11 \%$ and formed nanoaggregates with the size ranging from 39 to $127 \mathrm{~nm}$. These forms were used as luminescent dots to image bacterial cells and exhibited an increase of antibacterial activity against E. coli, probably due to their higher local concentration or enhanced uptake [35].

\section{Polymers}

Polymer antibiotic conjugates afford lower toxicity, increased solubility, and prolonged activity of the drug, which have extensive applications in many fields, such as food packing or medical items [36]. They show remarkable high activity against the resilient biofilms [37]. Localized delivery methods based on physical stabilization of antibiotics in a polymer matrix such as a hydrogel or selfeluting polymer can release chemotherapeutics at the target region to maintain a high local concentration without exceeding systemic toxicity limits [38].

Gelatin is a water-soluble functional protein obtained by partial hydrolysis of collagen, widely employed in biomedical (tissue engineering) and food science. Especially in pharmaceutical field is commonly used for the preparation of drug delivery system (e.g., capsules, tablets, and emulsions) [39]. Cirillo and coworkers performed synthesis of biomacromolecules based on gelatin with antimicrobial properties of fluoroquinolone-type synthetic antibiotics [40]. Covalent linkage of the antibiotic was carried relatively simple by a radical process without the use of organic solvents, under mild reaction conditions, involving the residues in the side chains of gelatin able to undergo oxidative modifications. Ciprofloxacin, levofloxacin, and lomefloxacin were conjugated to gelatin in the presence of water-soluble redox initiators able to generate free radical species at room temperature under an inert atmosphere (Scheme 3). The synthetic strategy involved application of the ascorbic acid/hydrogen peroxide redox pair as radical initiators. Biocompatibility was tested on hBM-MSCs cell lines and all the samples were found to be non-toxic and well tolerated. No significant reduction in the cell viability was recorded after incubation with the anti-microbial conjugates up to concentration of $2 \mathrm{mg} / \mathrm{cm}^{3}$. Bioactive polymers were investigated against $K$. pneumoniae and E. coli. Biomacromolecules were able to inhibit growth of pathogen species; however, only ciprofloxacin conjugate showed the same minimal inhibitory concentration (MIC) values in comparison with the free drug, while for levofloxacin and lomefloxacin conjugates, lower antibacterial activities were recorded with respect to the corresponding parent drugs [40].

Poly(2-oxazoline)s (POx) are also non-toxic polymers with adjustable hydrophilicity and easily modified endgroups [41]. The antibiotic ciprofloxacin was covalently attached to the chain of poly(2-methyloxazoline) (PMOx), poly(2-ethyloxazoline) (PEtOx), and PEG (Scheme 4) [42]. Anti-microbial activity of the novel conjugates was tested against $S$. aureus, Streptococcus mutans, E. coli, $P$. aeruginosa, and $K$. pneumoniae. The direct coupling of PMOx and ciprofloxacin (compound 9a) resulted in drastically low biological activity. It could be caused by reduced affinity to an enzyme or lowered diffusion ability into the bacterial cell; thus, alternative conjugates having a spacer between antibiotic and the polymer were prepared. The conjugates with spacer (9b) exhibited molar MIC values for some strains (e.g., S. aureus) lower than the pristine drug, while the activity was linearly increasing with shorter PMOx chain lengths. Conjugation of ciprofloxacin and quaternary ammonium compound via PMOx did not result in higher activity. The conjugates prepared with PEtOx as well as PEG (9c) revealed a strong activity dependence of the conjugate type, increasing in the order PEG $>$ PEtOx $>$ PMOx. The hemocompatibility of the prepared polymers was explored and $\mathrm{HC}_{50}$ (hemolytic concentration at with $50 \%$ blood cells is lysed) was 
Scheme 2<smiles>[R]CC(=N[Al])N1CCN(c2cc3c(cc2F)c(=O)c(C(=O)O)cn3[R1])CC1</smiles>

\section{or}

ethyl (norfloxacin)

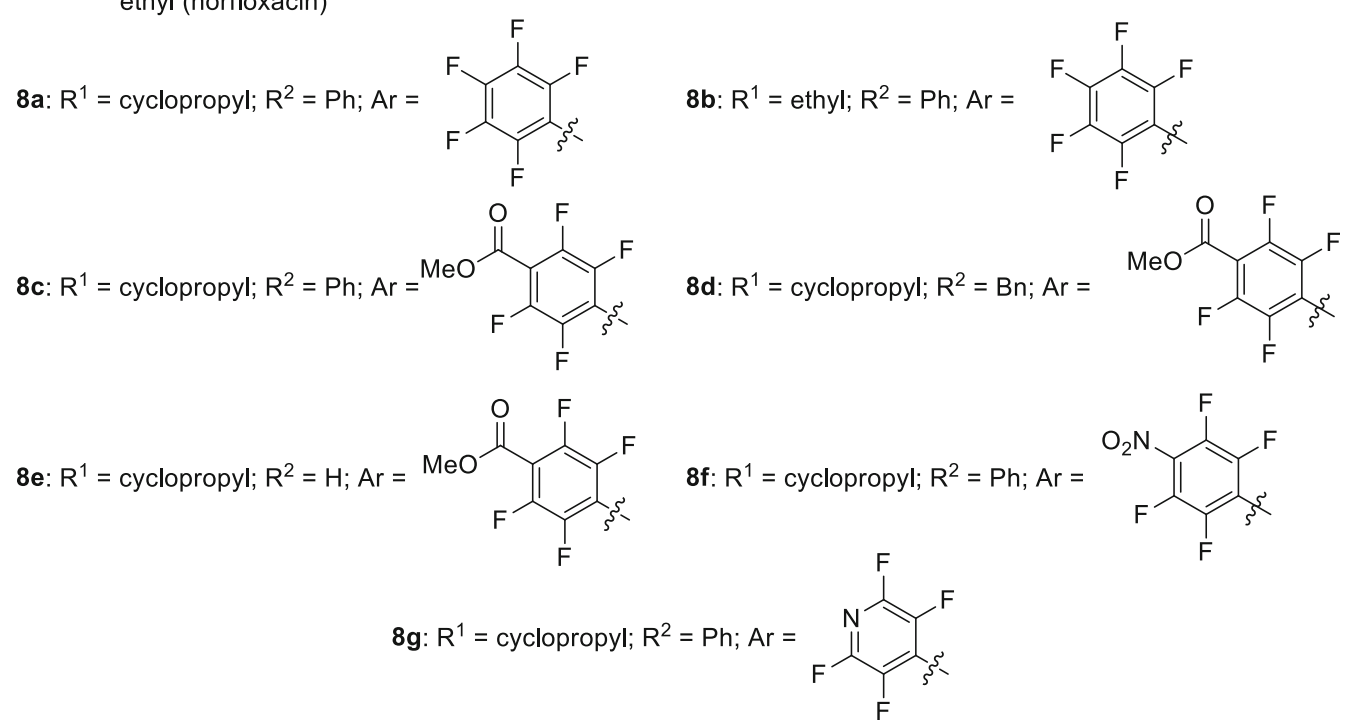

\section{Scheme 3}

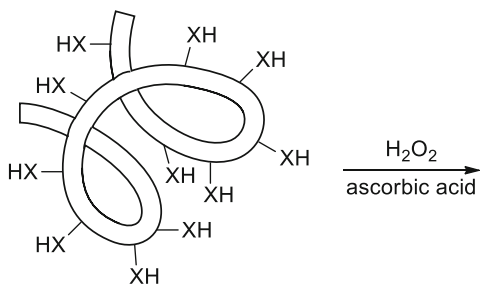

$\mathrm{X}=\mathrm{NH}, \mathrm{O}, \mathrm{S}$

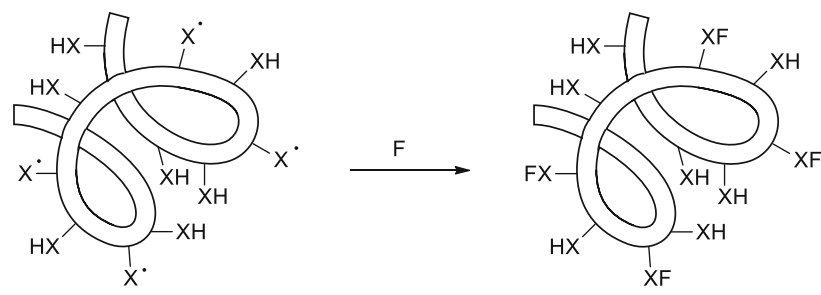

$F=$ ciprofloxacin, levofloxacin, lomefloxacin determined with use of porcine blood cells. All values were above $5000 \mu \mathrm{g} / \mathrm{cm}^{3}$ indicating low hemotoxicity of the conjugates obtained [42].

Polyphosphazenes are hybrid polymers with an inorganic backbone of alternating phosphorus and nitrogen atoms with two side groups attached to each phosphorus. Hydrolytically sensitive polyphosphazenes are formed when amino-acid ethyl ester groups are linked to the polymer backbone via the amino terminus [43]. The products of hydrolysis are nontoxic and contain parent amino acids, ethanol, phosphates, and ammonia, a mixture that results in a near-neutral $\mathrm{pH}$ [44]. Tian and coworkers prepared polyphosphazenes containing amino-acid esters (glycine, alanine, and phenylalanine) and ciprofloxacin or norfloxacin linked by piperazinyl group (Fig. 3). The polymers containing 12-25 mol\% antibiotics and $75-88 \mathrm{~mol} \%$ amino-acid esters were synthesized by macromolecular substitution using allyl protected carboxyl group of antibiotic, followed by the removal of allyl group under mild condition. Nano/microfibers of selected antibiotics were prepared by electrospinning technique. Hydrolysis behavior over a 6-week period was studied using different polymers as films and as nano/microfiber mats for in vitro experiments based on their mass lost and the $\mathrm{pH}$ of the hydrolysis media. All polymers were sensitive to hydrolysis. The degradation speed was dependent on the amino-acid esters attached to a polymer backbone and 
Scheme 4

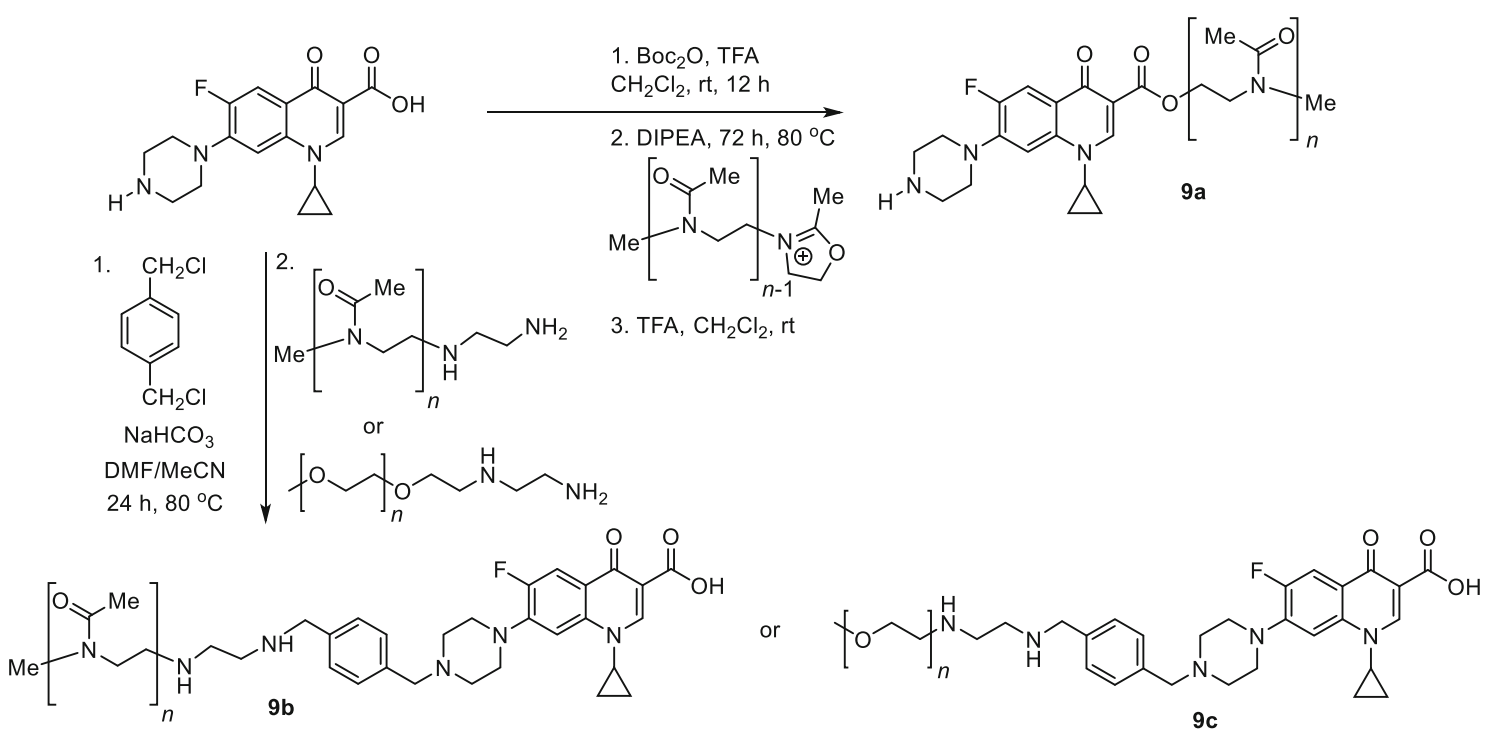

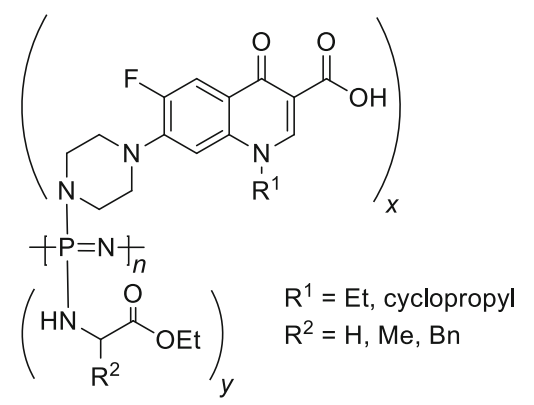

Fig. 3 Structures of polyphosphazene-fluoroquinolone polymers. $\mathrm{R}^{1}=\mathrm{Et}$ for norfloxacin and cyclopropyl for ciprofloxacin, $\mathrm{R}^{2}=\mathrm{H}$, $\mathrm{Me}, \mathrm{Bn}$ for glycine, alanine, or phenylalanine, respectively

followed a trend glycine $>$ alanine $>$ phenylalanine. The bulkier substituents more effectively shielded the polyphosphazene backbone from access to water. After the 6-week study, about 87 and $82 \%$ of polymers were left as films for alanine and glycine ciprofloxacin conjugates. In vitro antibacterial tests performed against $E$. coli demonstrated antibacterial capabilities as long as the antibiotic was being released [45].

He and coworkers synthesized copolymers containing monomers of methacrylate with ciprofloxacin, quaternary ammonium salts (QAS), and butyl acrylate by free radical copolymerization (Scheme 5). QAS were incorporated into polymers to increase water solubility as well as to improve the anti-microbial activities. These antibacterial agents exhibited excellent cell membrane penetration properties [46]. When positively charged, QAS adsorb onto the negatively charged bacterial cell by electrostatic interaction surface, diffuse through the cell wall, disrupt plasma membrane, and lead to bacterial death by the release of the

\section{Scheme 5}

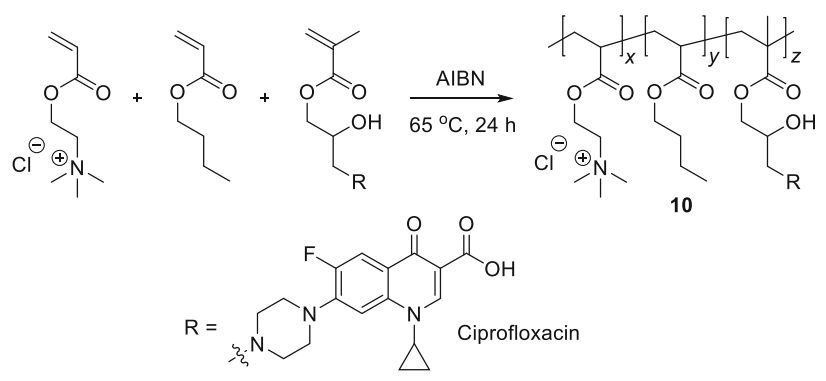

cytoplasmic contents [47]. Polymerization was performed in ethanol at $65^{\circ} \mathrm{C}$ for $24 \mathrm{~h}$ using azobisisobutyronitrile as an inhibitor. The molecular weight of the copolymers was ranging from 10,000 to 15,000 . Anti-microbial activity was tested against $E$. coli by means of zone inhibition method. Bacterial growth was inhibited which indicated excellent antibacterial properties. The highest antibacterial activity was obtained for the copolymer 10 which consisted of 56.4, 4.3 , and 39.3 mol\% monomers of QAS $(x)$, ciprofloxacin $(z)$, and butyl acrylate $(y)$, respectively. MIC value determined by serial dilution method against $E$. coli reached $4.0 \mathrm{ppm}$. Hydrophobicity increase by incorporation of more butyl side chains enhanced biological activity; however, excessive hydrophobicity caused aggregation and precipitation in water. The morphology of bacteria $10 \mathrm{~min}$ after treatment with $50 \mathrm{ppm}$ of $\mathbf{1 0}$ was characterized by confocal laser scanning microscope and showed bacterial membrane damage, as well as bacterial components leakage [48]. 
Prodrugs are molecules that contain drug pharmacophore and specialized non-toxic protective groups utilized in a transient manner to alter or eliminate the undesirable properties of the parent drug molecule. They allow to release of the drug moiety in the site of action and thus exploit localized activity of free drug molecule. Sobczak and coworkers synthesized polyester prodrugs of norfloxacin based on two-, three- and four-arm, star-shaped oligoesters: poly( $\varepsilon$-caprolactone) (11a), poly(D,L-lactide) (11b), and the copolymer of these homopolymers. The polymerization reactions were performed via ring-opening of cyclic esters in the presence of stannous octoate as a catalyst and poly(ethylene glycol) $(m=2)$, glycerol $(m=3)$, or penthaerythritol $(m=4)$ as initiators. The reaction yields were in the $44-100 \%$ range and the determined average molecular weights were assessed between 2900 and $9600 \mathrm{Da}$. The oligomers were subsequently reacted with fluoroquinolone antibiotic (Scheme 6). Authors suggest that these polymers are potential candidates to be applied as drug delivery carriers [49].

Polysaccharides can serve as polymers for prodrugs' formation of delayed or targeted delivery [50]. The cellulose ethers hydroxypropylcellulose (HPC) and hydroxyethylcellulose (HEC) were used by Hussain research group to obtain macromolecular prodrugs of moxifloxacin and ofloxacin. The carboxyl groups of the antibiotics were activated by $p$-toluenesulfonyl chloride and esterification was performed in the presence of trimethylamine (Scheme 7). The products of esterification were soluble in water and organic solvents. The degree of substitution was high; the polymers contained 21-29 mg of moxifloxacin or $32-42 \mathrm{mg}$ of ofloxacin per $100 \mathrm{mg}$ of conjugate, respectively, which make them useful for tablets production with acceptable size (500-1000 mg). Moxifloxacin-HPC conjugate self-assembled into nanowires (diameter approximately $30 \mathrm{~nm}$ ), while one of the moxifloxacin-HEC conjugates formed nanoparticles with diameters ranging from 150 to $350 \mathrm{~nm}$. Nanoparticles of ofloxacin were obtained in the size range $100-250$ and $150-210 \mathrm{~nm}$ for HPC and HEC conjugates, respectively. Pharmacokinetic studies were performed using a rabbit model upon oral administration. Both the conjugated polymers were able to hydrolyze and the release was highly delayed enhancing antibiotics plasma half-life, for moxifloxacin over $24 \mathrm{~h}$ and for HPC and HEC conjugates of ofloxacin 18.07 and $20.71 \mathrm{~h}$, respectively. These values are close to once daily dosing ideal value. Drug release tests of the moxifloxacin conjugates were performed in simulated gastric and intestinal fluids at $37{ }^{\circ} \mathrm{C}$. Hydrolysis occured faster at $\mathrm{pH}$ 7.4 than 1.2 which makes these prodrugs interesting for targeted delivery to the colon and distal small intestine [51, 52].

\section{Proteins and peptides}

Kumar and coworkers synthesized enrofloxacin conjugated with bovine serum albumin (BSA) to use the conjugate as an antigen capable of producing polyclonal antibodies against the antibiotic. Enrofloxacin belongs to antibacterials commonly used in veterinary practice in the treatment of infectious diseases as well as prophylactic agent; therefore, the produced antibodies could be employed for the detection of antibiotics in milk samples. To obtain immunogens, the carbodiimide reaction was employed with 1-ethyl-3-(3-dimethylaminopropyl)carbodiimide (EDCI) as a crosslinker. Polyclonal antibodies were successfully produced in rats, which were confirmed by indirect ELISA [53].

German and coworkers prepared conjugates of ciprofloxacin and ofloxacin with dipeptides or bisarylurea to expand action of the antibiotics on the substrate-based

Scheme 6<smiles>CCn1cc(C(=O)O)c(=O)c2ccc(N3CCNCC3)cc21</smiles>

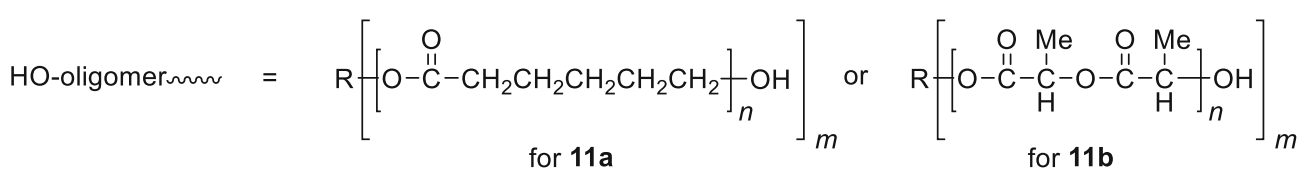

$m=2$ for polyethylene glycol

3 for glycerol

4 for pentaerythritol 
Scheme 7
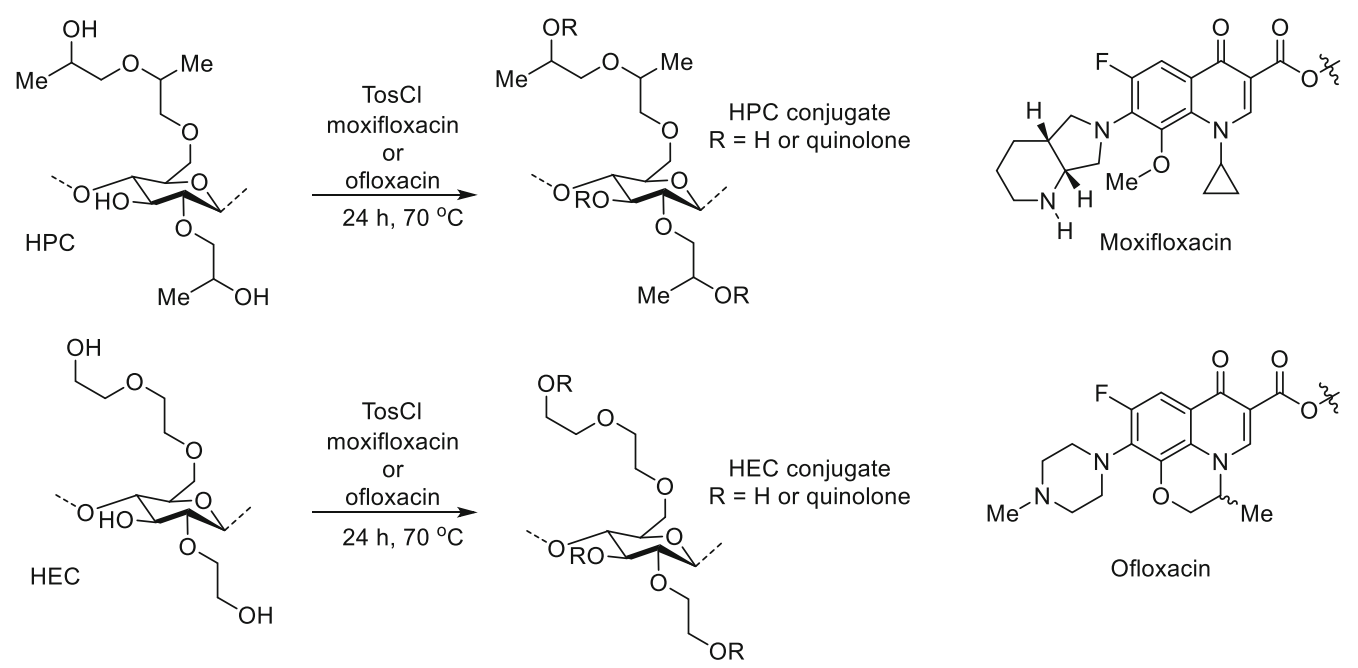

inhibitors of bacterial efflux pumps. Fluoroquinolone resistance in $S$. aureus may be caused by the norA-encoded and mepA-encoded fluoroquinolone efflux pump systems [54]; therefore, coadministration of bacterial efflux pump inhibitors with antibiotic agents led to overcome the effluxmediated resistance [55]. Bisaryl urea and dipeptide components, known inhibitors of NorA and MexAB pumps, respectively, were selected for incorporation to the $\mathrm{C} 7$ position of fluoroquinolone core. The conjugation of urea was achieved by attachment of bisaryl urea to the $\mathrm{C} 7$ piperazine of ciprofloxacin or $\mathrm{C} 7$ amine of ofloxacin precursor in direct alkylation (12a, 12b) (Scheme 8). Ciprofloxacin conjugates bearing Phe-Lys or Lys-Phe moiety was obtained with use of standard amino-acid coupling chemistry to modify the C7 piperazine moiety (13a, 13b) (Scheme 8). The novel compounds were tested against $E$. coli, $P$. aeruginosa, and $S$. aureus strains. In all cases, activities of conjugates were significantly lower than the parent drugs. None of the conjugates achieved appreciable inhibition of efflux pump system at any tested concentration in $P$. aeruginosa efflux inhibition studies. However, ofloxacin-urea conjugate 12b exhibited the highest inhibitor potencies of NorA and MepA efflux pump systems in $S$. aureus efflux inhibition assays and at $0.5 \mu \mathrm{M}$ concentration inhibited NorA-mediated and MepA-mediated efflux by 73.6 and $53.4 \%$, respectively [56].

Ahmed and Kelley designed conjugates of nalidixic acid and small peptides (3-12 amino acids) containing cationic and hydrophobic amino-acid residues to improve cellular uptake. Oligopeptides bearing positive charge exhibit affinity to negatively charged phosphodiester anions of DNA allowing for accumulation of the drug at the fluoroquinolone site of action [57]. The novel compounds were prepared by solid-phase peptide synthesis by incorporation of hydrophobic cycohexylalanine and positively charged Darginine. Subsequently, nalidixic acid was conjugated to peptide scaffolds by carbodiimide chemistry. The conjugates were tested against $S$. aureus MRSA and MSSA strains. The most hydrophobic compounds carrying a net +3 molecular charge were found to be highly active in both strains of the bacteria and exhibited the highest potency as DNA gyrase inhibitors by attenuating replication levels. Compound $\mathbf{1 4}$ was evaluated for membrane disruption properties and the results indicated that it does not alter membrane perturbation. Toxicity of $\mathbf{1 4}$ was tested in two types of human fibroblasts and the $\mathrm{IC}_{50}$ values were more than tenfold higher for the fibroblasts vs. the $S$. aureus strains tested. This trend indicates that the antibacterial agent $\mathbf{1 4}$ possess a suitable therapeutic window [58] (Fig. 4).

Riahifard and coworkers prepared conjugates of antimicrobial cationic peptides with fluoroquinolones. They conjugated amphiphilic linear or cyclic peptides bearing arginine and tryptophan residues with levofloxacin or

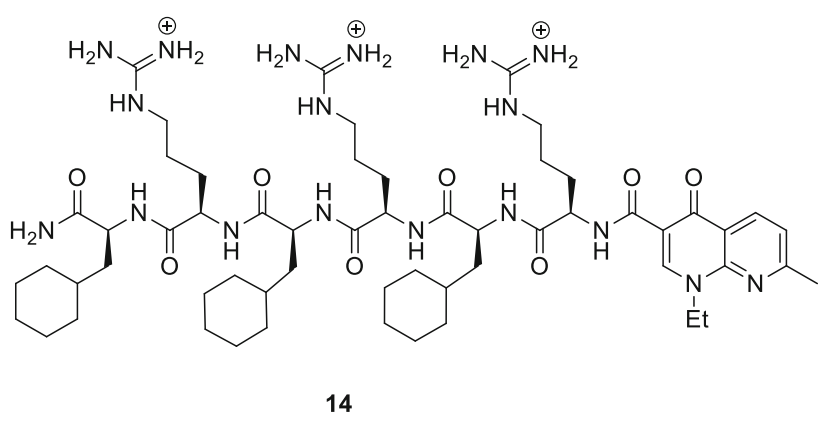

Fig. 4 Structure of peptide-quinolone conjugate 14 
levofloxacin-Q to enhance their ability to penetrate through bacterial lipopolysaccharides (Scheme 9). The compounds were synthesized using Fmoc/tert-Bu solid-phase peptide synthesis and tested against $K$. pneumoniae and $S$. aureus MRSA strains. The conjugate $\mathbf{1 5 b}$ demonstrated higher antibacterial activity than the parent drug. Other compounds exhibited reduced activity and no synergistic antibacterial effect, probably due to the incomplete hydrolysis of the conjugate [59] (Scheme 9).

Another research group, Ceccherini and coworkers, employed solid-phase peptide synthesis to conjugate carboxylic group of levofloxacin with an amine group of lysine side chain in the M33 peptide. M33 is a tetrabranched peptide with high activity against Gram-negative bacteria currently under preclinical development [60]. Antibacterial activity of the obtained conjugate $\mathbf{1 7}$ was tested in anti-microbial assays against $P$. aeruginosa and E. coli; however, the results indicated that the conjugation did not induce enhanced antibacterial properties [61] (Fig. 5).

Next example of cationic anti-microbial peptide conjugated with fluoroquinolone consists of levofloxacin modified with the Pep-4 peptide, which is based on human beta defensin-3 of RGRRSSRRKK-NH $\mathrm{N}_{2}$ sequence. The incorporation of antibiotic was performed by covalent modification of levofloxacin carboxyl moiety (preactivated to an acyl fluoride) to three primary amino groups present in the peptide (two lysine side chains and N-terminus) via direct acylation (Scheme 10). The antibacterial properties of the obtained conjugate 18 were evaluated against Gram-positive bacterium Bacillus cereus and Gram-negative E. coli. The antibacterial assays were conducted at three different

\section{Scheme 8}<smiles>O=C(O)c1cn(C2CC2)c2cc(N3CCNCC3)c(F)cc2c1=O</smiles><smiles>CC1COc2c(N)c(F)cc3c(=O)c(C(=O)O)cn1c23</smiles><smiles>CC1COc2c(NCc3ccc(NC(=O)Nc4ccccc4)cc3)c(F)cc3c(=O)c(C(=O)O)cn1c23</smiles>

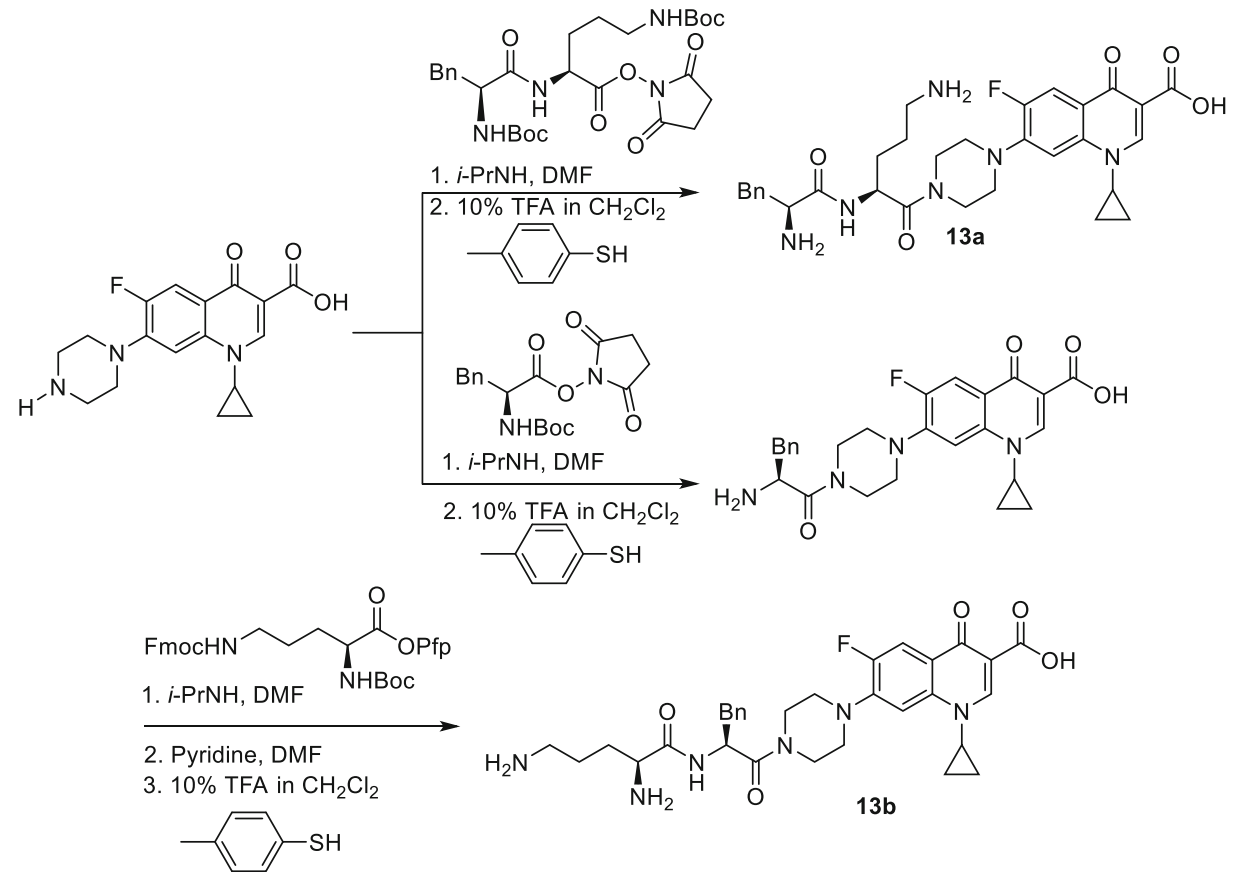


Scheme 9

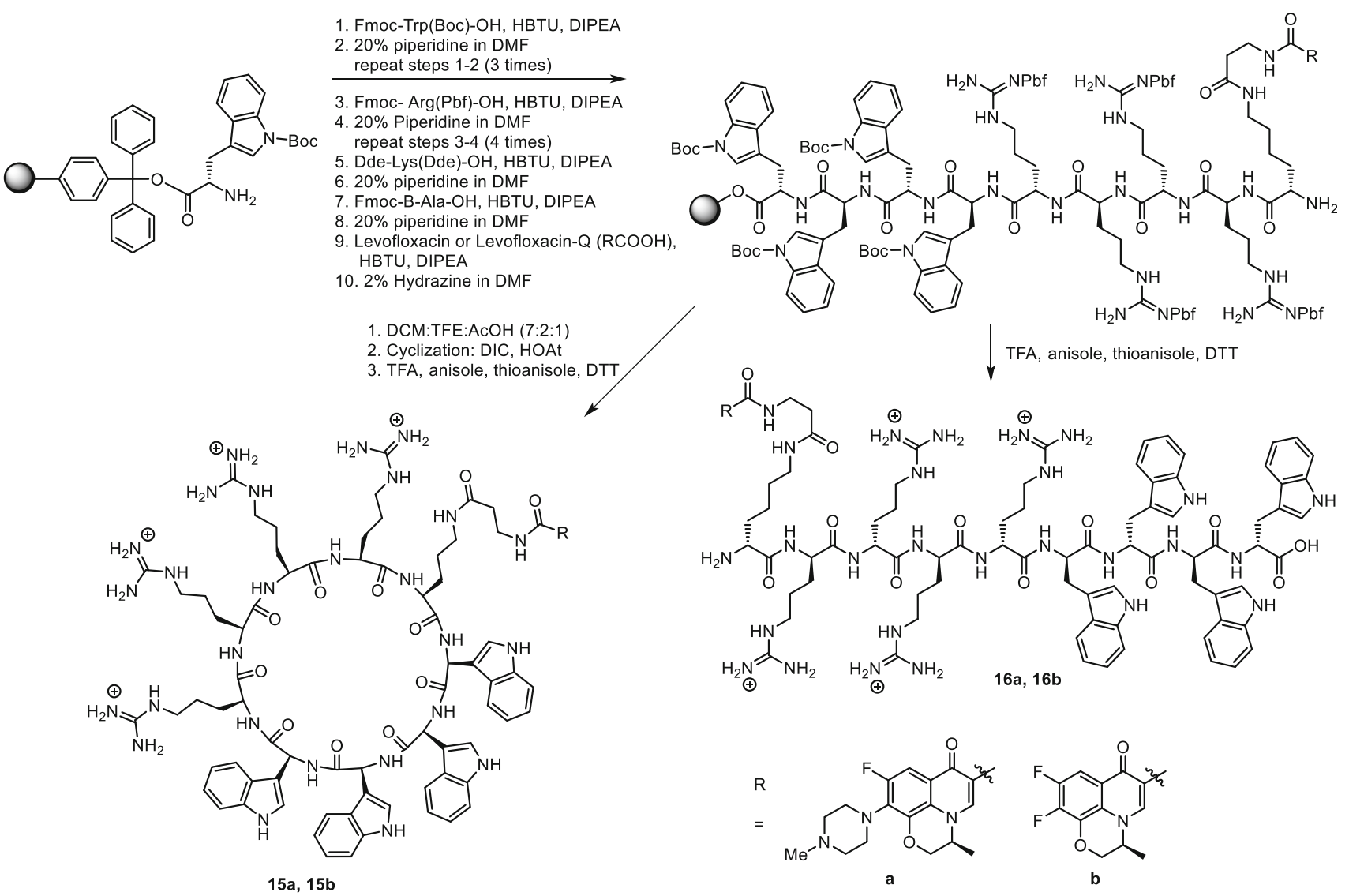

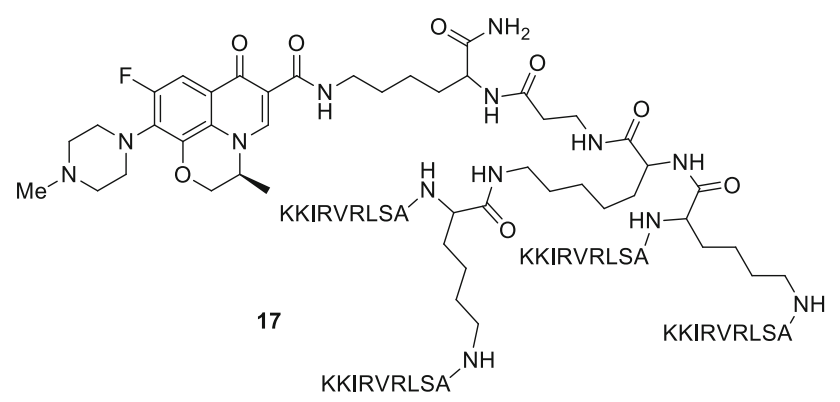

Fig. 5 Structure of peptide M33-levofloxacin hybrid 17

ionic strengths, because the effectiveness of the anti-microbial peptides may be limited under salt conditions consistent with physiologically relevant environments. The conjugate exhibited substantially better activity in comparison with the free peptide at higher ionic strengths. Depolarization studies indicated that the conjugate was able to disrupt membrane integrity in E. coli to a greater degree than the free peptide possibly due to its higher hydrophobicity $(\log D$ of conjugate measured in $10 \mathrm{mM}$ phosphate buffer $\mathrm{pH} 7.4$ and 1-octanol was - 1.65, while the non-conjugated peptide demonstrated $\log D$ of -2.57 ). Moreover, the findings suggested that enhanced antibacterial potency is not caused by the extracellular release of the free drug, since coadministration of unmodified Pep-4 with free levofloxacin resulted in significantly lower activity than in case of the conjugate [62].

Other research group designed enrofloxacin and ciprofloxacin derivatives of $\beta$-octaarginine, polycationic cellpenetrating peptide non-metabolized, and stable against proteases. The peptide scaffold was attached at the piperazine amino and at the carboxylic acid groups of ciprofloxacin (19a) and enrofloxacin (19b), respectively, to create amide bonds resistant to enzymatic cleavage. Evaluation of antibacterial properties was performed on a panel of 20 aerobic Gram-positive and Gram-negative bacterial strains; however, none of the obtained conjugates exhibited enhanced anti-microbial activity with reference to parent drugs [63] (Fig. 6).

\section{NO donors and analogs}

Nitric oxide (NO) is an inorganic free radical gaseous molecule important in a variety biofilm-forming species for signaling. Used at low, sub-lethal concentrations, NO is 


\section{Scheme 10}<smiles>NCCCC[C@H](NC(=O)[C@H](CCCCN)NC(=O)[C@H](CCCCC(N)=[NH2+])NC(=O)[C@H](CCCCC(N)=[NH2+])NC(=O)[C@H](CO)NC(=O)[C@H](CO)NC(=O)[C@H](CCCCC(N)=[NH2+])NC(=O)[C@H](CCCCC(N)=[NH2+])NC(=O)CNC(=O)[C@H](N)CCCCC(N)=[NH2+])C(N)=O</smiles>

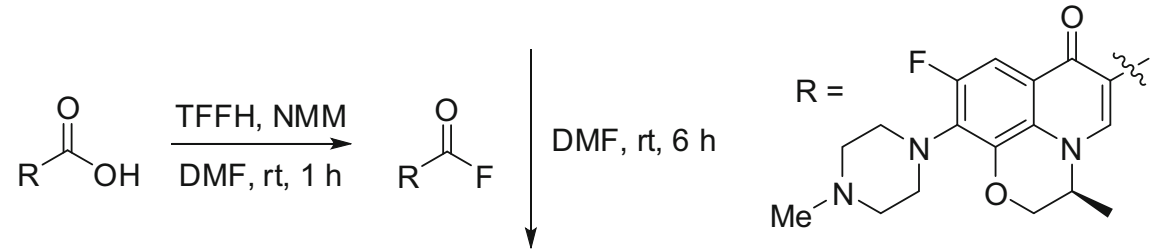<smiles>[R]C(=O)NCCCC[C@H](NC(=O)[C@H](CCCCNC([R])=O)NC(=O)[C@H](CCCCC(N)=[NH2+])NC(=O)[C@H](CCCCC(N)=[NH2+])NC(=O)[C@H](CO)NC(=O)[C@H](CO)NC(=O)[C@H](CCCCC(N)=[NH2+])NC(=O)[C@H](CCCCC(N)=[NH2+])NC(=O)CNC(=O)[C@H](CCCCC(N)=[NH2+])NC([R])=O)C(N)=O</smiles>

Fig. 6 Structures of fluoroquinolone- $\beta$-octaarginine conjugates 19a, 19b<smiles>CCN1CCN(c2cc3c(cc2F)c(=O)c(C(=O)NC(C)CC(C)(N)C(=O)O)cn3C2CC2)CC1</smiles>

capable to induce a transition from the sessile biofilm state to a dispersed (planktonic) mode of growth [64]. Due to a short half-life of NO (0.1-5 s) and its extreme chemical reactivity, NO-donor molecules are used to deliver the drug into systems, where biofilms are prevalent [65].

Benzofuroxans are stable in the air compounds able to generate external NO. They find applications as vasodilators and exhibit antianginal properties [66]. Chugunova and coworkers synthesized benzofuroxan salts 2022 with several fluoroquinolones, namely, sparfloxacin (a), ciprofloxacin (b), norfloxacin (c), and lomefloxacin (d), formed by hydrolysis of benzofuroxans (Scheme 11). The bacteriostatic and bacteriocidal activity of obtained salts was tested for anti-microbial efficacies in Gram-positive ( $S$. 
aureus and B. cereus) and Gram-negative ( $P$. aeruginosa and $E$. coli) bacterial strains. The compound 20d showed the best antibacterial activity, even eight times higher than original drug lomefloxacin. Moreover, the tested compounds exhibited very weak toxicity to human blood cells-hemolysis did not exceed $1 \%$ in concentrations $0.19-3.9 \mathrm{mg} / \mathrm{dm}^{3}$ [67].

Nitroxides are also useful crystalline solids structurally similar to NO. They undergo redox chemistry and exhibit antibacterial effect. Ciprofloxacin-nitroxide hybrids 23b, 24b, 23d, 24d, and 24f were synthesized and evaluated as anti-biofilm agents (Scheme 12). The methoxyamine derivatives 23a, 24a, 23c, 24c, and 24e were prepared as a control to enable direct comparison (Scheme 12). Compounds 23a-23d were obtained via a tertiary amine linker by reductive amination followed by deprotection of ethyl ciprofloxacin esters, while compounds $\mathbf{2 4 a - 2 4 f}$ were synthesized using amide bond coupling with corresponding acyl chloride. The desired products were obtained in goodto-excellent yields (64-98\%) and antibacterial activity was measured against biofilm-forming $P$. aeruginosa strain. The results indicate that the nitroxide hybrids possess dualaction effect. The most active hybrid $\mathbf{2 3 b}$ showed dispersal activity towards mature biofilm and antibiotic action by means of eradication of the newly dispersed bacteria up to 95\% at $40 \mu \mathrm{M}$ [68]. Compounds 24b, 24d, and 24f also displayed good anti-biofilm activity. Compound 24d removed $85 \%$ of existing biofilms at $20 \mu \mathrm{M}(10.95 \mu \mathrm{g} /$ $\mathrm{cm}^{3}$ ). Free ciprofloxacin was ineffective at biofilm removal; however, the addition of nitroxide moiety to the piperazine ring through amide bonds, in general, has resulted in decreased activity against planktonic forms of bacteria. Selected compounds examined in human muscle rhabdomyosarcoma and human embryonic kidney 293 (HEK-293) cells were found to be non-toxic up to the highest concentrations used $(40 \mu \mathrm{M})$ [69].

\section{Anionic compounds}

Chronic lung infections are caused by accumulation mucus lining the airway of the lungs, where Gram-negative aerobes are known to evade host defenses. P. aeruginosa is one of the common pathogens with an ability to form biofilm and colonize pulmonary tract. Long and coworkers hypothesized that negatively charged compounds bearing sulfoxy or carboxy groups could serve as inhibitors of these biofilm-producing strains and penetrate the alginate

\section{Scheme 11}

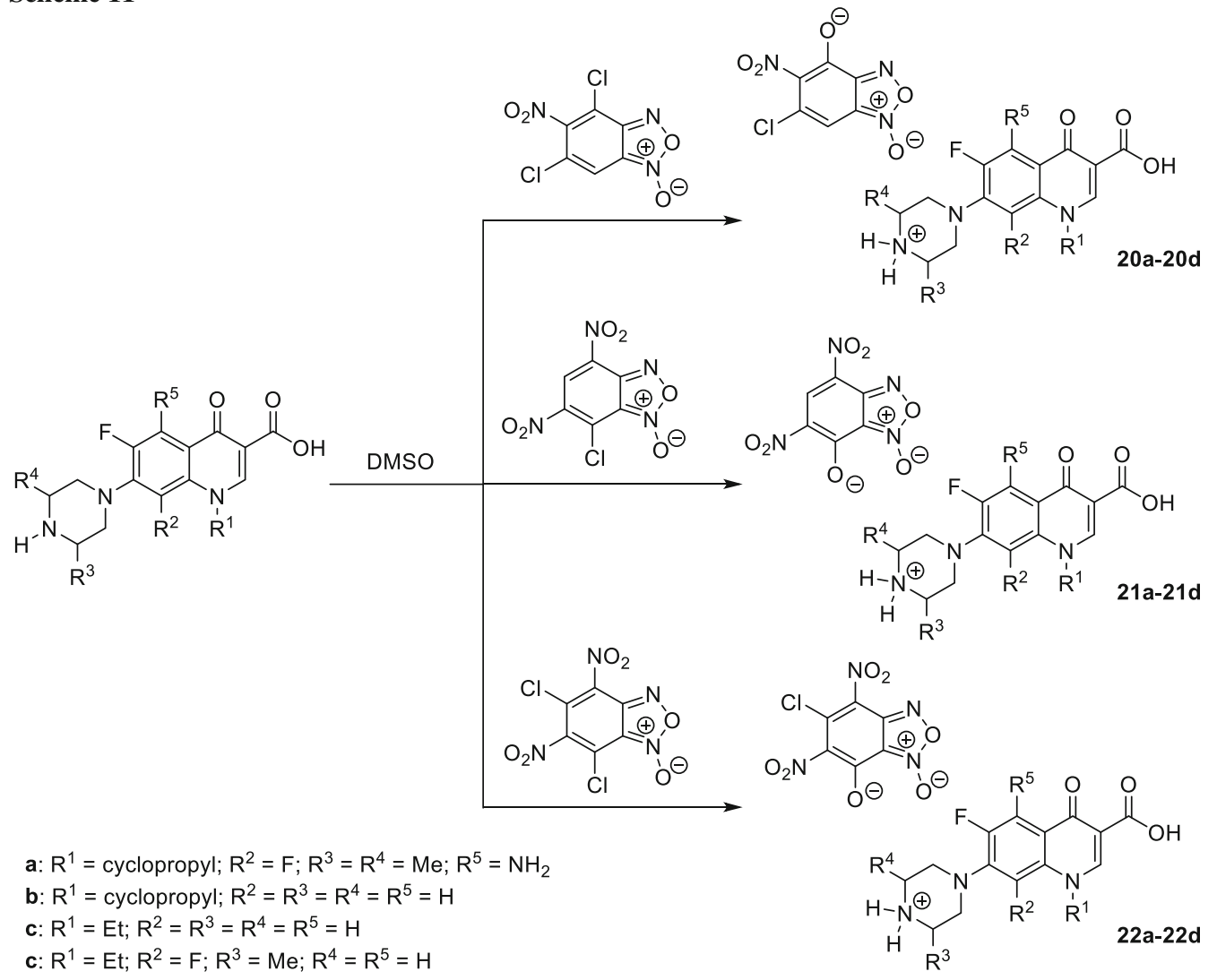


Scheme 12

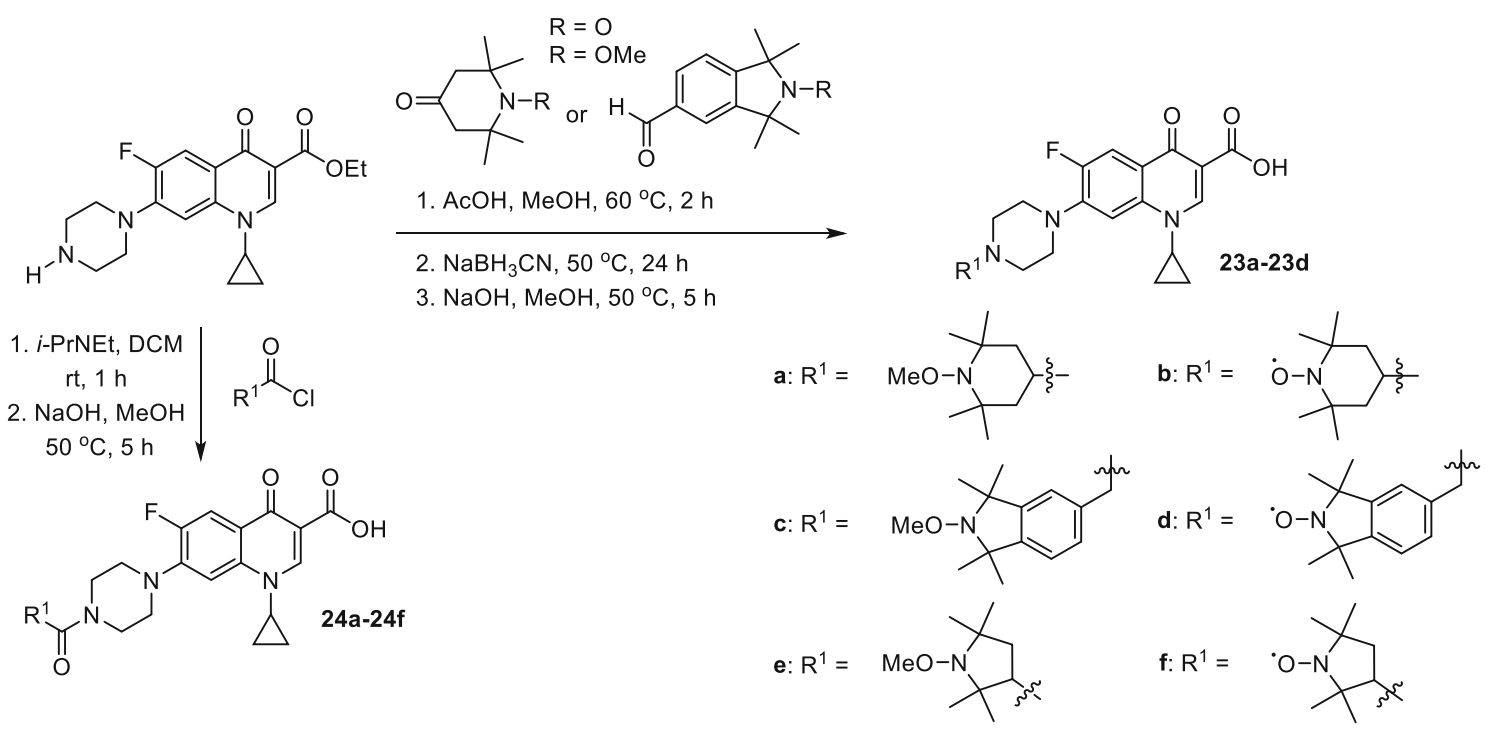

component of $P$. aeruginosa extracellular polymeric substance. To evaluate this hypothesis, they designed anionic fluoroquinolones and tested their pseudomonal inhibition efficiency against non-mucoid and mucoid strains $(P$. aeruginosa PAO1 and PAO581, respectively) by determining zones of inhibition, MIC, and MBC (minimal bactericidal concentration). Compounds 25a-25c were prepared from ciprofloxacin and the appropriate cyclic anhydrides in DMSO, while hybrids 25d and 25e were obtained by alkylation of the piperazinyl ring with bromides of corresponding methyl esters followed by acid hydrolysis (Scheme 13). The modifications resulted in decrease of the antibacterial activity. The most active compound 25c was found to be inferior compared to the lead compound, ciprofloxacin. The data suggest that novel compounds penetrate biofilm less efficiently than standard antibiotics [70].

\section{Siderophores}

Certain pathogenic microorganisms under iron-limited conditions synthesize and excrete low-molecular-weight molecules called siderophores, able to chelate lowbioavailable Fe(III) from the surrounding environment and compete with the host for this element [71]. Siderophore$\mathrm{Fe}(\mathrm{III})$ complex is recognized by the dedicated membrane receptors and transported into the bacterial cell. Then iron is released from the complex for further use, which allows the bacteria to survive in iron-deficient media. Sideromycins are natural conjugates of an antibiotic molecule and a siderophore analog, often connected by a hydrolyzable linker that can be cleaved by endogenous enzymes. These components are recognized and transported into the targeted bacteria by the siderophore-dependent iron uptake pathways. After the sideromycin has been transferred across the bacterial envelope, the antibiotic is released [72]. This natural strategy can be used in Trojan horse approaches using synthetic siderophores as vectors to transport antibiotics into the bacterial cells [73].

Although citrate has relatively low affinity to $\mathrm{Fe}(\mathrm{III})$ [74], it is used by E. coli as an exogenous siderophore [75]. Md-Saleh and coworkers prepared conjugates of ciprofloxacin with a monocitrate unit linked via stable amide bond on the piperazinyl ring. Methanoate ciprofloxacin esters were subjected to the reaction with citrates by EDCImediated coupling, then deprotected furnishing conjugates 26a and 26b in good yields (Scheme 14). Anti-microbial activity of the obtained compounds was tested against several common pathogens, inter alia S. aureus, Staphylococcus epidermidis, P. aeruginosa, Serratia marcescens, Burkholderia cepacia, and E. coli. The inhibition activity for both novel compounds was comparable to the clinic drug ciprofloxacin and, however, slightly lower for the majority of the strains tested. Compound 26b has been subjected to additional tests to explore its cell membrane permeability; however, the data showed that there was no additional uptake via an iron-citrate pathway and the conjugate was not recognized by Fec system [76].

Milner and coworkers continued the study and synthesized analogical conjugates with longer linkers between siderophore and ciprofloxacin molecules 26c and 26d (Scheme 14). The modification resulted in decrease of antibacterial action as well as gyrase inhibitory activity. 
Scheme 13<smiles>O=C(O)c1cn(C2CC2)c2cc(N3CCNCC3)c(F)cc2c1=O</smiles>

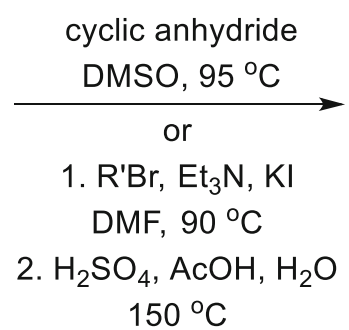<smiles>[R16]c1cc2c(cc1F)c(=O)c(C(=O)O)cn2C1CC1</smiles>

$150{ }^{\circ} \mathrm{C}$

a: $\mathrm{R}=$<smiles>CC(C)(C)CCCC(=O)O</smiles>

b: $R=$<smiles>CC(=O)CCC(=O)O</smiles>

c: $R=$<smiles>CC(=O)c1ccccc1C(=O)O</smiles>



\section{Scheme 14}

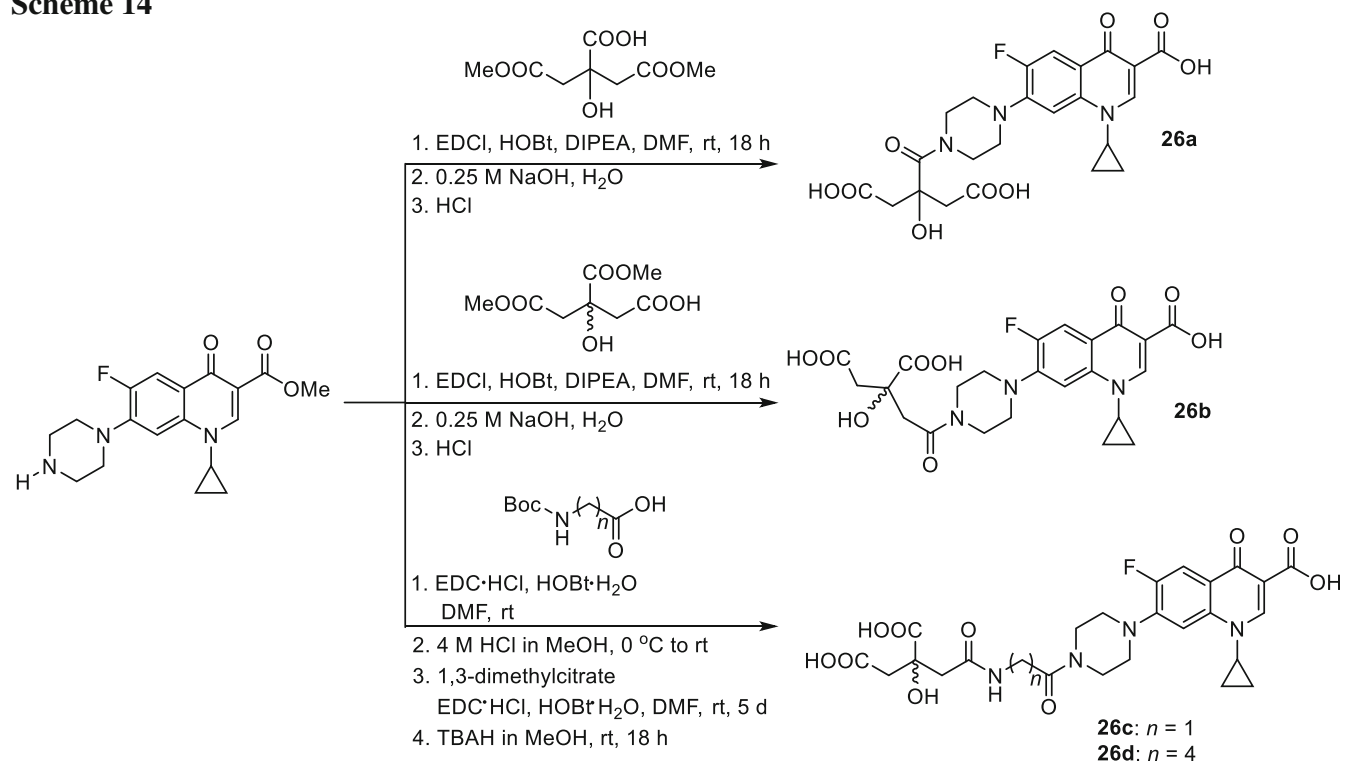

They designed also staphylococci-targeted citric acidciprofloxacin or norfloxacin conjugates based on staphyloferrin A, siderophore that is secreted by S. aureus. This siderophore is the most efficient under slightly acidic conditions. Its optimum $\mathrm{pH}$ lies close to that found for the average skin (5.5). Therefore, novel compounds could be employed in skin infection treatment. Moreover, this type of modification could improve water solubility of the conjugates. Compounds 27 were screened against a collection of reference and clinical isolates associated with infections in humans. They exhibited reduced activity and were less effective at inhibiting DNA gyrase than ciprofloxacin on its own, probably due to electrostatic repulsion or steric clashes of the modified drug when interacting with its binding site in the enzyme [77, 78] (Fig. 7).

Pyochelin is a siderophore recognized by FptA receptor common to several pathogenic Pseudomonas and Burkholderia species, Gram-negative bacteria causing severe and lethal lung infections especially for immunocompromised patients or subjects with cystic fibrosis [79]. Mislin research group synthesized pyochelin-fluoroquinolone conjugates using various types of linkers for norfloxacin or ciprofloxacin (Scheme 15). The adducts 


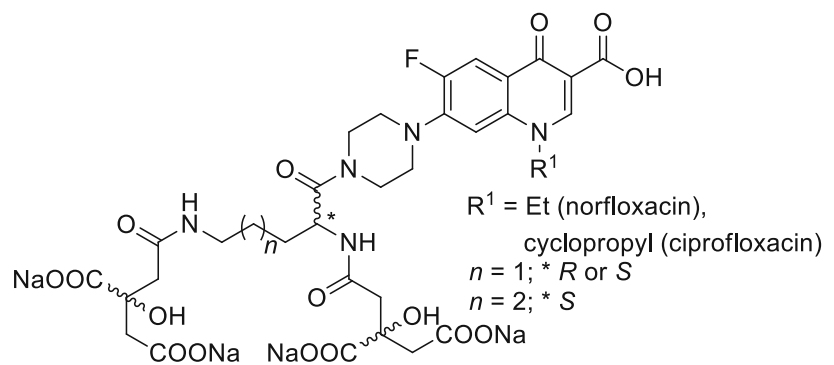

27

Fig. 7 Structures of siderophore and fluoroquinolone hybrids $\mathbf{2 7}$

were tested against $P$. aeruginosa strains: wild-type, pyochelin-deficient, and TonB-deficient (TonB is a key protein involved in the iron assimilation process). Labilearm conjugates $\mathbf{2 8 b}$, 28d, 28f, $\mathbf{2 8 h}$ showed lethal activity; however, only for compounds $\mathbf{2 8 b}, \mathbf{2 8 d}$, the effects were as pronounced as for free norfloxacin. Compounds 28f, 28h were less active, presumably due to their poor water solubility [80, 81].

Enterobactin is a tricatecholate siderophore secreted by Escherichia, Salmonella, and Klebsiella species [82]. Zheng and coworkers obtained ciprofloxacin-enterobactin conjugates in the synthetic route, as presented in
Scheme 16. The conjugate $\mathbf{2 9 a}$ was found to be recognized by transport system proteins and successfully delivered to the cytoplasm of $P$. aeruginosa as well as $E$. coli causing growth inhibition of these microbes [83]. The conjugates 29b, 29c having labile (alkoxy)alkyl ethers linkers were found to be hydrolyzable in the hydrolytic stability tests; however, in anti-microbial activity assays performed for $E$. coli strains, their activity was attenuated by tenfold (MIC of $1 \mu \mathrm{M}$ ) relative to ciprofloxacin. The modest growth inhibitory activity was probably caused by the release of unmodified ciprofloxacin in the growth medium rather than by targeted delivery [84].

Catecholate-ciprofloxacin conjugates (Fig. 8) were also synthesized by Fardeau and coworkers and tested against $P$. aeruginosa strains. The antibacterial activities of the hybrids were moderate in both iron-rich and iron-deficient media and inferior to ciprofloxacin. This could be related to low solubility in aqueous media and/or the absence of hydrolysis of the hybrids. The hemolytic activity of the conjugates was low which indicated low cytotoxicity of obtained compounds [85].

Miller's research group designed and prepared a series of sideromycins, which were evaluated for their antibacterial properties against Enterococcus faecium, S. aureus,

Scheme 15<smiles>[R]n1cc(C(=O)O)c(=O)c2cc(F)c(N3CCNCC3)cc21</smiles>

1. chloromethylchloroformate 1,8-bis(N,N-dimethylamino)naphthalene $\mathrm{CHCl}_{3}, 20^{\circ} \mathrm{C}$

2. succinic acid mono-tert-butyl ester $\mathrm{Ag}_{2} \mathrm{CO}_{3}, \mathrm{DMF}, 95^{\circ} \mathrm{C}$

3. TFA, $\mathrm{CH}_{2} \mathrm{Cl}_{2}, 20^{\circ} \mathrm{C}$

4. EDCl, pentafluorophenol, dioxane, $20^{\circ} \mathrm{C}$<smiles>[R]n1cc(C(=O)O)c(=O)c2cc(F)c(N3CCN(C(=O)OCOC(=O)CCC(=O)OC(F)(F)F)CC3)cc21</smiles>

1. succinic anhydride pyridine, DMSO, $95^{\circ} \mathrm{C}$

2. pentafluorophenol, EDCl dioxane, $60^{\circ} \mathrm{C}$<smiles>[R]n1cc(C(=O)O)c(=O)c2cc(F)c(N3CCN(C(=O)CCC(=O)OCC(C)C)CC3)cc21</smiles>



$\underset{\text { DIPEA }}{\stackrel{\text { or } \mathbf{Z}}{\longrightarrow}}$

dry DMF, $20^{\circ} \mathrm{C}$

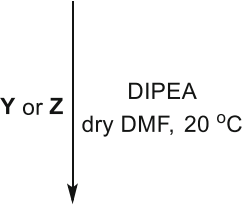<smiles>[R]N1CCN(c2cc3c(cc2F)c(=O)c(C(=O)O)cn3[R])CC1</smiles>

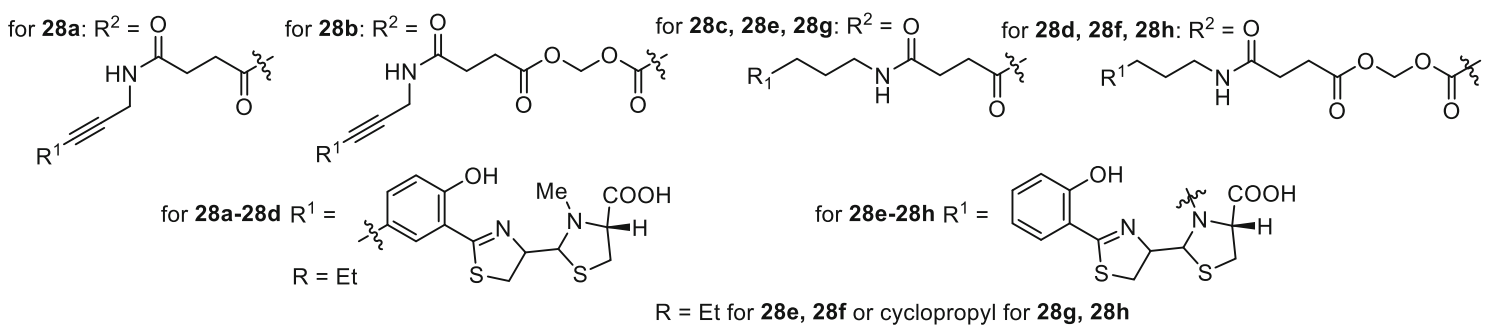


Scheme 16<smiles>[R]NC(=O)C([R1])NC(=O)OC(C)C(=O)OC([R1])N1CCN(c2cc3c(cc2F)c(=O)c(C(=O)O)cn3C2CC2)CC1</smiles>

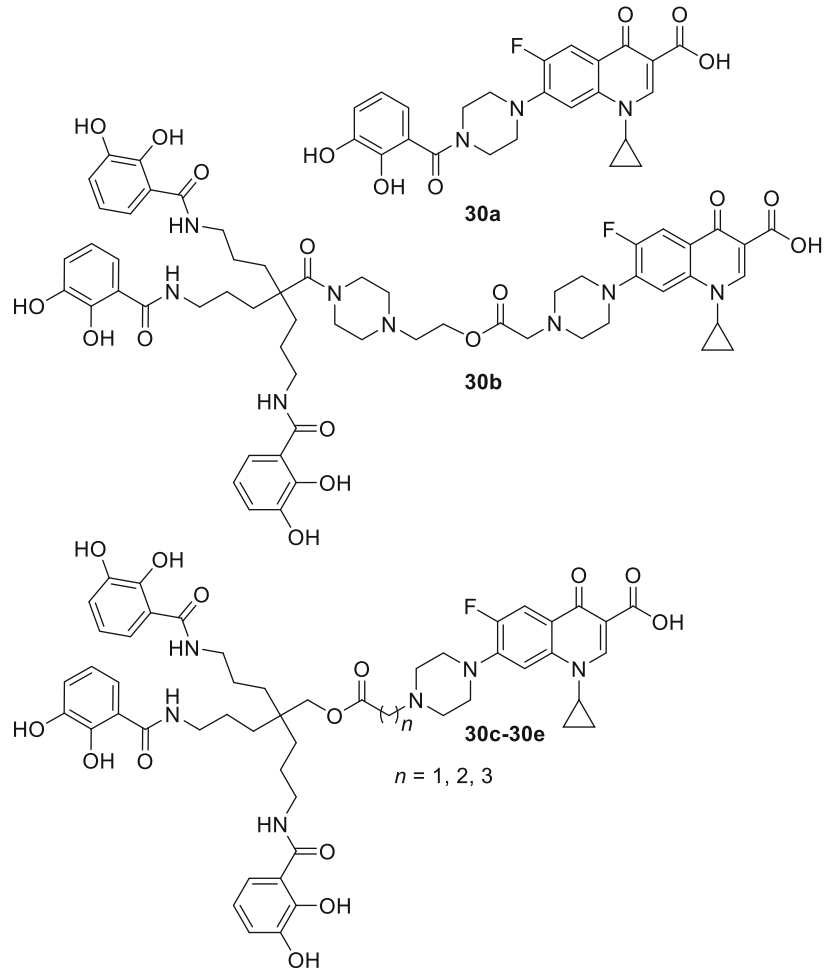

Fig. 8 Structures of catecholate-ciprofloxacin conjugates $30 \mathbf{a}-30 \mathbf{e}$
K. pneumoniae, A. baumannii, $P$. aeruginosa, Enterobacter aerogenes, and E. coli bacterial strains. Biscatecholateciprofloxacin conjugate 31a showed no antibacterial activity against all tested bacteria, whereas the parent ciprofloxacin was highly active [86]. Mono-, bis-, and trihydroxymate derivatives of ciprofloxacin 31b-31d were synthesized based on the structure of desferrioxamine B, trihydroxymate siderophore produced by several species of Nocardia, Streptomyces, Micromonospora, Arthrobacter, Chromobacterium, and Pseudomonas [87]. This conjugates showed reduced spectrum of activity relative to the broadly active parent antibiotic. These compounds were subjected to further experiments to determine if they were actively transported into the bacterial cells. Compound 31d was found to enter $S$. aureus cell membrane via protein-mediated siderophore-uptake pathways [88]. Compounds 31e, 31f were synthesized using the thiol-maleimide strategy from desferrioxamine $\mathrm{B}$ and fluoroquinolone derivatives, ciprofloxacin and nadifloxacin, respectively. The conjugates featured $\mathrm{Ga}$ (III) as a chelator. Mycobacterium smegmatis and E. coli were not affected by these compounds; however, conjugate $\mathbf{3 1 f}$ acted as strong inhibitor of Bacillus subtilis growth [89]. Compounds 31g, 31h were designed to enhance antibacterial activity of prodrugs by ensuring the intracellular release of antibiotic from ciprofloxacin-desferrioxamine B conjugate. Biologically active 
components of the hybrids were joined with the use of esterase and phosphatase triggered drug release linkers containing 'trimethyl lock'. The chemical structure of 'trimethyl lock' is an $O$-hydroxycinnamic acid which unfavorable steric interactions between the three methyl groups encourage rapid spontaneous lactonization to form a hydrocoumarin after enzymatic hydrolysis [90]. The compound 31i possessing a succinyl linkage, stable under physiological conditions, was included in the biological studies as a control. The conjugates were evaluated for their ability to inhibit growth of B. subtilis, S. aureus, $P$. aeruginosa, E. coli, and Micrococcus luteus strains. The antibacterial activity of hybrid $\mathbf{3 1 g}$ was moderate to good, although weaker than that of the ciprofloxacin [91]. Siderophore-ciprofloxacin conjugates with 'trimethyl lock' incorporating a urea linkage $\mathbf{3 1 j}$, $\mathbf{3 1 k}$ were also prepared due to their appreciable stability and synthetic accessibility. Electrochemical and LC-MS studies revealed that the quinolone moiety in the linker was thermodynamically reducible and the expected lactonization was rapid. Complete release of the ciprofloxacin from the conjugate $\mathbf{3 1} \mathbf{j}$ was achieved after 25 min under mild conditions $\left(37^{\circ} \mathrm{C}\right.$, 20 -fold excess of sodium dithionite). Antibacterial activity assays indicated that drug release occurred inside the bacterial cells; however, the conjugates $\mathbf{3 1 j}$, 31k were less active relative to the parent drug [92] (Fig. 9).

$N$-Acylated ciprofloxacin derivatives based on the 'trimethyl lock' without siderophore molecule 311-31p were also prepared and tested against E. coli, P. aeruginosa, Mycobacterium vaccae, M. luteus, S. aureus, B. subtilis, and $A$. baumannii. These compounds showed moderate-togood activity against $M$. vaccae and Gram-negative pathogens, although inhibition was decreased in comparison with ciprofloxacin by $2-50$-fold. The most active conjugate was found to be compound 31n with MIC values against Gram-positive S. aureus and M. luteus superior to these determined for ciprofloxacin. This result suggests that compound 31n may act through a dual-action mechanism presented in Scheme 17 by serving as a prodrug and covalent thiol-containing enzyme inhibitor [93].

\section{Phosphonates}

Osteomyelitis is an inflammatory process localized in bones often accompanied by bone necrosis resulting from an underlying microbial infection (caused primarily by $S$. aureus) [94, 95]. Difficulties in effectively treating this disease are consequence of physiochemical environment poorly accessible to the immune system. Therapy requires a large concentration of antibiotic to be maintained in infected bone over a long period of time; therefore, frequent intravenous administration of high drug doses is needed. Bisphosphonates are used in the medical praxis as anti-osteoporosis drugs due to their ability to adsorb to the hydroxyapatite, calcium phosphate bone mineral [96]. These strong metal ions chelators serve as targeting medicinal agents in bone diseases through rapid diffusion to osseous tissues in vivo [97]. Far's research group prepared a series of osteotropic prodrugs for osteomyelitis prevention. The conjugates contained fluoroquinolone antibiotic and phosphonate moiety aimed at delivery the drug directly to the site of action. Moxifloxacin, gatifloxacin, and ciprofloxacin were used to produce prodrugs efficiently binding to bone tissue and able to release active fluoroquinolone molecules. The synthesized compounds included C3 aryl (32a), glycoamide (32b-32h), and thioglycoamide (32i) esters (Scheme 18) [98].

Furthermore, C7 hybrids have been prepared through addition of alkenes (33a, 33b) or $\alpha, \beta$-unsaturated carbonyl compound (33c) bearing bisphosphonate moiety to the amine group of fluoroquinolone. Similar phosphinyl 33d33g and methylenebisphosphonate 33h, 33i C7 conjugates were prepared [99]; however, only compounds 33c, 33d exhibited good inhibition activity against $S$. aureus (MIC values $<0.12$ and $0.12 \mu \mathrm{g} / \mathrm{cm}^{3}$, respectively). Lower activity than the parent quinolones indicated that during $24 \mathrm{~h}$ assay, prodrugs were not able to release the parent drug. Binding to bone powder was at the very efficient level. The prepared compounds 32a-32d, 32g-32i, 33a33c, 33h, and 33i have been absorbed in 80-90\% over $1 \mathrm{~h}$, while conjugates 33d-33g in 35-76\%. Compounds 32b32d and 33c-33g were proved to hydrolyze in plasma and release the free drug efficiently. Prodrugs 32b-32d and 33c did not require the participation of an enzyme to appreciably regenerate the parent fluoroquinolone in vitro. Prodrugs 32b, 32c, and 33c tested in rats significantly reduced bacterial titer in the bone under exposure of 20.8, 15.8, and $17.3 \mathrm{mg} / \mathrm{kg}$ of body weight, respectively [97-99] (Scheme 19).

1-Hydroxybisphosphonates derivatives of ciprofloxacin (34a), gatifloxacin (34b), and moxifloxacin (34c) were synthesized with use copper(I) catalyzed azide-alkyne 1,3dipolar cycloaddition reaction by McPherson III and coworkers (Scheme 20). Ciprofloxacin derivative 34a possessed the highest antibacterial activity against a panel of clinically relevant bacteria including B. subtilis, $S$. aureus, S. epidermidis, Enterococcus faecalis, E. coli, K. pneumoniae, $P$. vulgaris, and $P$. aeruginosa. The osteotropic properties of the obtained compounds were evaluated using synthetic nanosized hydroxyapatite bone model. The adsorption level was in the range of 70-100\% [100]. These hydroxybisphosphonate derivatives of fluoroquinolones can be considered as potential candidates for bone-targeted drugs. 


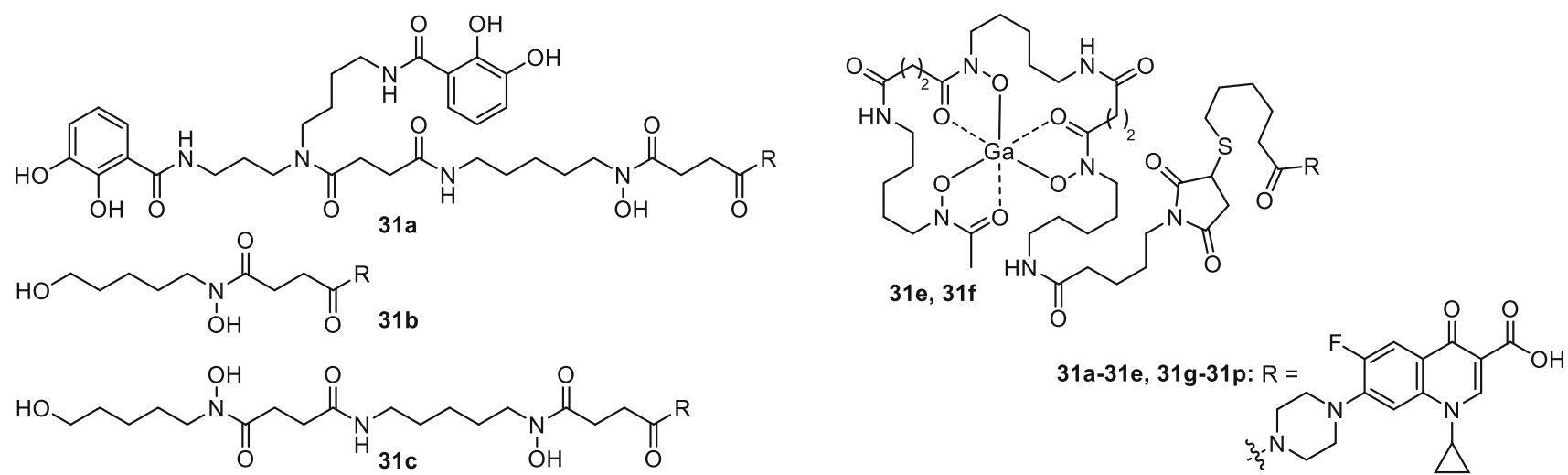<smiles>[R]C(=O)CCC(=O)N(O)CCCCCCNC(=O)CCC(=O)N(O)CCCCCNC(=O)CCC(=O)N(O)CCCCCO</smiles><smiles>[Y9]OC1CCN(c2c(F)cc3c(=O)c(C(=O)O)cn4c3c2CCC4C)CC1</smiles><smiles>[R]C(=O)CCC(=O)Oc1cc(C)cc(C)c1C(C)(C)CC([R])=O</smiles>

$31 \mathrm{~g}$

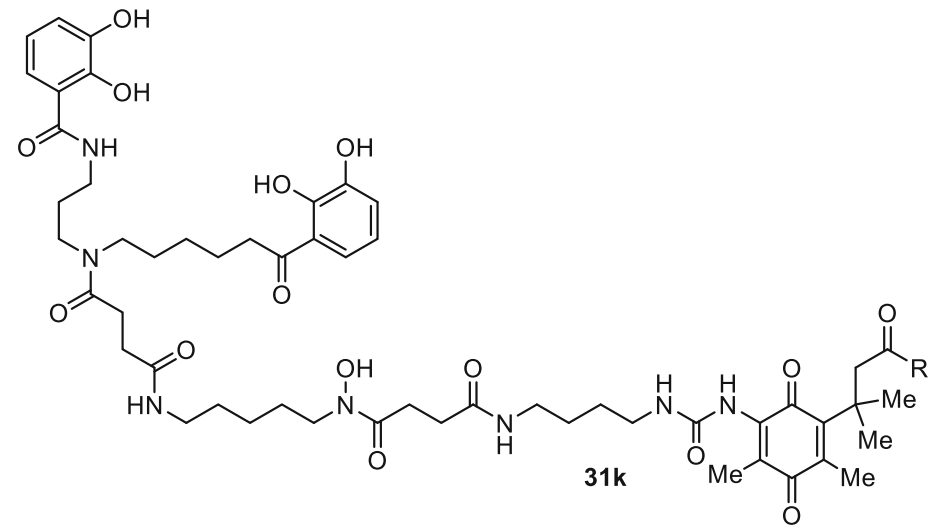<smiles>[R]C(=O)CCC(=O)Oc1c(C)cc(CP=O)c(C(C)(C)CC([R])=O)c1C</smiles><smiles>[R]C(=O)CCC([R])=O</smiles><smiles>[R]C(=O)CC(C)(C)C1=C(C)C(=O)C(C)=C(NC([R])=O)C1=O</smiles><smiles>[R1][R]CC(=O)NCCCCCN(O)C([Y])=O</smiles>

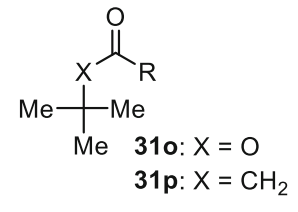

Fig. 9 Structures of fluoroquinolone-siderophore hybrids 31a-31k

\section{Prodrugs with enhanced lipophilicity}

Dubar and coworkers have proposed bioorganometallic strategy that led to improvement in antimalarial activity of fluoroquinolones. They designed ethyl esters of ciprofloxacin prodrugs bearing a ferrocenyl substituent at position $\mathrm{N} 1$ or $\mathrm{C} 7$ of the quinolone core 35a-35c. The conjugates were obtained from fluorobenzoic acid transformed in two-step procedure into ethyl 3-(diethylamino)2-(2,4,5-trifluorobenzoyl)acrylate (Scheme 21). The ester has been cyclized with the corresponding amines and subsequently reacted with ferrocenyl compounds. The products 35a-35c were more active than ciprofloxacin against Plasmodium falciparum, malaria-causing parasite, possibly due to their enhanced lipophilicity. The drug molecule needs to penetrate multiple membranes present in the intracellular parasite to reach fluoroquinolone target, gyrase, or topoisomerase IV. Thus, the strong antiplasmodial effect was achieved as a result of hydrophobic capacity which facilitated transport of the drug across membranes. Toxicity of novel compound was tested in vitro using mouse spleen cells; however, therapeutic index was relatively low (selectivity index for the most active compound $\mathbf{3 5 b}$ reached 8) [101]. Ferrocenyl 
Scheme 17

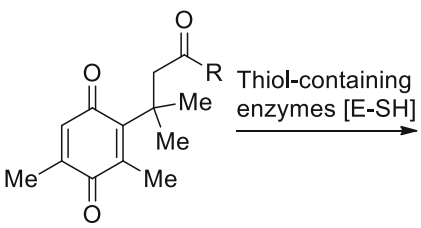

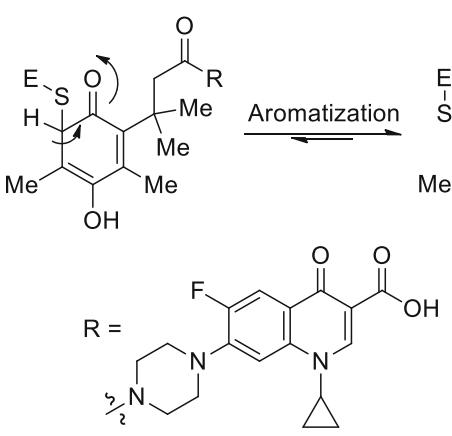


derivatives seemed to be promising antimalarials, but considering their toxicity, they required further structure optimization. For this reason, the study was extended for conjugates 35d, 35e prepared in a similar way. The new conjugates were found to be dramatically more active than the parent drug not only against $P$. falciparum but also against tachyzoites of Toxoplasma gondii at very low concentrations. Toxicity was examined against mouse spleen cells and LLC-MK22 cell line. Cytotoxic effect was greatly reduced and therapeutic index for the adamantly derivative was above 60 and 100 for T. gondii and P. falciparum, respectively [102].

Dhaneshwar and coworkers employed ester prodrug strategy to improve oral bioavailability of norfloxacin, fluoroquinolone which enter into cells by diffusion [103]. Because of low lipophilicity, diffusion process is very low and the drug is unable to attain therapeutic concentration at the site of infection. Dhaneshwar research group used diglyceride promoiety to enhance bioavailability of poorly absorbed norfloxacin. They synthesized norfloxacin 1,3dipalmitin ester via coupling of 2-hydroxypropane-1,3-diyl dipalmitate with BOC-protected piperazinyl ring of norfloxacin, followed by deprotection with the TMSBr (Scheme 21). Thus, lipases mediated hydrolysis of the diglyceride ester linkage would release the parent drug norfloxacin in the tissue. The partition coefficient of the novel prodrug 36 determined in chloroform/phosphate buffer reached 5.25 and was 2.7 times higher compared to the parent drug. The release kinetics was examined in vivo in blood, faeces, and urine in Wistar rats' model. The studies indicated improved pharmacological profile [104].

\section{Phototherapeutics}

Photoresponsive drugs are conjugates of existing biologically active compounds with molecular photoswitches able to undergo remote activation and deactivation. The activity of these drugs can be externally controlled inside the body with light by switching between two or more isomeric states [105]. Local action of such drugs is used to prevent side effects. Velma and coworkers synthesized ciprofloxacin conjugates modified with spiropyran (37a) and azobenzene (37b) photoswitches by reaction of acyl chlorides of the photoswitches with fluoroquinolone. Spiropyran may be switched to merocyanine form upon $365 \mathrm{~nm}$ light irradiation and switched back upon visible-light irradiation or thermal relaxation. The same phenomenon occurs in the structure of azobenzene that undergoes transcis and cis-trans isomerizations in analogical pattern (Scheme 22). The spiropyran state of the first conjugate 37a was found to be thermodynamically stable at $555 \mathrm{~nm}$; however, after each round of irradiation significant fatigue was observed, which limits the use of this hybrid to a single round of switching. The other conjugate $\mathbf{3 7 b}$ exhibited no instability and reversible switching between cis and trans forms in water. The transformation could be performed more than ten times without any observable fatigue. Evaluation of MIC values in E. coli revealed that the spiropyran conjugate 37a had higher antibacterial activity in its light-induced zwitterionic merocyanine form. This effect may be caused by a change in dipole moment which affects cellular uptake and drug-receptor interactions. In $M$. luteus, no difference before and after irradiation was observed. Azobenzene conjugate 37b showed the same MIC values in both states tested on $E$. coli, but trans isomer had higher anti-microbial activity against $M$. luteus than the cis form [106].

Photodynamic therapy of cancer combines the use of photosensitizing drug, oxygen, and visible light to produce lethal cytotoxic agents like reactive oxygen species (ROS) responsible for the destruction of malignant tissues [107]. Porphyrin derivatives are an example of photosensitizes giving rise to ROS in high yield. Cavaleiro's research group designed and synthesized porphyrin-quinolone conjugates 38a-38d by 1,3-dipolar cycloaddition of an 


\section{Scheme 18}

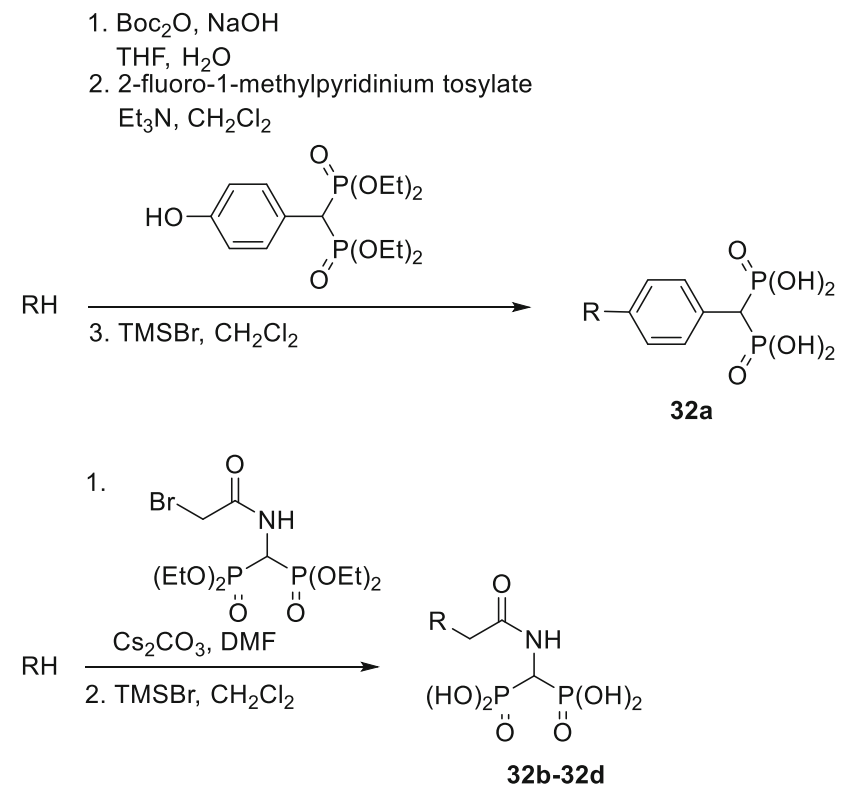

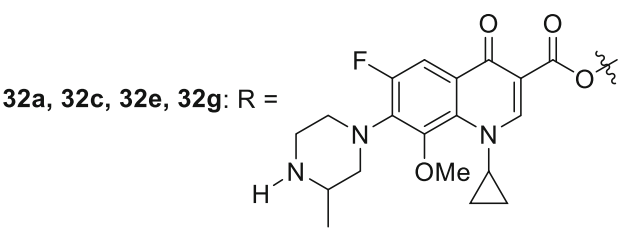

$32 b: R=$<smiles>[Z20]OC(=O)c1cn(C2CC2)c2cc(N3CCNCC3)c(F)cc2c1=O</smiles>

$32 d, 32 f, 32 h, 32 i: R=$<smiles>[Z]OC(=O)c1cn(C2CC2)c2c(OC)c(N3C[C@H]4CCCNC4[C@H]3C)c(F)cc2c1=O</smiles>

1.<smiles>CCO[P+](=O)C(N(C)C(=O)CBr)[PH](=O)OCC</smiles><smiles>[R]CC(=O)N(C(P(=O)(O)O)P(=O)(O)O)[N+](=O)[O-]</smiles>

$32 e, 32 f$
1.<smiles>[R]CC(=O)Nc1ccc(CC(P(=O)(O)O)P(=O)(O)O)cc1</smiles>

$32 \mathrm{~g}, 32 \mathrm{~h}$<smiles>CCOC(=O)C(P=O)N(C)C(=O)CS</smiles>

$\mathrm{ROH} \underset{\text { 2. } \mathrm{TMSBr}, \mathrm{CH}_{2} \mathrm{Cl}_{2}}{\stackrel{\text { 2-fluoro-1-methylpyridinium tosylate }}{\mathrm{Et}_{3} \mathrm{~N}, \mathrm{CH}_{2} \mathrm{Cl}_{2}}}$

$32 \mathrm{i}$

azidoquinolone to porphyrins bearing alkynyl groups [108]. They also prepared another type of conjugates 39a39d with use of the Suzuki-Miyaura coupling reaction of a $\beta$-borylated porphyrin with bromo-4-quinolones bearing $N$ ethyl and $N$-D-ribofuranosyl substituents and hybrids 40a, 40b in the Buchwald-Hartwig reaction between 2-amino$5,10,15,20$-tetraphenylporphyrinatonickel(II) and the 6-bromo-4-quinolone substrates followed by an oxidative intracyclization (Scheme 23). The photosensitizing properties of the conjugates 39, 40 were evaluated in singlet oxygen generation studies. The results were compared to meso-tetraphenylporphyrin, well-known singlet oxygen generator. The conjugates 39a-39d and 40c, 40d were found to generate singlet oxygen better than the reference photosensitizer [109, 110]. Compounds 40c, 40d showed interesting intense absorption bands in the red region of visible spectrum, which makes them potential candidates in PDT. Conjugates 40a, 40b were capable of generating singlet oxygen and, however, were slightly less efficient than the standard. Compounds $\mathbf{4 0 a}-\mathbf{4 0 d}$ were subjected to photoinactivation tests against $S$. aureus and all of the conjugates were found to be effective anti-microbials. 


\section{Scheme 19}

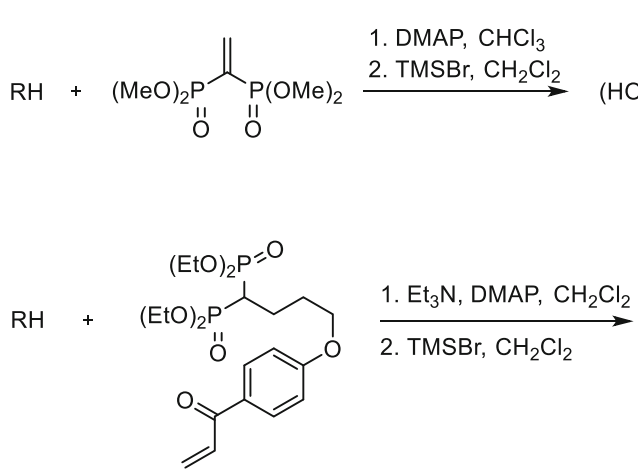<smiles>[R]CC(P(=O)(O)O)P(=O)(O)O</smiles>

33a, 33b<smiles>[R]CCC(=O)c1ccc(OCCCC(P(=O)(O)O)P(=O)(O)O)cc1</smiles><smiles>COc1c(N2CCNC(C)C2)c(F)cc2c(=O)c(C(=O)O)cn(C3CC3)c12</smiles>

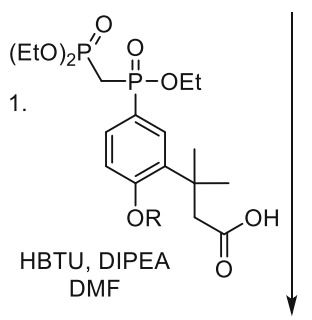

2. $\mathrm{TMSBr}$ 2,6-lutidine $\mathrm{CH}_{2} \mathrm{Cl}_{2}$
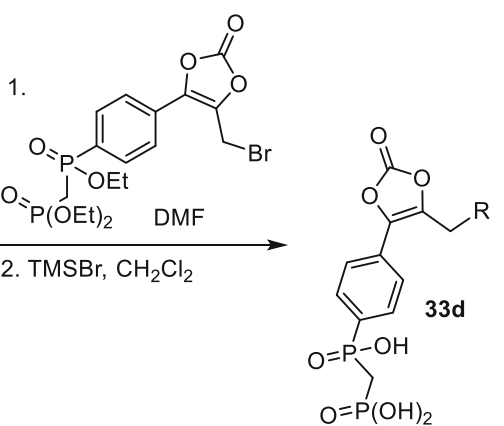

33a: $R=$<smiles>[Y]N1CCN(c2cc3c(cc2F)c(=O)c(C(=O)O)cn3C2CC2)CC1</smiles>

33b: $R=$<smiles>COc1c(N2C[C@@H]3CCCN(C)[C@@H]3C2)c(F)cc2c(=O)c(C(=O)O)cn(C3CC3)c12</smiles>

$33 c-33 h: R=$<smiles>COc1c(N2CCN([Y4](C)(C)C)C(C)C2)c(F)cc2c(=O)c(C(=O)O)cn(C3CC3)c12</smiles>

$33 i: R=$<smiles>COc1c(N2C[C@@H]3CCCN(C)[C@@H]3C2)c(F)cc2c(=O)c(C(=O)O)cn(C3CC3)c12</smiles><smiles>[R]C(=O)CC(C)(C)c1cc(P(=O)(O)CP(=O)(O)O)ccc1O</smiles>

33e-33g $\mathrm{R}=\mathrm{Ac}, i-\mathrm{PrCO},(\mathrm{HO})_{2} \mathrm{P}(\mathrm{O})$<smiles>CCOP(=O)(OCC)C(NC(=O)CCCC(=O)O)P(=O)(OC(C)=O)OC(=O)Cl</smiles>

1. $\mathrm{ClCH}(\mathrm{Me}) \mathrm{OCOC}$<smiles>[R]C(=O)OC(C)OC(=O)CCCC(=O)NC(P(=O)(O)O)P(=O)(O)O</smiles>

$33 h, 33 i$
Derivatives 40a and 40c were the most active and can be considered to be used in photodynamic inactivation of Gram-positive bacteria [110].

Methylene blue is another example of photoanti-microbial active against a wide range of bacteria, fungi, and viruses [111]. As its structure is related to phenothiazinium, Wainwright and coworkers coupled phenothiazinium derivatives with norfloxacin core to use the obtained conjugates in photoantibacterial targeting. The products were synthesized in reaction between the monosubstituted 3-dialkylaminophenothiazinium intermediates and norfloxacin (Scheme 24). Phenothiazinium compounds 41a41f absorb light wavelengths in the range of $620-670 \mathrm{~nm}$; thus, singlet oxygen production was measured under red light. In vitro singlet oxygen yields for the hybrids were too low to be determined using the standard spectrophotometric 
Scheme 20

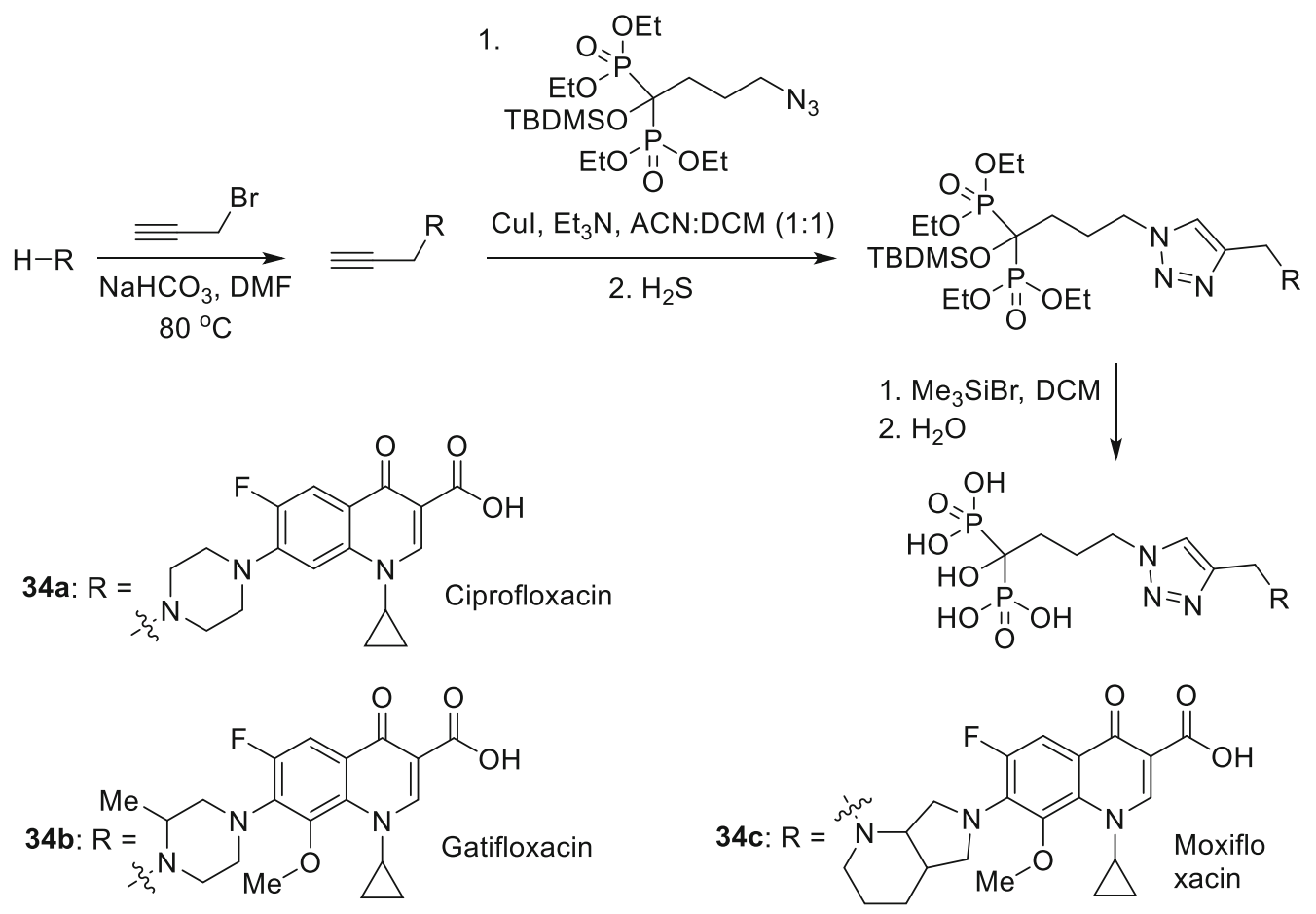

assay employed. The conjugates were found to be much stronger DNA binders and exhibited higher activity against $S$. aureus and $E$. coli bacterial strains than the parent drug after 20 min illumination with $660 \mathrm{~nm}$. Nevertheless, MIC values measured in the foil-covered controls providing dark conditions were high (approximately $100 \mu \mathrm{M}$ ), which suggest lack of essential targeting and does not support the specific DNA-localising hypothesis [112].

Some of the fluoroquinolones, namely, lomefloxacin and fleroxacin, which have two fluorine atoms, are able to act as photocleavers which upon photoirradiation generate arylcarbene that cause DNA damage. The arylcarbenes exhibit DNA cleaving activity by hydride abstraction from the phosphate backbone of nucleic acid. Suzuki and coworkers combined fluoroquinolone moiety with DNAbinding molecules, di- and tri-( $N$-methylpyrrole) known as DNA minor groove binders. Unexpectedly, the obtained conjugates 42 were photosensitive and undergone gradually decomposition under UV irradiation [113] (Fig. 10).

\section{Fluorescent compounds}

1,8-Naphthylimide derivatives have been described as fluorescent sensors and cellular imaging agents [114]. Kumar and coworkers synthesized hybrids of fluoroquinolone by an aromatic nucleophilic substitution of naphthalimide derivatives with norfloxacin (Scheme 25). Absorption and emission maxima of the conjugates 43 were 338-395 and 505-509 nm, respectively. Fluorescence measured in ethyl acetate, dichloromethane, and chloroform was found to be enhanced in comparison with the free quinolone and red shift of the emission maxima was observed in comparison with 4-bromo-1,8-naphthalic anhydride at excitation wavelength of $380 \mathrm{~nm}$. Antibacterial activity tests were performed against $E$. coli and $S$. aureus strains and compound $43 \mathrm{~b}$ showed the highest inhibition of both bacterial strains tested. Docking studies with ATP-binding pocket of E. coli topoisomerases (Gyrae $\mathrm{B}$ and ParE) revealed that this compound exhibits the highest binding affinity to ATP-site. The results described above make the conjugates potential drug candidates [115].

\section{Triazoles}

Substituted triazoles demonstrate considerable activity towards Gram-positive and Gram-negative bacteria [116] and are very well-recognized pharmacophores [117]. Ozdemir and coworkers performed Mannich condensation of 1,2,4-triazole-3-thioles with a secondary amine groups of piperazinyl moiety within norfloxacin $(44 a-44 c)$ or ciprofloxacin (44d-44f) (Scheme 26). Anti-microbial activity of the conjugates was evaluated against $E$. coli, 
1222

J. Fedorowicz, J. Sączewski

Scheme 21

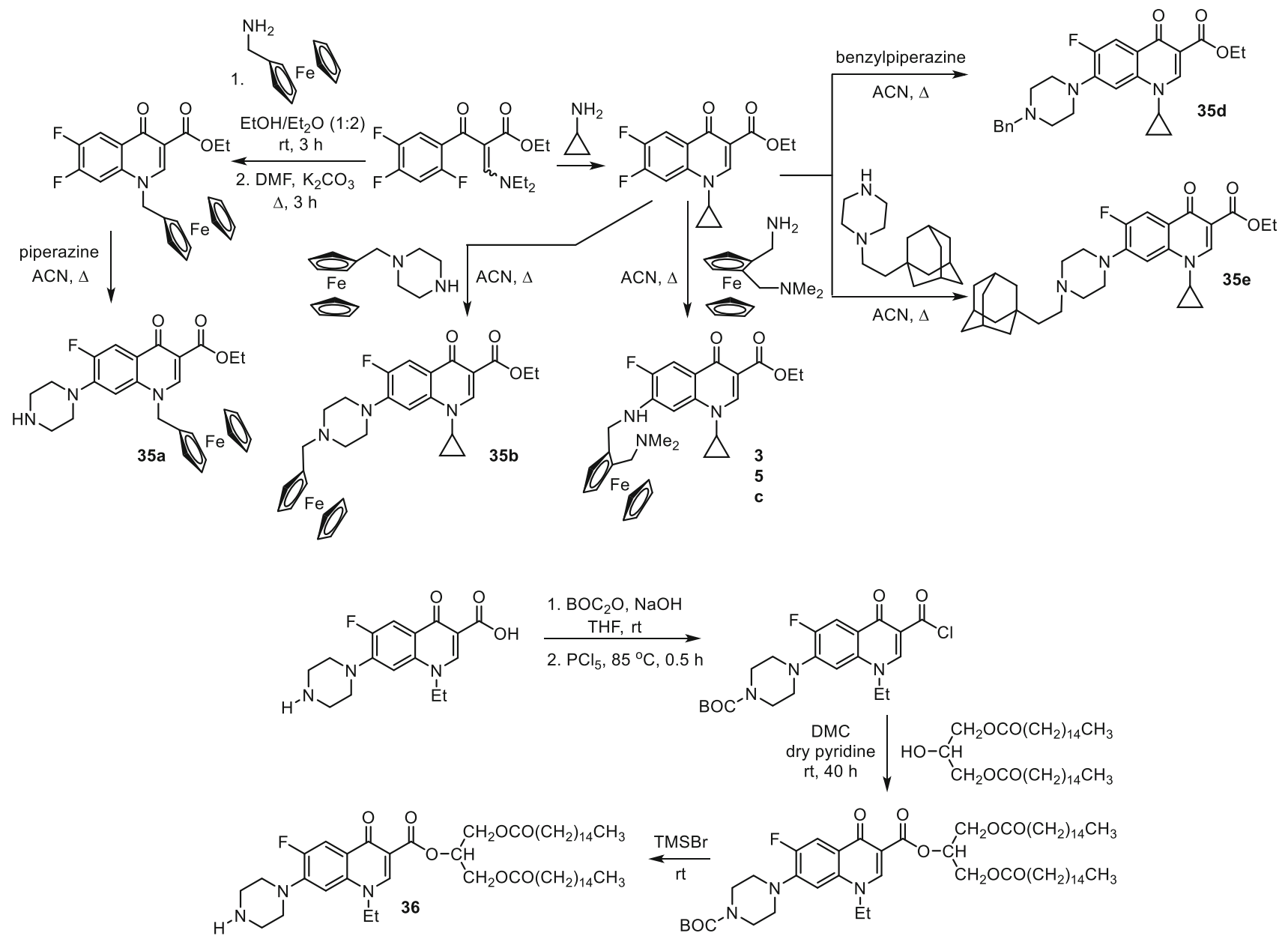

Scheme 22
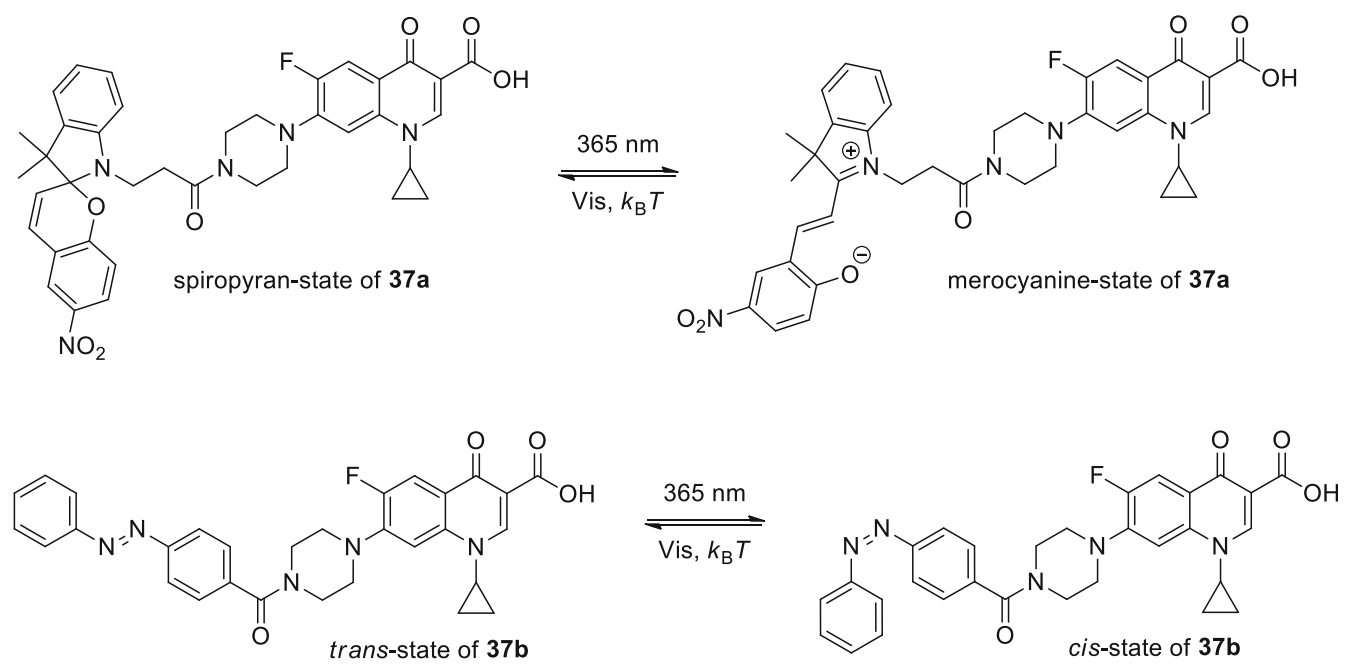

Springer 
Scheme 23<smiles>Fc1c(F)c(F)c(C(=C2C=CC(C(c3c(F)c(F)c(F)c(F)c3F)=c3ccc(=C(c4c(F)c(F)c(F)c(F)c4F)c4c(F)c(F)c(F)c(F)c4F)[nH]3)=N2)c2c(F)c(F)c(F)c(F)c2F)c(F)c1F</smiles>

1. propargyl alcohol, $\mathrm{K}_{2} \mathrm{CO}_{3}$ DMSO

2. $\mathrm{Zn}(\mathrm{OAC})_{2} \cdot 5 \mathrm{H}_{2} \mathrm{O}$

$\mathrm{CHCl}_{3} / \mathrm{MeOH}(2: 1)$

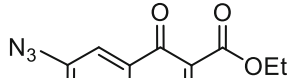

3. $\mathrm{CuSO}_{4} \cdot 5 \mathrm{H}_{2} \mathrm{O}$, ascorbic acid DMF, $50{ }^{\circ} \mathrm{C}$

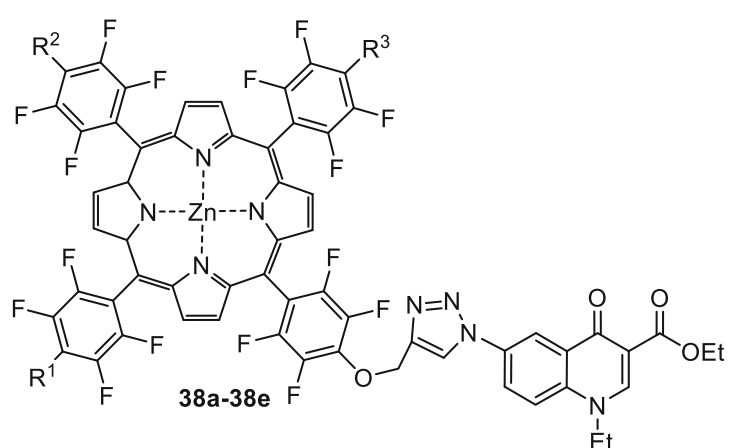

38a: $R^{1}=R^{2}=R^{3}=F$

38b: $R^{1}=X ; R^{2}=R^{3}=F$

38c: $R^{1}=F ; R^{2}=X ; R^{3}=F$

38d: $R^{1}=R^{2}=X ; R^{3}=F$

38e: $R^{1}=R^{2}=R^{3}=X$<smiles>[Y][Y6]Cc1cn(-c2ccc3c(c2)c(=O)c(C(=O)OCC)cn3CC)nn1</smiles>

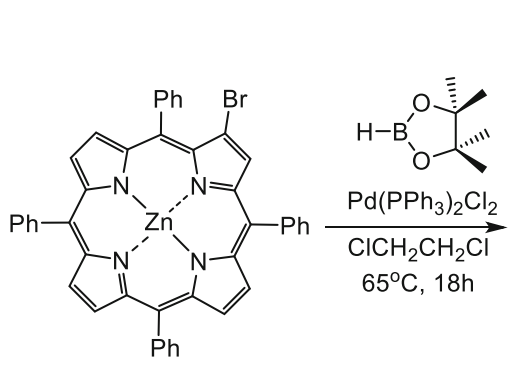

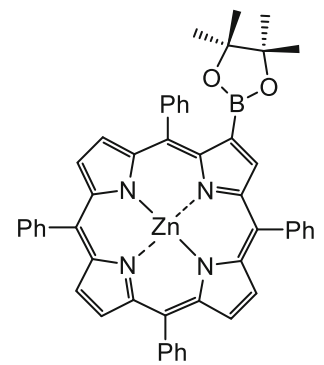

1. $\mathrm{R}-\mathrm{Br}$ $\mathrm{Pd}\left(\mathrm{PPh}_{3}\right)_{4}, \mathrm{Cs}_{2} \mathrm{CO}_{3}$ toluene/DMF, $80^{\circ} \mathrm{C}$ 2. $\mathrm{KOH} / \mathrm{MeOH}, 80^{\circ} \mathrm{C}$ 3. $\mathrm{CHCl}_{3} / \mathrm{TFA}$, rt

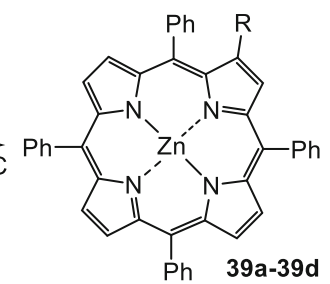

39a: $R=$<smiles>CCn1cc(C(=O)O)c(=O)c2cc([14CH3])ccc21</smiles><smiles>[R16][13CH2]c1ccc2c(=O)c(C(=O)O)cn(CC)c2c1</smiles><smiles>[R][Y9](=O)c1ccc2c(c1)c(=O)c(C(=O)O)cn2[C@@H]1O[C@H](CO)[C@@H](O)[C@H]1O</smiles>

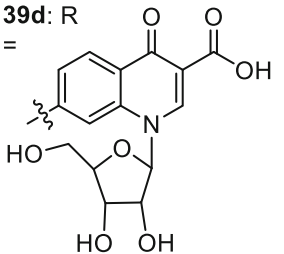

<smiles>[R]OC(=O)c1cn([R])c2ccc(Br)cc2c1=O</smiles>

1. $\mathrm{Pd}(\mathrm{OAc})_{2}, \mathrm{XPhos}$ or DTPB or rac-BINAP $\mathrm{KO}-\mathrm{t}$-Bu, toluene, $110^{\circ} \mathrm{C}$

2. $\mathrm{PhNO}_{2}$

3. $\mathrm{CH}_{2} \mathrm{Cl}_{2}, \mathrm{H}_{2} \mathrm{SO}_{4}$

4. $\mathrm{K}_{2} \mathrm{CO}_{3}$

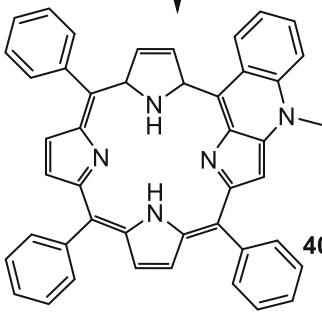

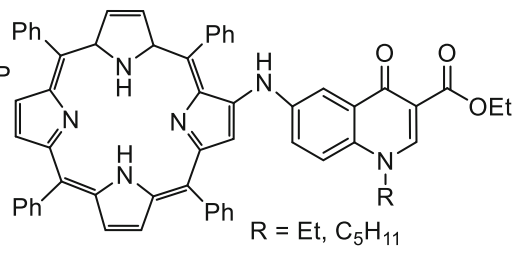

40a, 40b $R=E t$ for $40 a, C_{5} H_{11}$ for $40 b$ 
Scheme 24

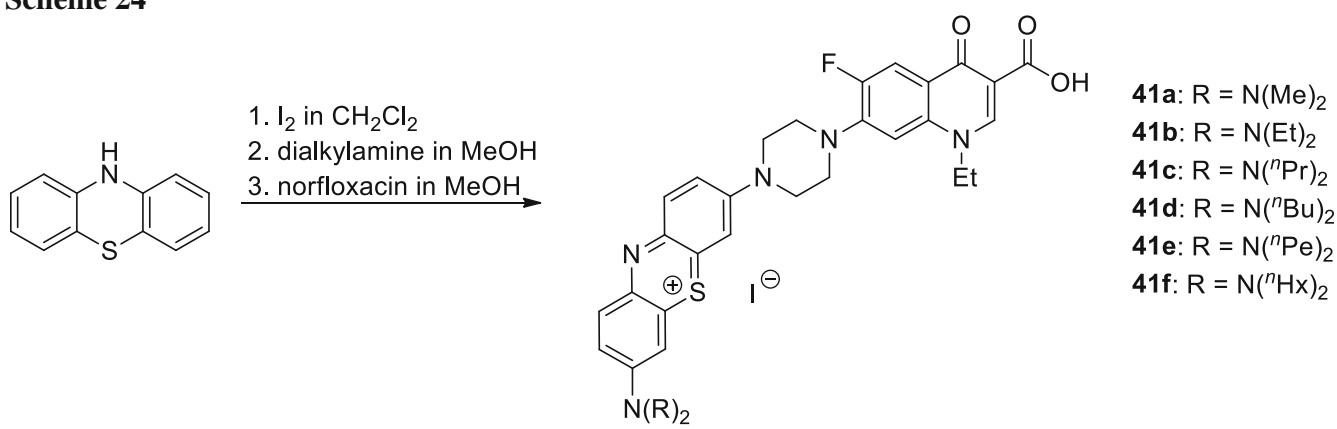

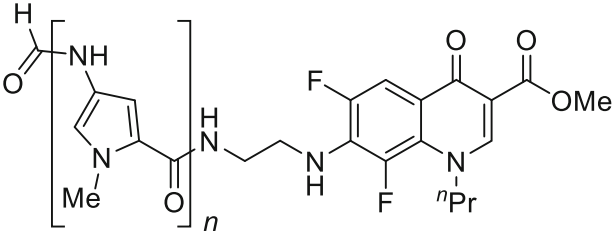

$42 a, 42 b$<smiles>CCCn1cc(C(=O)NCC(=O)Nc2cc(C(=O)NCCCNC)n(C)c2)c(=O)c2cc(F)c(NCCN)c(F)c21</smiles>

$42 c, 42 d$

$n=2$ for $42 a, 42 c ; 3$ for $42 b, 42 d$

Fig. 10 Structures of fluoroquinolone conjugates $\mathbf{4 1 ,} \mathbf{4 2}$

\section{Scheme 25}<smiles>CCn1cc(C(=O)O)c(=O)c2cc(F)c(N3CCNCC3)cc21</smiles><smiles></smiles>



Yersinia pestis, P. aeruginosa, S. aureus, E. faecalis, B. cereus, and $M$. smegmatis. The conjugates exhibited excellent activity towards tested strains with MIC values between 0.24 and $1.9 \mu \mathrm{g} / \mathrm{cm}^{3}$, comparable to the parent quinolones [118].

Dixit and coworkers employed click chemistry to synthesize fluoroquinolone analogs $\mathbf{4 5}$ bearing triazole ring on N1 nitrogen atom. The obtained compounds were tested against malaria parasite, $P$. falciparum. The compound $\mathbf{4 5}$ with unsubstituted triazole ring $(\mathrm{R}=\mathrm{H})$ was found to be the most active with $\mathrm{IC}_{50}$ of $1.33 \mu \mathrm{g} / \mathrm{cm}^{3}$, and proved to be almost sevenfold more potent than ciprofloxacin. In vitro cytotoxicity experiments revealed that this compound was the least toxic among screened compounds against HEK293 cells [119] (Fig. 11).

Fluoroquinolones bearing triazole moiety linked to piperazinyl ring 46-48 were also analyzed. Ciprofloxacin $\left(\mathrm{R}^{1}=\right.$ cyclopropyl; $\left.\mathrm{R}^{2}=\mathrm{F} ; \mathrm{X}=\mathrm{CH} ; \mathrm{Y}=\mathrm{C}\right)$, norfloxacin
$\left(\mathrm{R}^{1}=\mathrm{Et} ; \mathrm{R}^{2}=\mathrm{F} ; \mathrm{X}=\mathrm{CH} ; \mathrm{Y}=\mathrm{C}\right)$, and pipemidic acid $\left(\mathrm{R}^{1}=\mathrm{Et} ; \mathrm{X}=\mathrm{Y}=\mathrm{N}\right)$ were converted to alkyne derivatives, then subjected click reactions with amino-acid azides (46a-46g), dipeptide azide (47a-47c), or aryl azides (48a48i) utilizing the microwave-assisted technique (Scheme 27). The conjugates were obtained in fair yields (40-72\%) and tested against S. aureus, Staphylococcus pyogenes, Salmonella typhi, $P$ aeruginosa, and $E$. coli. The compounds possessing aryl substituents $\mathbf{4 8 a}-\mathbf{4 8 i}$ were the most active within the series [120].

Plech and coworkers also synthesized ciprofloxacin derivatives 49 with triazole bind to the piperazinyl ring. They obtained 40 novel conjugates through Mannich reactions in yields of $63-80 \%$ (Scheme 28 ). The compounds showed an increase of lipophilic properties $(\log \mathrm{P}$ of obtained conjugates of 1.63-4.62 vs. - 0.70 determined for ciprofloxacin). Most of the derivatives were found to be more active than the parent ciprofloxacin against strains 
Scheme 26
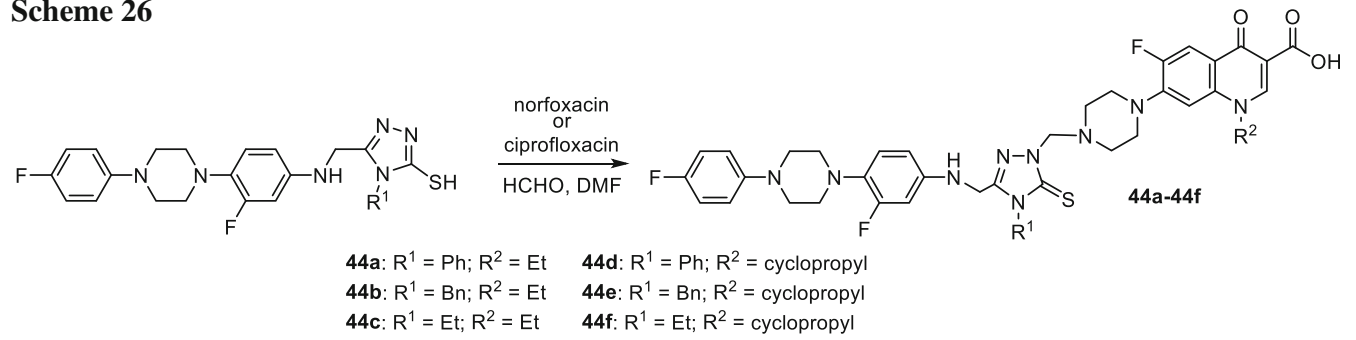

44b: $R^{1}=B n ; R^{2}=E t$

44c: $R^{1}=E t ; R^{2}=E t$

44f: $\mathrm{R}^{1}=\mathrm{Et} ; \mathrm{R}^{2}=$ cyclopropyl

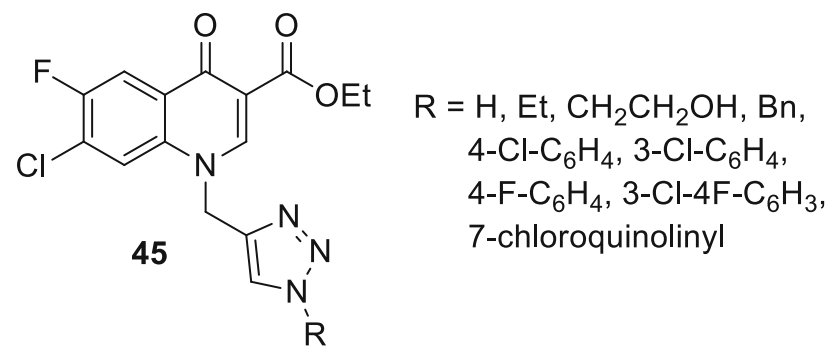

Fig. 11 Structures of triazole-fluoroquinolone hybrids $\mathbf{4 5}$ causing life-threatening infections (i.e., S. aureus, S. epidermidis, B. subtilis, B. cereus, M. luteus, E. coli, Proteus mirabilis, and $P$. aeruginosa), despite the fact that the majority of the conjugates were found to be weaker DNA gyrase and topoisomerase IV inhibitors than the parent drug in enzymatic studies. This high antibacterial activity may be caused by easier permeation inside bacterial cells or by the fact that these agents are not substrates or are poorer substrates for the bacterial endogenous efflux systems. Cytotoxicity of the selected compounds was

\section{Scheme 27}

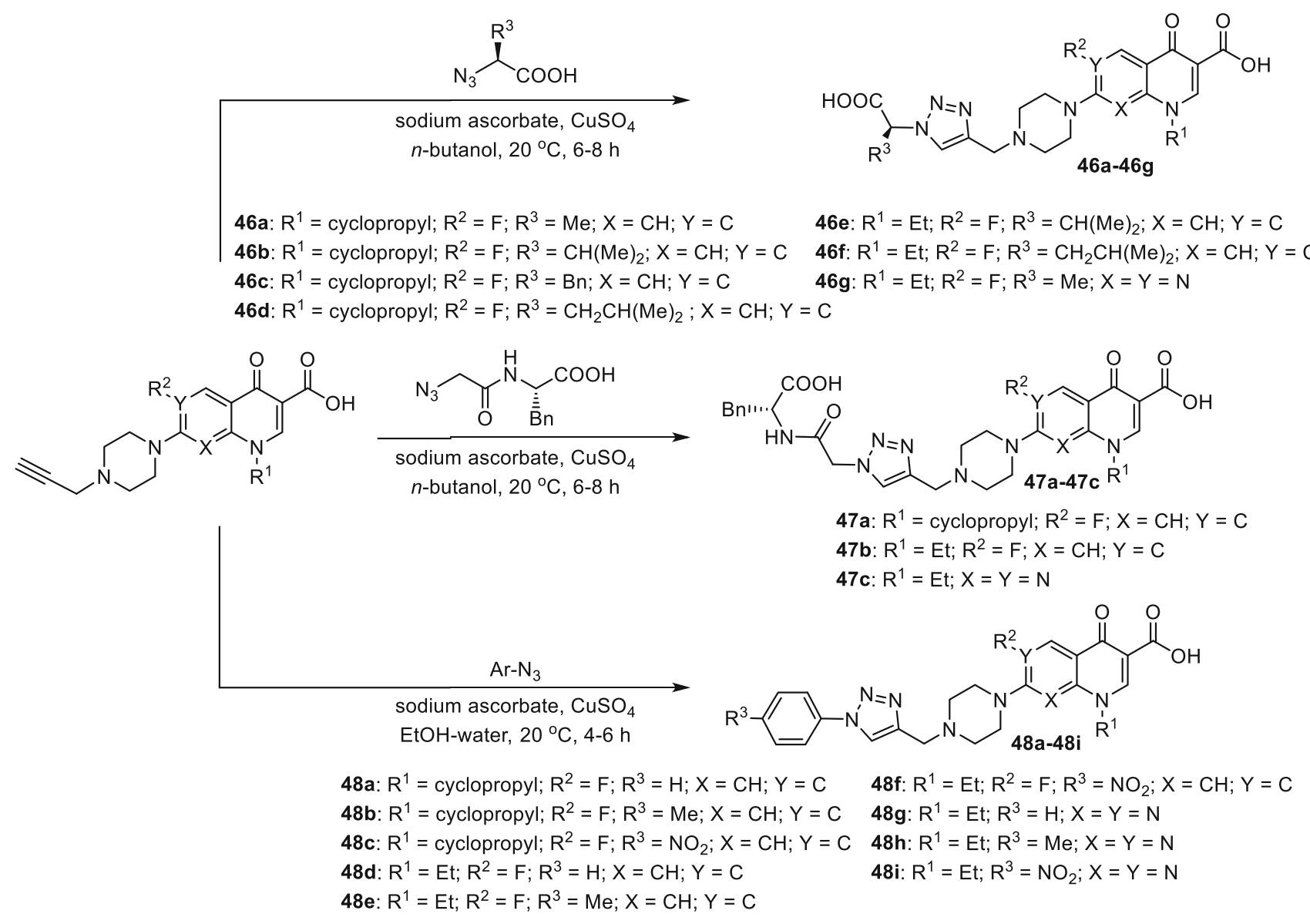




\section{Scheme 28}

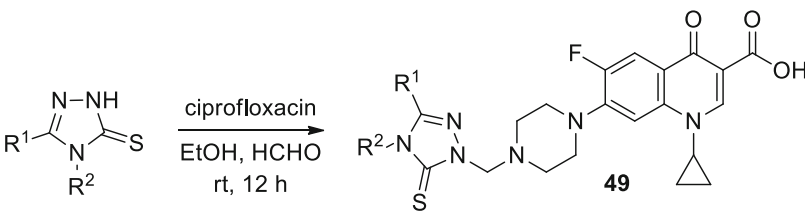

$\mathrm{R}^{1}=\mathrm{H}, \mathrm{Me}, n-\mathrm{C}_{3} \mathrm{H}_{7}, 3-\mathrm{Cl}-\mathrm{C}_{6} \mathrm{H}_{4}, 2-\mathrm{OH}-\mathrm{C}_{6} \mathrm{H}_{4}, 3-\mathrm{OH}-\mathrm{C}_{6} \mathrm{H}_{4}, 4-\mathrm{OH}-\mathrm{C}_{6} \mathrm{H}_{4}$ $\mathrm{R}^{2}=\mathrm{Me}, \mathrm{Et}, n-\mathrm{C}_{4} \mathrm{H}_{9}, \mathrm{Bn}, 4-\mathrm{Br}-\mathrm{C}_{6} \mathrm{H}_{4}, 4-\mathrm{OMe}-\mathrm{C}_{6} \mathrm{H}_{4}, 3-\mathrm{I}-\mathrm{C}_{6} \mathrm{H}_{4}, 4-\mathrm{I}-\mathrm{C}_{6} \mathrm{H}_{4}$, 4- $-\mathrm{Cl}-\mathrm{C}_{6} \mathrm{H}_{4}, 4-\mathrm{Cl}-\mathrm{C}_{6} \mathrm{H}_{4}-\mathrm{CH}_{2}, 4-\mathrm{OMe}-\mathrm{C}_{6} \mathrm{H}_{4}, 4-\mathrm{OMe}-\mathrm{C}_{6} \mathrm{H}_{4}-\mathrm{CH}_{2}$, $4-\mathrm{F}-\mathrm{C}_{6} \mathrm{H}_{4}, 4-\mathrm{F}-\mathrm{C}_{6} \mathrm{H}_{4}-\mathrm{CH}_{2}, 2,4-\mathrm{diF}-\mathrm{C}_{6} \mathrm{H}_{4}$

determined towards HEK-293 cells using MTT assay and was found to be remarkably lower than MIC values [121-123].

Kant and coworkers synthesized bis-triazole conjugates of ciprofloxacin 50a-50r in two-step procedure. The first step involved the reaction of ciprofloxacin with propargyl bromide in the presence of $\mathrm{NaHCO}_{3}$ at $100{ }^{\circ} \mathrm{C}$. In the next step, the obtained intermediate was reacted with substituted aromatic azides via copper-catalyzed azide-alkyne cycloaddition that afforded the desired products (Scheme 29). All hybrids were screened in vitro for their antibacterial activity against $S$. aureus, $S$. epidermidis, $E$. faecalis, E. coli, P. aeruginosa, Aeromonas hydrophila, $S$. typhimurium, S. typhi, Sphingomonas paucimobilis, and Plesiomonas shigelloides. Compared to the parent drug, compounds 50h, 50j, 50m displayed two to tenfold more potent activity against the tested species. The structure activity relationship revealed that the novel compounds with strong electron withdrawing substituents at the position 4 of the benzene ring enhanced the anti-microbial action, while electron-releasing groups decreased inhibitory activity. Hemotoxicity studies of the evaluated compounds revealed negligible toxicity profiles [124].
Zhang and coworkers prepared a series of novel azolylthioether modified quinolones 51-53. Azolylthioethers constitute a class of structural fragments common in many natural and synthetic active compounds exerting their function by transforming thioether into thiol moiety that disrupt structural integrity of many important proteins and deregulate the rate of intracellular oxidoreductive species [125]. In addition, the sulfur moiety is able to improve lipophilicity and moderate electron density of azole ring as an electron-rich center, thereby influencing the transmembrane diffusion ability. Commercially available quinolones were subjected reaction with 2-(chloromethyl)oxirane and subsequently reacted with azoles to produce the target compounds 51-53 in 21-35\% yield. Anti-microbial potency was tested in vitro against a panel of bacteria and fungi (Cyberlindnera utilis, Aspergillus flavus, Saccharomyces cerevisiae, Candida albicans, Candida mycoderma, M. luteus, S. aureus, B. subtilis, $P$. aeruginosa, E. coli, P. vulgaris, and Escherichia typhosa). Biological activities of the obtained compounds were high, especially for derivative $53(\mathrm{Z}=\mathrm{CH}, \mathrm{X}=$ pyrrolidin-3amine, $\mathrm{R}^{1}=$ cyclopropyl, $\mathrm{R}^{2}=\mathrm{F}$ ) with the lowest MIC values of $0.25 \mu \mathrm{g} / \mathrm{cm}^{3}$ against $S$. aureus MRSA and $P$. aeruginosa, superior to reference drugs. Docking studies with topoisomerase IV and genomic DNA form S. aureus MRSA revealed that this compound could interfere with nucleic acid through a copper-ion bridge to form a steady ternary complex which might block DNA replication. Moreover, studies of resistance development for compound 52 ( $\mathrm{X}=$ piperazine, $\mathrm{R}^{1}=\mathrm{Et}, \mathrm{R}^{2}=\mathrm{H}, \mathrm{R}^{3}=\mathrm{CH}_{2} \mathrm{C}_{6} \mathrm{H}_{3}-2,4-$ $\mathrm{diCl})$ revealed that after 25 passages bacterial resistance towards $S$. aureus MRSA did not increase, while norfloxacin showed increase of resistance after six passages [126] (Fig. 12).

\section{Scheme 29}
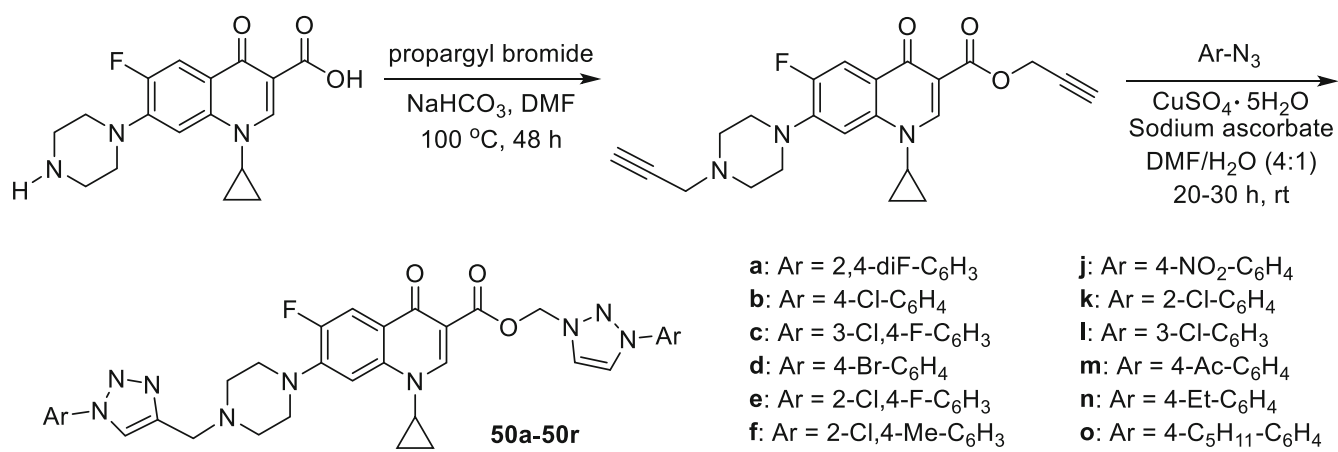
a: $\mathrm{Ar}=2,4-\mathrm{diF}-\mathrm{C}_{6} \mathrm{H}_{3}$
b: $\mathrm{Ar}=4-\mathrm{Cl}-\mathrm{C}_{6} \mathrm{H}_{4}$
c: $\mathrm{Ar}=3-\mathrm{Cl}, 4-\mathrm{F}-\mathrm{C}_{6} \mathrm{H}_{3}$
d: $\mathrm{Ar}=4-\mathrm{Br}-\mathrm{C}_{6} \mathrm{H}_{4}$
e: $\mathrm{Ar}=2-\mathrm{Cl}, 4-\mathrm{F}-\mathrm{C}_{6} \mathrm{H}_{3}$
f: $\mathrm{Ar}=2-\mathrm{Cl}, 4-\mathrm{Me}-\mathrm{C}_{6} \mathrm{H}_{3}$
g: $\mathrm{Ar}=2,4-\mathrm{diCl}-\mathrm{C}_{6} \mathrm{H}_{3}$
h: $\mathrm{Ar}=4-\mathrm{OCF}_{3}-\mathrm{C}_{6} \mathrm{H}_{4}$
i: $\mathrm{Ar}=2,3-\mathrm{diCl}-\mathrm{C}_{6} \mathrm{H}_{3}$
j: $\mathrm{Ar}=4-\mathrm{NO}_{2}-\mathrm{C}_{6} \mathrm{H}_{4}$
k: $\mathrm{Ar}=2-\mathrm{Cl}-\mathrm{C}_{6} \mathrm{H}_{4}$
I: $\mathrm{Ar}=3-\mathrm{Cl}-\mathrm{C}_{6} \mathrm{H}_{3}$
$\mathrm{m}: \mathrm{Ar}=4-\mathrm{Ac}-\mathrm{C}_{6} \mathrm{H}_{4}$
n: $\mathrm{Ar}=4-\mathrm{Et}^{-\mathrm{C}_{6}} \mathrm{H}_{4}$
o: $\mathrm{Ar}=4-\mathrm{C}_{5} \mathrm{H}_{11}-\mathrm{C}_{6} \mathrm{H}_{4}$
p: $\mathrm{Ar}=3,5-\mathrm{diMe}-\mathrm{C}_{6} \mathrm{H}_{3}$
q: $\mathrm{Ar}=2-\mathrm{OMe}-\mathrm{C}_{6} \mathrm{H}_{4}$
$\mathbf{r}: \mathrm{Ar}=\mathrm{Ph}$


Fig. 12 Structures of fluoroquinolone-triazole hybrids 51-53<smiles>[X]c1c(F)cc2c(=O)c(C(=O)O)cn([R])c2c1[R]</smiles><smiles>[X]c1c(F)cc2c(=O)c(C(=O)O)cn([R1])c2c1[R]</smiles><smiles>[X]c1c(F)cc2c(=O)c(C(=O)O)cn([R])c2c1[R]</smiles>

53

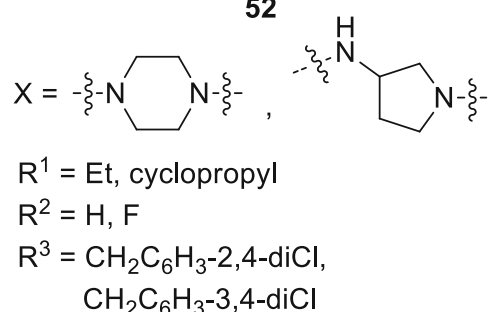

\section{Hybrid drugs}

Combining of two existing drugs into one molecule is a common approach to extend biological activity and avoid antibiotic multidrug resistance caused by microorganism mutations. CBR-2029 (54) is a novel hybrid antibiotic with a structure of covalently combined rifampicin and quinolone. Rifamycin drugs inhibit bacterial DNA-dependent RNA synthesis, exhibit excellent tissue distribution [127], and efficiently penetrate biofilm formed in vitro [128]. Recent studies demonstrated that CBR-2029 exhibit prolonged bactericidal activity against $S$. aureus, superior to rifampicin, ciprofloxacin, moxifloxacin, or cocktail of rifampicin and moxifloxacin. Moreover, this drug did not cause resistance development and was not a substrate for the NorA or MepA efflux pumps of S. aureus [129]. The CBR-2029 potency of $S$. aureus RNA polymerase inhibition was twofold less than rifampin $\left(\mathrm{IC}_{50}\right.$ of $0.034 \mu \mathrm{M}$ vs. $0.015 \mu \mathrm{M}$ for the reference drug); however, this drug exhibited nearly equipotent activity against $S$. aureus DNA topoisomerase IV and gyrase as ciprofloxacin and gatifloxacin $\left(\mathrm{IC}_{50}\right.$ values of 1.7 and $1.5 \mu \mathrm{M}$ for corresponding enzymes, respectively). CBR-2092 revealed delayed additional mode of action: i.e., rifampin-like effect on protein and cell wall synthesis [130] (Fig. 13).

Oxazolidones are class of antibiotics that act at early step in bacterial protein synthesis. Cadazolid (Fig. 14) is an experimental drug bearing both oxazolidinone and fluoroquinolone moiety, invented by Actelion Pharmaceuticals Ltd. Recently, it had been extensively investigated for the treatment of Clostridium difficile, a Gram-positive toxinand spore-forming anaerobe which is the most common cause of antibiotic-associated diarrhea and colitis. Cadazolid was tested in vitro against references as well as clinical isolates of $C$. difficile with an MIC range of $0.125-0.5 \mu \mathrm{g} / \mathrm{cm}^{3}$ [131]. The propensity of spontaneous resistance development found to be low; MIC values in tested strains increased only very slowly upon 13 passages [132]. Inhibition of translation was tested in biochemical

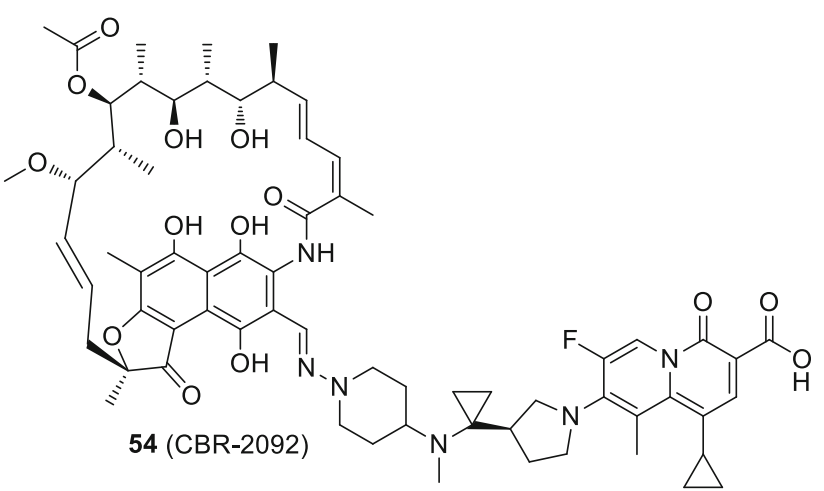

Fig. 13 Structure of rifamycin-quinolone conjugate 54 (CBR-2029)<smiles>O=C(O)c1cn(C2CC2)c2cc(N3CCC(O)(COc4ccc(N5C[C@H](CO)OC5=O)cc4F)CC3)c(F)cc2c1=O</smiles>

Fig. 14 Structure of cadazolid

assays and it was determined as the primary mode of action of cadazolid in $C$. difficile. Cadazolid potently inhibited protein synthesis in wild type and quinolone-resistant strains. Inhibition of DNA synthesis was suggested as a second mode of action, which was proved on the basis of macromolecular labeling studies. Inhibitory effects in DNA topoisomerase assays were weak. Concentrations needed to observe that half-maximal inhibition of DNA synthesis was more than 60-fold higher than these for protein synthesis inhibition [132]. Cadazolid strongly inhibited toxin formation and delayed the formation of spores at sub-growthinhibitory concentrations. Tests in mouse and hamster models for prevention of diarrhea and mortality showed that cadazolid markedly decreased the risk of death [131]. Cadazolid demonstrated narrow spectrum activity eliminating $C$. difficile while having a very limited impact on the 
normal gut microbiota. In the in vitro gut model, it rapidly reduced counts of vegetative cell and cytotoxin titers of $C$. difficile in simulated infection, which declined to the limit of detection by the end of the 7-day dosing period, and showed no sign of recurrence. Regimen of $250 \mathrm{mg} / \mathrm{dm}^{3} \mathrm{did}$ not appear to have a more inhibitory effect on microflora populations. Cadazolid application provoked sparing of the enumerated gut microflora with the exception of bifidobacteria and only a slight decreases in total Clostridium and Enterococcus populations [133]. Phase 1 clinical trials were performed in total of 64 healthy male subjects in single or multiple (twice daily for 10 days) oral doses of cadazolid between 30 and $3000 \mathrm{mg}$, or placebo. After first trials in humans cadazolid found to be well tolerated and its systemic exposure was low. The high concentrations of the drug were found at the site of action (colon). Probably due to its poor water solubility, cadazolid mostly retained in the gastrointestinal tract after oral administration. The lack of metabolites or potential degradation products was detected in plasma and majority of the compound was recovered unchanged in the faeces within $72 \mathrm{~h}$ of single oral administration, which together suggests high stability of the compound in the tested human matrices [134]. In the phase 2 clinical study, efficacy and safety of three oral dosages of cadazolid $(250,500$, or $1000 \mathrm{mg}$ ) were investigated in comparison with vancomycin (reference drug) in 84 patients with $C$. difficile infections. The cure rates for both drugs were similar: $68.2 \%$ for vancomycin and $68.4-80.0 \%$ for cadazolid. The recurrence rates were lower with all cadazolid dosages (18.2-25.0\%) than with vancomycin $(50.0 \%)$ [135]. Moreover, the susceptibilities of C. difficile isolates to cadazolid were evaluated. The MIC values of epidemic strains isolated from patients from phase 2 clinical trial were low an in the narrow range. Even for the lowest dosage of cadazolid, the faecal concentration of the drug was in higher than MIC for C. difficile [136]. To our best knowledge, results from phase 3 trials have not been published yet and are still analyzed.

Darekhordi and coworkers synthesized oxazolidone derivatives of fluoroquinolones $\mathbf{5 5}$ via amination of $\mathrm{N}$-aryltrifluoroacetimidolyl chlorides with norfloxacin or ciprofloxacin piperazinyl group (Scheme 30). The conjugates were obtained in good yields (60-86\%) and some of them were selected to antibacterial activity tests performed against S. aureus, E. coli, and K. pneumoniae. Compounds 55a and $\mathbf{5 5 c}$ were found to be better antibacterial agents than ciprofloxacin against all strains tested at concentrations of $10-15 \mu \mathrm{g} / \mathrm{cm}^{3}$ in agar diffusion test [137].

Azithromycin is one of the macrolide antibiotics that act by inhibition of bacterial protein synthesis. A series of azithromycin-quinolone hybrids 56a-56f linked with ether linkers were synthesized in the route, as presented in Scheme 31. Antibacterial activities of the hybrids were tested on S. aureus, Streptococcus pneumoniae, and S. pyogenes. Most of the conjugates were poorly active; however, compound 56c exhibited the highest antibacterial activity against tested strains [138].

Another antibiotic used in fluoroquinolone conjugates is tobramycin. This drug belongs to broad-spectrum antibiotic aminoglycosides that works by binding to a site on the bacterial $30 \mathrm{~S}$ and $50 \mathrm{~S}$ ribosome units preventing the formation of the 70S complex and can cause outer membrane disruption [139]. Gorityala and coworkers synthesized conjugates 57-59 of ciprofloxacin and moxifloxacin with tobramycin linked by long carbon chains and evaluated antibacterial properties of the obtained conjugates. Hybrids 58a, 58b and 59a, 59b showed weak antibacterial action; nevertheless, compounds 57a, 57b were found to be good antibacterials, even against resistant $P$. aeruginosa strains. The most active conjugates 57a, 57b demonstrated an ability to destabilize membrane and better inhibit DNA gyrase A and topoisomerase IV than the parent fluoroquinolone. However, reduction in protein translation inhibition was observed. The hybrids displayed also delayed bacterial resistance development, low cytotoxicity against cancer cell lines, and hemolysis of human erythrocytes below 10\% [140, 141]. Moxifloxacin derivative 57a showed no toxic effect in Galleria mellonella up to the maximal dose of $600 \mathrm{mg} / \mathrm{kg}$. Efficacy studies in larvae infected with XDR $P$. aeruginosa strain revealed $100 \%$ survival after $24 \mathrm{~h}$ with single-dose therapy of $50 \mathrm{mg} / \mathrm{kg}$ and enhanced the long-survival effect, while treatment with moxifloxacin or tobramycin resulted in $20-27 \%$ survival [141] (Fig. 15).

Scheme 30

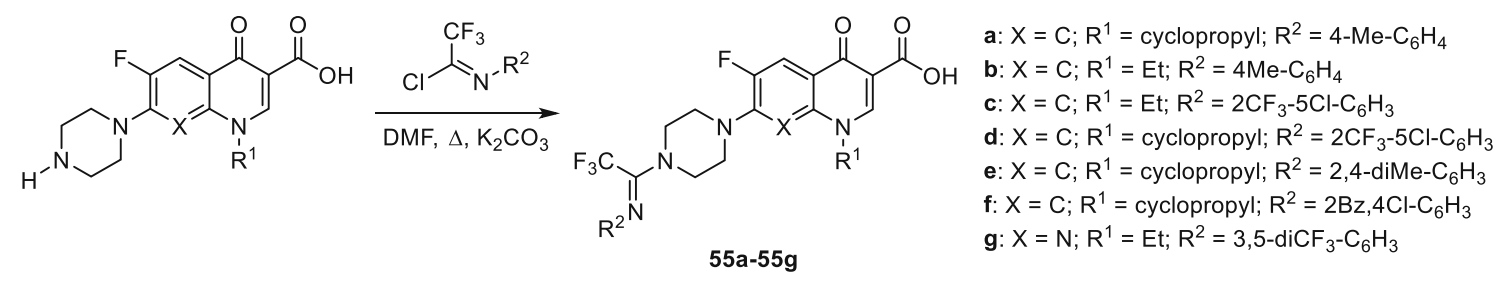


Scheme 31

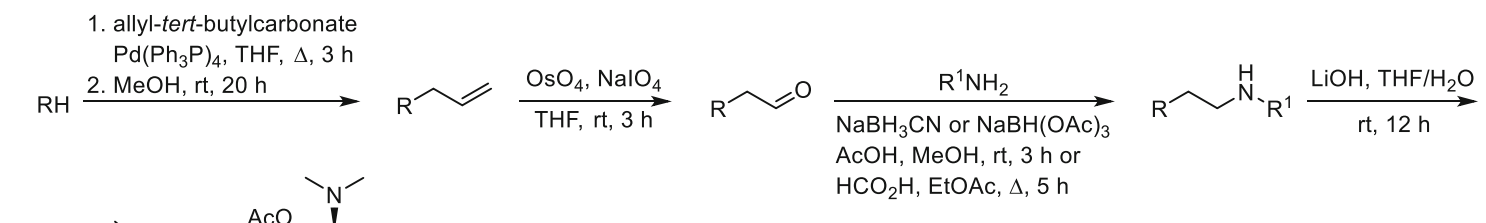

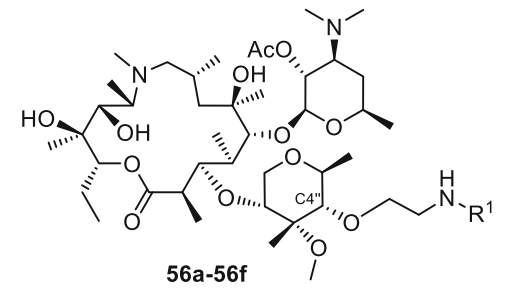

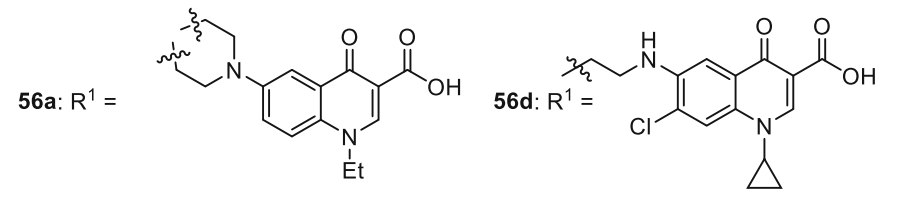

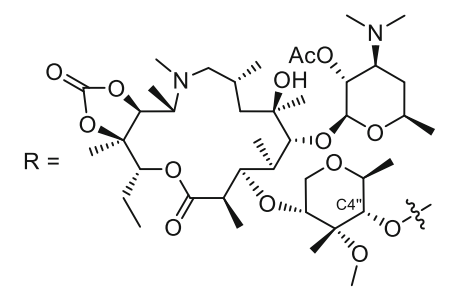<smiles></smiles><smiles>CC(C)(C)COCCNc1cc2c(=O)c(C(=O)O)cn(C3CC3)c2cc1Cl</smiles><smiles>CC(C)(C)COCCOCCNc1cc2c(=O)c(C(=O)O)cn(C3CC3)c2cc1Cl</smiles>

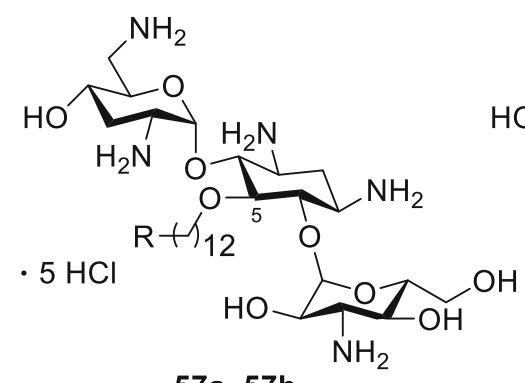

$57 a, 57 b$

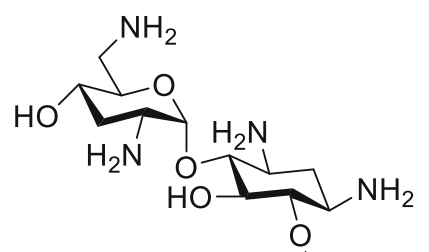

. $5 \mathrm{HCl} \mathrm{RY}_{12} \mathrm{O} \underbrace{\mathrm{N}}_{2^{\prime \prime}} \mathrm{NH}_{\mathrm{OH}} \mathrm{OH}$

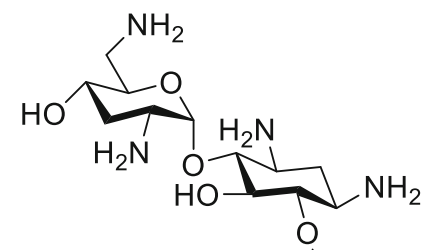

$\cdot 5 \mathrm{HCl}$

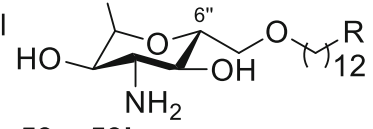

$59 a, 59 b$ a: $\mathrm{R}$<smiles>COc1c(N2C[C@H]3CCCN(C)[C@@]3(C)C2)c(F)cc2c(=O)c(C(=O)O)cn(C3CC3)c12</smiles>

$5 \mathrm{a}, 58 \mathrm{~b}$

b: $\mathrm{R}=$<smiles>CN1CCN(c2cc3c(cc2F)c(=O)c(C(=O)O)cn3C2CC2)CC1</smiles>

Fig. 15 Structures of tobramycin-fluoroquinolone conjugates 57-59

Pokrovskaya and coworkers also used aminoglycosides to form dual antibiotics with fluoroquinolones. They coupled ciprofloxacin-azide and neomycin B-alkyne derivatives via click chemistry to afford a library of 17 conjugates 60 with different spacer lengths. The reactions were performed under microwave irradiation in the presence of an organic base and the $\mathrm{Cu}(\mathrm{I})$ catalyst in excellent yields. Antibacterial activity of the obtained compounds in MIC assays was improved in comparison with neomycin B, however, lower than ciprofloxacin. Inhibition of DNA gyrase, topoisomerase IV, and protein synthesis of the most potent hybrids revealed that the novel compounds are better enzyme inhibitors than both parent drugs confirming desired dual mode of action. Higher MIC values might be a consequence of reduced cell penetration by the conjugates with higher molecular weights [142] (Fig. 16).

Quinine is a unique therapeutic agent with exceptional pharmacological efficacy as an antimalarial drug. Panda and coworkers prepared group of conjugates 61,62 that comprised quinolone antibiotics, quinine and amino-acid linkers utilizing benzotriazole chemistry (Scheme 32). They used levofloxacin, enrofloxacin, oxolinic acid, and 


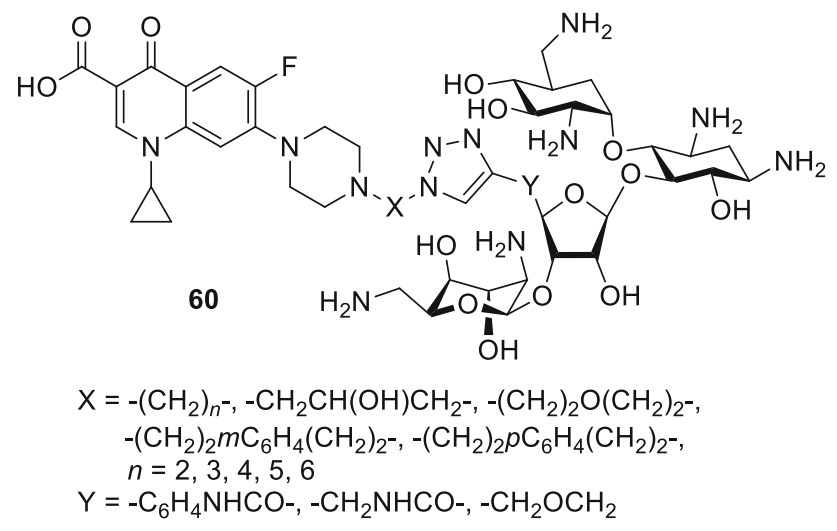

Fig. 16 Structures of ciprofloxacin-neomycin B hybrids $\mathbf{6 0}$

nalidixic acid as precursors of the conjugates to enhance the antimalarial activity of the drugs. The obtained hybrids retained in vitro antimalarial activity with $\mathrm{IC}_{50}$ values ranging from 12 to $207 \mu \mathrm{M}$ determined in antimalarial bioassay against $P$. falciparum 3D7, chloroquine-sensitive strain. The results were comparable to that assessed for quinine $\left(\mathrm{IC}_{50}=18 \mu \mathrm{M}\right)$ [143].

The same research group in a similar way prepared fluoroquinolone-pyrazine hybrids 63a-63h with aminoacid linkers. Pyrazinamide is one of the first-line antituberculosis drugs which has multiple mechanisms of action. It acts as a prodrug, since it is metabolized to pyrazinoic acid via mycobacterial enzyme pyrazinamidase [144]. Linkers between biologically active compounds were used to modify lipophilicity and increase drugs ability to penetrate into mammalian tissue. The novel compounds were synthesized in acetonitrile under microwave irradiation at $20 \mathrm{~W}, 50{ }^{\circ} \mathrm{C}$ for $1 \mathrm{~h}$, by coupling amino acid or $\gamma$ aminobutyric acid-fluoroquinolone conjugates of norfloxacin or ciprofloxacin with $(1 H$-benzo[ $d][1,2,3]$ triazol1-yl)(pyrazin-2-yl)methanone in the presence of DBU (Scheme 33). Subsequently, they were investigated against $S$. typhi, P. aeruginosa, S. aureus, and S. pyogenes bacteria. The ciprofloxacin derivative $\mathbf{6 3 h}$ was found to be the most promising antibacterial agent against $S$. aureus ATCC29523 and S. pyogenes ATCC19615 with MIC values 74.6 and $149.3 \mu \mathrm{M}$, respectively. These two strains were resistant to both reference drugs. However, $\mathbf{6 3 h}$ was less active than investigated fluoroquinolones against $S$. typhi and $P$. aeruginosa bacteria, which were susceptible to both norfloxacin and ciprofloxacin [145].

Markad and corworkers investigated quinolone-pyrazinamide hybrid 64 as potential antituberculosis drug candidate. This compound exhibited improved antitubercular activity in comparison with pyrazinamide and wide antibacterial action against common bacterial pathogens; however, it was inactive in DNA supercoiling assay indicating novel mechanism of action [146] (Fig. 17).

Zhou and coworkers used dihydroartemisinin (DHA) to produce fluoroquinolone conjugates 65-67 aiming to treat tuberculosis. DHA is artemisinin derivative exhibiting better solubility, bioavailability, and biological activity than artemisinin. Both drugs find applications as antimalarial agents [147]; however, DHA was under investigation for its antitubercular activity and showed potent inhibition of Mycobacteria. Ciprofloxacin, norfloxacin, sarafloxacin, and clinafloxacin were coupled with DHA

Scheme 32
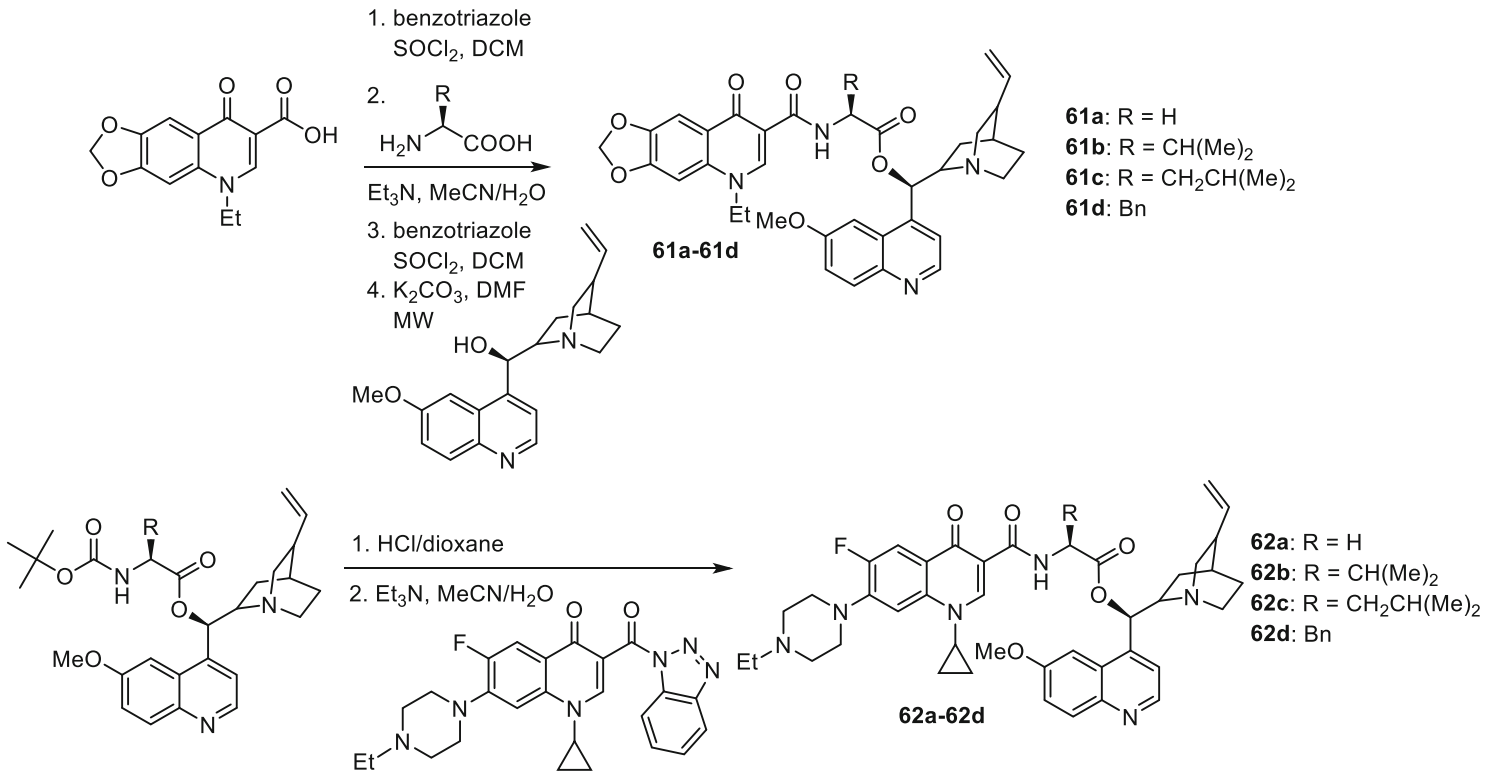


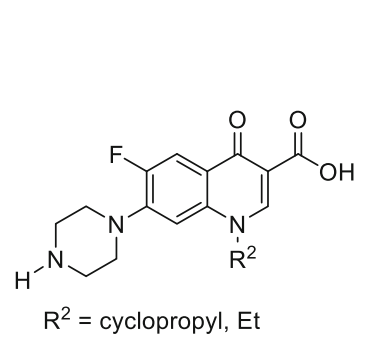<smiles>[R]C(NC(C)(C)C)C(=O)n1nnc2ccccc21</smiles><smiles>[R1]C(NC(=O)c1cnccn1)C(=O)N1CCN(c2cc3c(cc2F)c(=O)c(C(=O)O)cn3[R])CC1</smiles><smiles>NC(=O)c1cnc(CNc2nc3c(cc2F)c(=O)c(C(=O)O)cn3C2CC2)cn1</smiles>

Fig. 17 Structure of quinolone-pyrazinamide hybrid 64

derivatives and subjected anti-microbial experiments. The majority of the newly synthesized conjugates $\mathbf{6 5 - 6 7}$ were active and selective against Mycobacterium tuberculosis. Clinafloxacin derivatives 66 and 67 ( $\mathrm{R}=$ cyclopropyl, $\mathrm{X}=\mathrm{Cl}, \mathrm{Y}=$ pyrrolidin-3-amine) exhibited stronger activity than the parent drug and were extremely potent against reference strain as well as clinical isolates, both sensitive and multidrug resistant [148] (Fig. 18).

Sriram and coworkers designed tetracycline-fluoroquinolone hybrids which were investigated for their antimycobacterial and antiviral properties. As tetracycline exhibit HIV-1 integrase inhibitory activity, they hypothesized these hybrid compounds could act both as HIV-1 integrase inhibitors and as antibiotics in M. tuberculosis treatment. Compounds $\mathbf{6 8 a}-\mathbf{6 8 d}, \mathbf{6 8 j}$ were found to be excellent anti-HIV agents preventing virus replication and exhibited lower cytotoxicity against CEM cell line, while conjugates $68 \mathrm{~d}, 68 \mathrm{j}$, and $68 \mathrm{I}$ exhibited high activity against M. tuberculosis [149] (Scheme 34).

Metronidazole is an example of synthetic antibiotic. This drug demonstrates inhibitory efficacies against Gram-negative anaerobic bacteria, such as Helicobacter pylori, and protozoa, i.e., Giardia, Lamblia, and Entamoeba histolytica [150]. Nitro fragment present in its structure undergoes

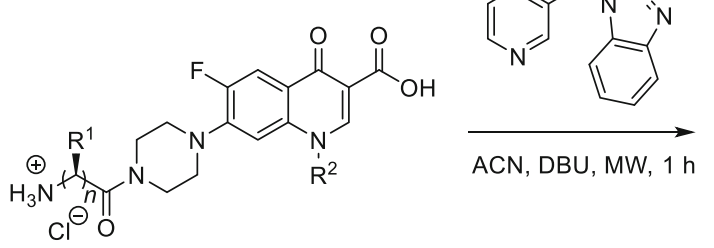

$$
\begin{aligned}
& \text { 63a: } n=1 ; \mathrm{R}^{1}=\mathrm{H} ; \mathrm{R}^{2}=\mathrm{Et} \\
& \text { 63b: } n=1 ; \mathrm{R}^{1}=\mathrm{Me} ; \mathrm{R}^{2}=\mathrm{Et} \\
& \text { 63c: } n=2 ; \mathrm{R}^{1}=\mathrm{H} ; \mathrm{R}^{2}=\mathrm{Et} \\
& \text { 63d: } n=3 ; \mathrm{R}^{1}=\mathrm{H} ; \mathrm{R}^{2}=\mathrm{Et} \\
& \text { 63e: } n=1 ; \mathrm{R}^{1}=\mathrm{H} ; \mathrm{R}^{2}=\text { cyclopropyl } \\
& \text { 63f: } n=1 ; \mathrm{R}^{1}=\mathrm{Me} ; \mathrm{R}^{2}=\text { cyclopropyl } \\
& \text { 63g: } n=2 ; \mathrm{R}^{1}=\mathrm{H} ; \mathrm{R}^{2}=\text { cyclopropyl } \\
& \text { 63h: } n=3 ; \mathrm{R}^{1}=\mathrm{H} ; \mathrm{R}^{2}=\text { cyclopropyl }
\end{aligned}
$$

reduction process by metabolic pathway and the reactive intermediate is able to damage nucleic acids [151]. The conjugates of metronidazole and quinolones 69,70 were prepared by Cui and coworkers in multi-step synthesis (Scheme 35) and evaluated in vitro against Gram-positive (S. pneumoniae, M. luteus, 2 strains of $S$. aureus, and $B$. subtilis) and Gram-negative (P. aeruginosa, E. coli, Shigella dysenteriae, and $E$. typhosa) bacteria as well as fungi ( $C$. albicans, C. mycoderma, and A. flavus). Antifungal activity of the obtained compounds was found to be moderate or weak. The measured MIC values were in the range of 64-512 $\mu \mathrm{g} / \mathrm{cm}^{3}$ only with small exception for the hybrids 69b and 70b, which were more potent than the reference drug, fluconazole. The synthesized compounds exhibited divergent activity in antibacterial assays. The most potent conjugates were compounds 70b and 70d (MIC values of $0.5-8 \mu \mathrm{g} / \mathrm{cm}^{3}$ ). Hybrids $69 \mathbf{b}, \mathbf{7 0 b}$, and 70d were further examined for their cytotoxic properties on A549 and normal human hepatocyte LO2 cell lines and no obviously reducing trends to the cell viability were observed within the concentration of $128-256 \mu \mathrm{g} / \mathrm{cm}^{3}$. Molecular modeling studies were performed with use of the crystal structure of S. pneumoniae topoisomerase IV-DNA complex and the docking results of the target hybrids showed that the substituents on benzene ring of quinolone could affect the antibacterial activities. Compound 70d was tested in binding assay with calf-thymus DNA and exhibited stronger interferation with nucleic acid than norfloxacin. These conjugates exhibited also good aqueous solubility, which combined make them good potential drug candidates [152].

Miconazole is a well-established drug that acts by competitive inhibition of the cytochrome P-450 enzyme through direct intercalation [153]. This action leads to lethal disruption in the normal sterol biosynthesis chain in 


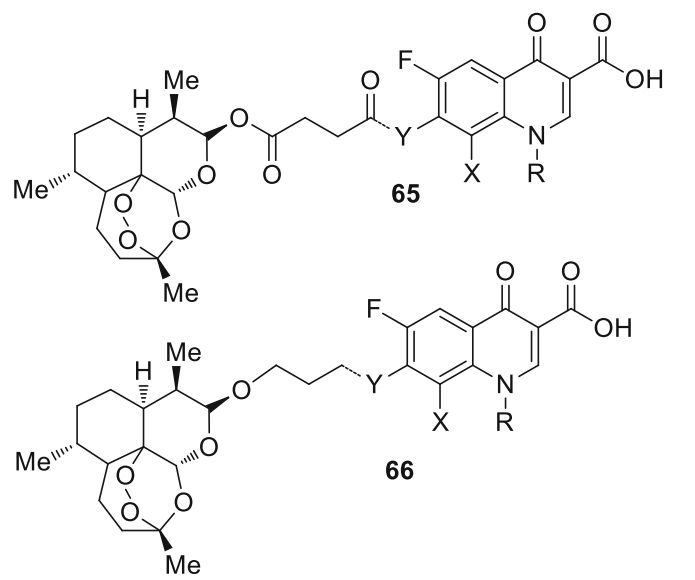

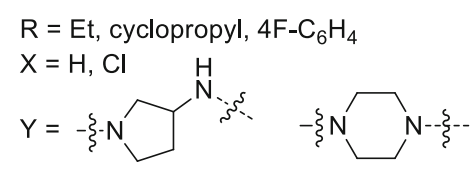

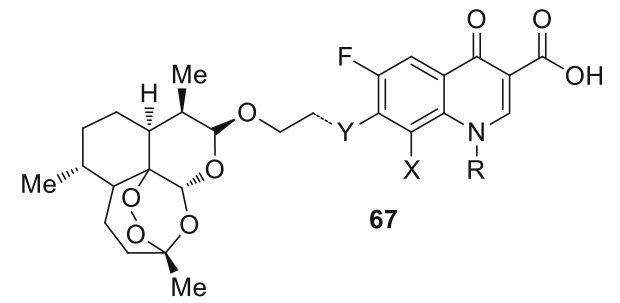

Fig. 18 Structures of dihydroartemisinin-fluoroquinolone conjugates 65-67

\section{Scheme 34}



68a: $R^{1}=H ; R^{2}=M e ; R^{3}=O H ; R^{4}=H ; R^{5}=E t ; R^{6}=H ; R^{7}=H$

68b: $R^{1}=H ; R^{2}=M e ; R^{3}=O H ; R^{4}=H ; R^{5}=E t ; R^{6}=F ; R^{7}=M e$

68c: $R^{1}=H ; R^{2}=M e ; R^{3}=O H ; R^{4}=H ; R^{5}=$ cyclopropyl; $R^{6}=H ; R^{7}=H$

68d: $R^{1}=H ; R^{2}=$ Me; $R^{3}=O H ; R^{4}=H ; R^{5}=$ cyclopropyl; $R^{6}=O M e ; R^{7}=M e$

68e: $R^{1}=H ; R^{2}=M e ; R^{3}=O H ; R^{4}=O H ; R^{5}=E t ; R^{6}=H ; R^{7}=H$

68f: $R^{1}=H ; R^{2}=\mathrm{Me} ; R^{3}=\mathrm{OH} ; R^{4}=\mathrm{OH} ; R^{5}=\mathrm{Et} ; R^{6}=\mathrm{F} ; R^{7}=\mathrm{Me}$

68g: $R^{1}=H ; R^{2}=M e ; R^{3}=O H ; R^{4}=O H ; R^{5}=$ cyclopropyl; $R^{6}=H ; R^{7}=H$

68h: $R^{1}=H ; R^{2}=M e ; R^{3}=O H ; R^{4}=O H ; R^{5}=$ cyclopropyl; $R^{6}=O M e ; R^{7}=M e$

68i: $R^{1}=\mathrm{N}(\mathrm{Me})_{2} ; \mathrm{R}^{2}=\mathrm{H} ; \mathrm{R}^{3}=\mathrm{H} ; \mathrm{R}^{4}=\mathrm{H} ; \mathrm{R}^{5}=\mathrm{Et} ; \mathrm{R}^{6}=\mathrm{H} ; \mathrm{R}^{7}=\mathrm{H}$

68j: $R^{1}=\mathrm{N}(\mathrm{Me})_{2} ; \mathrm{R}^{2}=\mathrm{H} ; \mathrm{R}^{3}=\mathrm{H} ; \mathrm{R}^{4}=\mathrm{H} ; \mathrm{R}^{5}=\mathrm{Et} ; \mathrm{R}^{6}=\mathrm{F} ; \mathrm{R}^{7}=\mathrm{Me}$

68k: $R^{1}=N(M e)_{2} ; R^{2}=H ; R^{3}=H ; R^{4}=H ; R^{5}=$ cyclopropyl; $R^{6}=H ; R^{7}=H$

68I: $R^{1}=N(M e)_{2} ; R^{2}=H ; R^{3}=H ; R^{4}=H ; R^{5}=$ cyclopropyl; $R^{6}=F ; R^{7}=M e$

\section{Scheme 35}<smiles>[R]c1cc2c(=O)c(C(=O)[O-])c[nH]c2c([R1])c1[R]</smiles><smiles>COC(=O)OCCCCCCO</smiles>

a: $R^{1}=F ; R^{2}=H ; R^{3}=F$

b: $\mathrm{R}^{1}=\mathrm{H} ; \mathrm{R}^{2}=\mathrm{H} ; \mathrm{R}^{3}=\mathrm{Me}$

c: $\mathrm{R}^{1}=\mathrm{H} ; \mathrm{R}^{2}=\mathrm{H} ; \mathrm{R}^{3}=\mathrm{F}$

d: $\mathrm{R}^{1}=\mathrm{H} ; \mathrm{R}^{2}=\mathrm{CF}_{3} ; \mathrm{R}^{3}=\mathrm{H}$

e: $\mathrm{R}^{1}=\mathrm{H} ; \mathrm{R}^{2}=\mathrm{Cl} ; \mathrm{R}^{3}=\mathrm{F}$

f: $R^{1}=\mathrm{Cl} ; \mathrm{R}^{2}=\mathrm{H} ; \mathrm{R}^{3}=\mathrm{Cl}$

g: $R^{1}=F ; R^{2}=H ; R^{3}=H$

h: $R^{1}=H ; R^{2}=H ; R^{3}=O M e$<smiles>[R]c1cc2c(=O)c(C(=O)OCC)cn(CC3CO3)c2c([R])c1[R]</smiles>

1. $\mathrm{O}_{2} \mathrm{~N}-\mathrm{N}_{\mathrm{N}}^{\mathrm{NH}}$

$\mathrm{K}_{2} \mathrm{CO}_{3}, \mathrm{EtOH}, \Delta, 2 \mathrm{~h}$

2. $3 \% \mathrm{NaOH}, 100^{\circ} \mathrm{C}$

1.<smiles>Cc1ncc([N+](=O)[O-])[nH]1</smiles>

$\mathrm{K}_{2} \mathrm{CO}_{3}, \mathrm{EtOH}, \Delta, 2 \mathrm{~h}$

2. $3 \% \mathrm{NaOH}, 100^{\circ} \mathrm{C}$<smiles>[R]c1cc2c(=O)c(C(=O)O)cn(CC(O)Cn3cnc([N+](=O)[O-])c3)c2c([R])c1[R]</smiles><smiles>[R]c1cc2c(=O)c(C(=O)O)cn(CC(O)Cn3c([N+](=O)[O-])cnc3C)c2c([R])c1[R]</smiles> 
fungi. $\mathrm{Gu}$ and coworkers designed miconazole-based ciprofloxacin conjugates 71. Antibacterial and antifungal activities of the newly prepared compounds were evaluated in vitro against Gram-positive (M. luteus, B. subtilis, and 2 strains $S$. aureus), Gram-negative ( $P$. aeruginosa, E. coli, and $P$. vulgaris) as well as fungi (C. albicans, C. mycoderma, C. utilis, and $S$. cerevisiae $)$. Compound $71\left(\mathrm{R}^{1}=\mathrm{F}\right.$, $\mathrm{R}^{2}=\mathrm{H}, \mathrm{R}^{3}=\mathrm{F}$ ) was found to be comparable or more potent than ciprofloxacin and miconazole in antibacterial and antifungal assays, respectively [154] (Fig. 19).

Fluconazole belongs to triazole antibiotics recommended by WHO as the first-line antifungal drug. Wang and coworkers prepared conjugates of clinafloxacin with fluconazole-like substituents $\mathbf{7 2}$ in a reaction of fluoroquinolone with the corresponding oxiranes (Scheme 36). The obtained hybrids were tested against a panel of Gram-positive and Gram-negative bacteria as well as fungi. In general, the novel conjugates exhibited good anti-microbial efficacies with MIC values of $0.5-32 \mu \mathrm{g} / \mathrm{cm}^{3}$. The modification not only effectively increased their biological activities and broadened their spectrum of action in comparison with the precursor clinafloxacin and fluconazole, but also improved their physiochemical properties and water solubility [155].

\section{Bis-quinolones}

Fluoroquinolones were also used as homodimeric and heterodimeric antibiotic agents. Panda and coworkers synthesized novel quinolone-fluoroquinolone conjugates

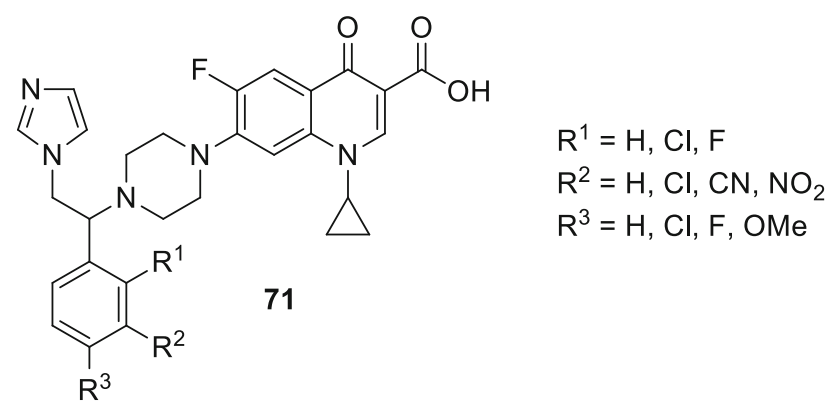

Fig. 19 Structures of miconazole-based ciprofloxacin conjugates $\mathbf{7 1}$ with amino-acid linkers 73-76 by means of benzotriazole chemistry in good yields (60-82\%) (Scheme 37). The obtained conjugates exhibited weak antibacterial activity against $S$. aureus, $S$. pyogenes, $S$. typhi, and $P$. aeruginosa, in most cases comparable with the parent drugs. However, the highly active compounds $\mathbf{7 3 b}$ and $\mathbf{7 3 f}$ were found to be much more potent than the parent fluoroquinolones against S. pyogenes and $S$. aureus, respectively [156].

Ross and coworkers designed amine- $(\mathbf{7 7}, \mathbf{7 8})$, peptoidal- (79), PEG- $(\mathbf{8 0}, \mathbf{8 1})$, or aryl-linked (82-84) ciprofloxacin dimers. The dimers were tested for biochemical inhibition of $E$. coli DNA gyrase; however, only for the compound $84\left(\mathrm{R}^{1}=\mathrm{H}\right)$ the inhibition activity was not suppressed. All the conjugates exhibited MIC values above or comparable to the parent monomer in assays performed against E. coli, P. aeruginosa, and S. aureus. However, efflux-deficient mutant JW5503-1 was substantially more susceptible to all compounds, which indicate that the dimers remained efflux pump substrates [157] (Fig. 20).

Azema and coworkers designed C7/C7-linked ciprofloxacin (85, 86) and C6/C6-linked levofloxacin (87) dimers. The conjugates of ciprofloxacin were synthesized via direct acylation of fluoroquinolone drug with carboxylic di-acids activated by $\mathrm{EDCl}$ and 1-hydroxybenzotriazole in DMF/dichloromethane mixture or in condensation of carboxylic di-acids with ciprofloxacin derivative in yields ranging from 31 to $70 \%$ (Scheme 38). Levofloxacin hybrids were obtained in the procedure involving an in situ-generated acyl chlorides, which were subsequently reacted with diamines. All the conjugates were evaluated for their in vitro inhibition of human cancer cells (pro-apoptotic stimuli U373-MG glioblastoma and A549 NSCLC as well as apoptosis-sensitive the PC-3 prostate, the LoVo colon and the MCF-7 breast carcinoma cell lines) in MTT assays. Compounds $85(n=14), 86$ ( $n=14)$, and $87(n=9)$ were found to be the most potent ( $\mathrm{IC}_{50}$ values below $10 \mu \mathrm{M}$ ). The anti-proliferative activity increased with the alkyl linker length; however, loss of activity was observed in compounds exhibiting poor solubility (conjugates with long linker chains tended to precipitate). Anti-microbial activity of the hybrids was tested against S. aureus, Enterococcus hirae, E. coli, P.

Scheme 36<smiles>NC1CCN(c2c(F)cc3c(=O)c(C(=O)O)cn(C4CC4)c3c2Cl)C1</smiles>

1. $\mathrm{NaHCO}_{3}, \mathrm{EtOH}, 70^{\circ} \mathrm{C}$

2. $\mathrm{HCOOH}, \mathrm{rt}$<smiles>[R]c1ccc(C(O)(CNC2CCN(c3c(F)cc4c(=O)c(C(=O)O)cn(C5CC5)c4c3Cl)C2)Cn2cncn2)c([R])c1[R]</smiles>

$\mathrm{R}^{1}=\mathrm{H}, \mathrm{F}, \mathrm{C}$ $\mathrm{R}^{2}=\mathrm{H}, \mathrm{F}, \mathrm{Cl}$ $\mathrm{R}^{3}=\mathrm{H}, \mathrm{Me}, \mathrm{F}, \mathrm{Cl}$ 
Scheme 37<smiles>[R]CN1CCN(c2cc3c(cc2F)c(=O)c(C(=O)O)cn3[R1])CC1</smiles>

aeruginosa, and $M$. tuberculosis. The conjugates of ciprofloxacin showed moderate-to-weak activity against bacterial and mycobacterial strains, lower than that found for the parent monomer. Only compound $87(n=4)$, proved to be more active against $S$. aureus strains than ciprofloxacin [158].

$\mathrm{C} 3 / \mathrm{C} 3$ heteroconjugates of fluoroquinolones crosslinked with $[1,2,4]$ triazolo[3,4- $b][1,3,4]$ thiadiazole 88, 89 were prepared by $\mathrm{Hu}$ and coworkers. The conjugates were synthesized with use of ciprofloxacin or its $N$-methyl and $N$-ethyl derivatives obtained through cyclocondensation of fluoroquinolone drug with carbon disulfide followed by base-catalyzed conversion into the 4 -amino- $4 \mathrm{H}$-1,2,4-triazole-3-thiols (Scheme 39). Coupling of the intermediate with other fluoroquinolones (ciprofloxacin, enrofloxacin, norfloxacin, ofloxacin, and levofloxacin) was performed with use of $\mathrm{POCl}_{3}$ (Scheme 39). The bis-fluoroquinolones were subjected to antitumor activity tests against murine leukemia (L1210), human leukocytoma (HL60) and Chinese hamster ovary ( $\mathrm{CHO}$ ) cell lines with the use of the MTT assay. The determined $\mathrm{IC}_{50}$ values were in the range 0.12-26.2 $\mu \mathrm{M}$. The ciprofloxacin-ciprofloxacin conjugate $88\left(\mathrm{R}^{1}=\mathrm{R}^{3}=\mathrm{H}, \mathrm{R}^{2}=\right.$ cyclopropyl $)$ and ciprofloxacinlevofloxacin $89\left(S-(-)-\mathrm{R}^{1}=\mathrm{H}\right)$ showed the highest antitumor activity against $\mathrm{HL} 60$ cell line $\left(\mathrm{IC}_{50}\right.$ values of 0.54 and 0.12 , respectively) [159].

\section{Other modifications}

Conjugation of fluoroquinolone with isatin had been proposed to improve the drug lipophilicity in treatment of Mycobacteria [160-164]. 8-Methoxyciprofloxacin was modified with methylene and ethylene derivatives of isatin bearing oxime, methyloxime, ethyloxime, semicarbazone, and thiosemicarbazone moieties (Scheme 40). The methylene conjugates 90 were obtained by Mannich reactions of substituted isatine, paraformaldehyde and 8-methoxy ciprofloxacin in refluxing alcohol under an argon atmosphere, while ethylene compounds 91 a were synthesized via nucleophilic substitutions in DMF at $40{ }^{\circ} \mathrm{C}$ and subsequent condensations with the corresponding amine hydrochlorides to form Schiff's bases 91b. The conjugates were obtained in moderate-to-high yields (40-85\%). The calculated $\log P$ values were assessed in the range of $1.26-3.33$ vs. 1.20 for the parent drug, which indicated remarkable improvement in the drug lipophilicity. This trend was reproduced for the experimental 
<smiles>[R]CC(=O)NC(=O)NN1CCN([13CH2][13CH2]N([13CH3])CC([R])=O)CC1</smiles>

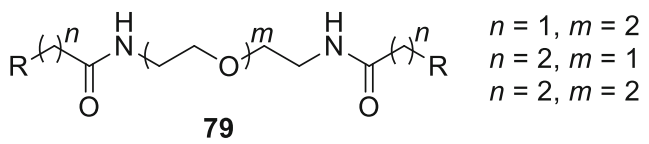<smiles>[R]C(=O)OCCOCCOC([R])=O</smiles><smiles>[R]CCOC(C[R])C[R]</smiles><smiles>[R]=C1CCN(c2cc3c(cc2F)c(=O)c(C(=O)O)cn3C2CC2)CC1</smiles>

80 $n=2,3,5$ or 7

81<smiles>[R]C(=O)[Al]NC(=O)c1cccc(C(=O)NNC(=O)C([R])[R])c1</smiles><smiles>[R]Cc1cccc(C[R])c1</smiles>

83<smiles>[R]C(=O)c1cc([R])cc(C([R])=O)c1</smiles>

Fig. 20 Structures of ciprofloxacin dimers 77-84

Scheme 38

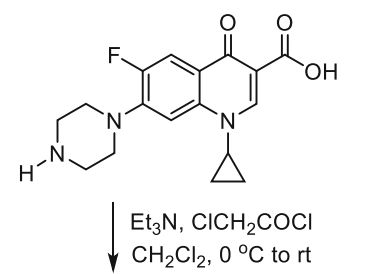<smiles>O=C(O)CC(=O)OCCCCO</smiles><smiles></smiles>

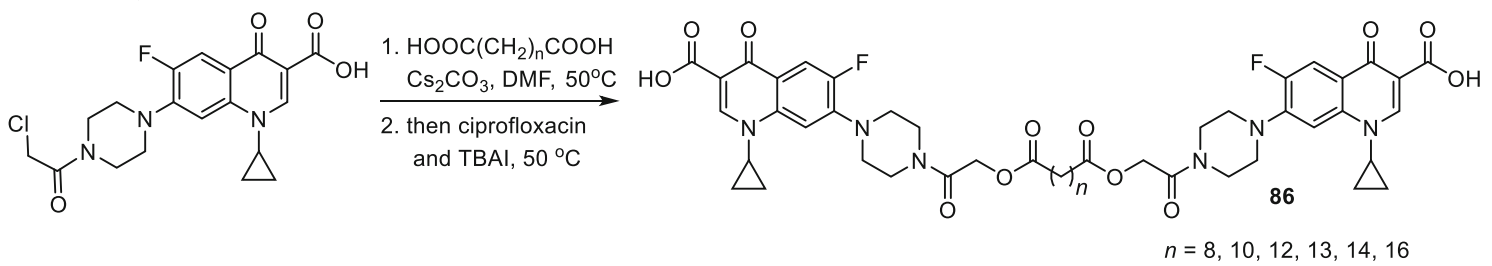



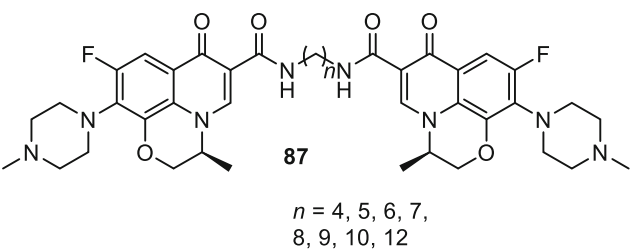

$\log P$ values determined by HPLC technique: $1.08-1.67$ for the conjugates and 0.79 for 8 -methoxyciprofloxacin. The conjugates were tested against M. smegmatis CMCC 93202 using serial double dilution technique in duplicate as well as against M. tuberculosis H37Rv ATCC 27294 and multidrug-resistant clinical isolate $M$. tuberculosis 09710 using a rapid direct susceptibility test technique. Most of the compounds exhibited relatively good activity against $M$. smegmatis strain, but they were less active than the parent quinolone. Nevertheless, in $M$. tuberculosis assays the conjugates were found to be notably more potent than the reference drug. Compound $90\left(\mathrm{R}=\mathrm{F}, \mathrm{R}^{2}=\mathrm{O}\right)$ was found to be highly active against reference $M$. tuberculosis (MIC: $0.074 \mu \mathrm{M})$, while conjugates $90\left(\mathrm{R}=\mathrm{F}, \mathrm{R}^{2}=\mathrm{NOMe}\right.$; $\mathrm{R}=\mathrm{H}, \quad \mathrm{R}^{2}=\mathrm{NNHCONH}_{2} ; \mathrm{R}=\mathrm{F}, \quad \mathrm{R}^{2}=\mathrm{NNHCONH}_{2} ;$ $\mathrm{R}=\mathrm{H}, \mathrm{R}^{2}=\mathrm{NNHCSNH}_{2}$ ) were extremely potent against the multidrug-resistant strain (MIC 6.72-7.05 $\mu \mathrm{M}$ ). Toxicity was examined in mammalian Vero cell line and the 
Scheme 39
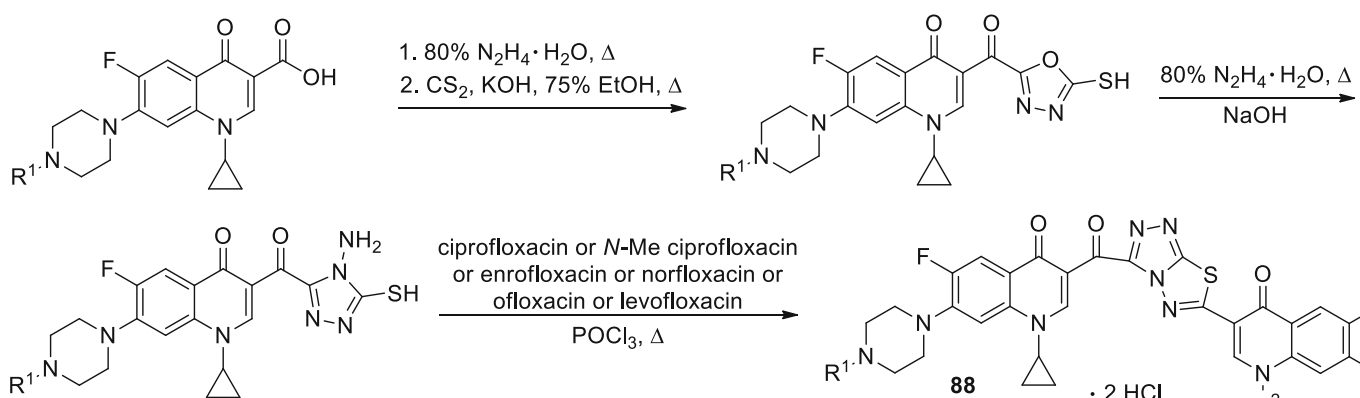

$\mathrm{R}^{1}=\mathrm{H}, \mathrm{Me}, \mathrm{Et}$

$\mathrm{R}^{2}=\mathrm{Et}$, cyclopropyl

$\mathrm{R}^{3}=\mathrm{H}, \mathrm{Me}, \mathrm{Et}$
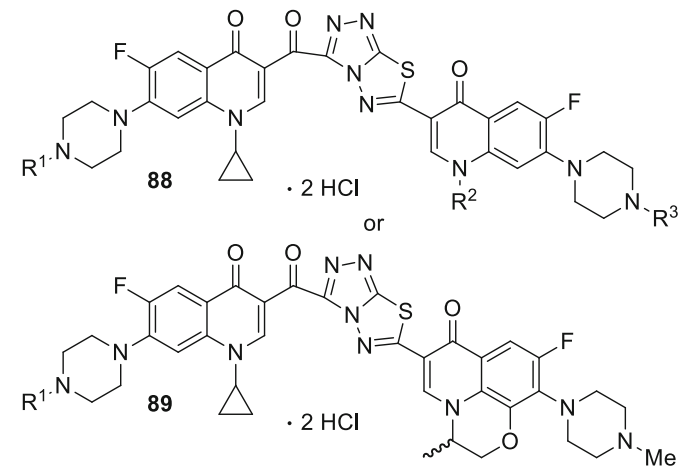

selectivity index for the most active compounds was assessed in the range of 954-1902, which make these compounds attractive potential therapeutic agents [160]. 1,2,3-Triazole-tethered ciprofloxacin-isatin hybrids $\mathbf{9 2 a}$ $\left(\mathrm{R}^{1}=\mathrm{R}^{2}=\mathrm{H}\right)$ were also designed and synthesized by $\mathrm{Cu}-$ promoted azide-alkyne cycloaddition in the presence of $\mathrm{CuI}$ and trimethylamine in acetonitrile/dichloromethane mixture giving rise to the formation of the desired products 92a in $22-35 \%$ yield. The resulted products were transformed into metoxime derivatives 93 via condensation with methoxyamine hydrochloride in the presence of $\mathrm{NaHCO}_{3}$ (32-44\% yield). All hybrids were less active than ciprofloxacin active against $M$. smegmatis (MIC values of conjugates in the range of $12.5-100$ vs. $6.25 \mu \mathrm{g} / \mathrm{cm}^{3}$ for ciprofloxacin) and exhibited comparable activity to the parent drug against $M$. tuberculosis H37Rv (1.56-25 vs. $\left.3.12 \mu \mathrm{g} / \mathrm{cm}^{3}\right)$. Fluorine metoxime derivative $93(\mathrm{R}=\mathrm{F}$, $\mathrm{R}^{1}=\mathrm{R}^{2}=\mathrm{H} ; \mathrm{R}^{3}=\mathrm{OMe}$ ) was twice more potent than the parent drug against M. tuberculosis (MIC $1.56 \mu \mathrm{g} / \mathrm{cm}^{3}$ ); however, this hybrid was found to be much more toxic against Vero cell line $\left(\mathrm{CC}_{50}\right.$ of $\left.4.95 \mu \mathrm{M}\right)$ [161]. In a similar way conjugates of gatifloxacin $92 a, 93\left(\mathrm{R}^{1}=\mathrm{OMe}\right.$, $\mathrm{R}^{2}=\mathrm{Me}$ ), triazole, and isatin were obtained. Cycloadditions were performed in DMF giving the target compounds 92a in 28-39\% yield, while condensations with amine hydrochlorides gave the desired products 93 in $43-67 \%$ yield. All hybrids showed greater lipophilicity compared to gatifloxacin. The conjugates showed divergent antitubercular activity. Fluorine thiosemicarbazone $\left(\mathrm{R}=\mathrm{F}, \mathrm{R}^{1-}\right.$ = OMe; $\left.\quad \mathrm{R}^{2}=\mathrm{Me} ; \quad \mathrm{R}^{3}=\mathrm{NHCSNH}_{2}\right), \quad$ chlorine methyloxime $\left(\mathrm{R}=\mathrm{Cl}, \mathrm{R}^{1}=\mathrm{OMe} ; \mathrm{R}^{2}=\mathrm{Me} ; \mathrm{R}^{3}=\mathrm{OMe}\right)$, and fluorine methyloxime $\left(\mathrm{R}=\mathrm{F}, \mathrm{R}^{1}=\mathrm{OMe} ; \mathrm{R}^{2}=\mathrm{Me}\right.$; $\mathrm{R}^{3}=\mathrm{OMe}$ ) derivatives $\mathbf{9 3}$ were found to be much more active than the parent drug against both $M$. tuberculosis strains, H37Rv and multidrug resistant; although these compounds were much more toxic than free gatifloxacin [162, 163]. Moxifloxacin derivatives $\mathbf{9 2 b}$ were synthesized in the same manner. The hybrids 94 were obtained by means of cycloaddition with $\mathrm{Cu}(\mathrm{OAc})_{2}$ in $\mathrm{DMF}$ followed by condensation reactions with amine hydrochlorides in 46-63\% (92b) and 55-71\% (94) yields, respectively. Most of the obtained compounds were less active against $M$. tuberculosis H37Rv and multidrug-resistant strains. The most active hybrid, fluorine methyloxime conjugate 94 $\left(\mathrm{R}=\mathrm{F}, \mathrm{R}^{4}=\mathrm{OMe}\right)$, was, however, twice more potent than moxifloxacin. Nevertheless, this compound was extremely cytotoxic in Vero cell line. The metabolic stability and in vivo pharmacokinetic profiles of the most active conjugate was tested in mice after single oral administration of $50 \mathrm{mg} / \mathrm{kg}$. The conjugate displayed much lower microsomal stability than the parent drug and inferior pharmacokinetic profile [164].

Figueroa-Valverde and coworkers synthesized dihydroxytestosterone-ciprofloxacin conjugate 95 in the reaction of ethylenediamine with fluoroquinolone to form an amide and subsequent coupling to dihydroxytestosterone hemisuccinate with $\mathrm{EDCl}$ to form the novel hybrid (Scheme 41). Since steroid derivatives may induce antibacterial effect [165] and cause membrane perturbation, the obtained conjugate was tested against $E$. coli and $S$. aureus bacterial strains. The novel hybrid 95 was found to be active against both pathogenic strains, but to the lesser extent than the parent drug ciprofloxacin [166].

Fluoroquinolones possessing coumarin moiety 96 were synthesized by Guo and coworkers by nucleophilic substitution reaction of ciprofloxacin, 8-methoxyciprofloxacin 


\section{Scheme 40}
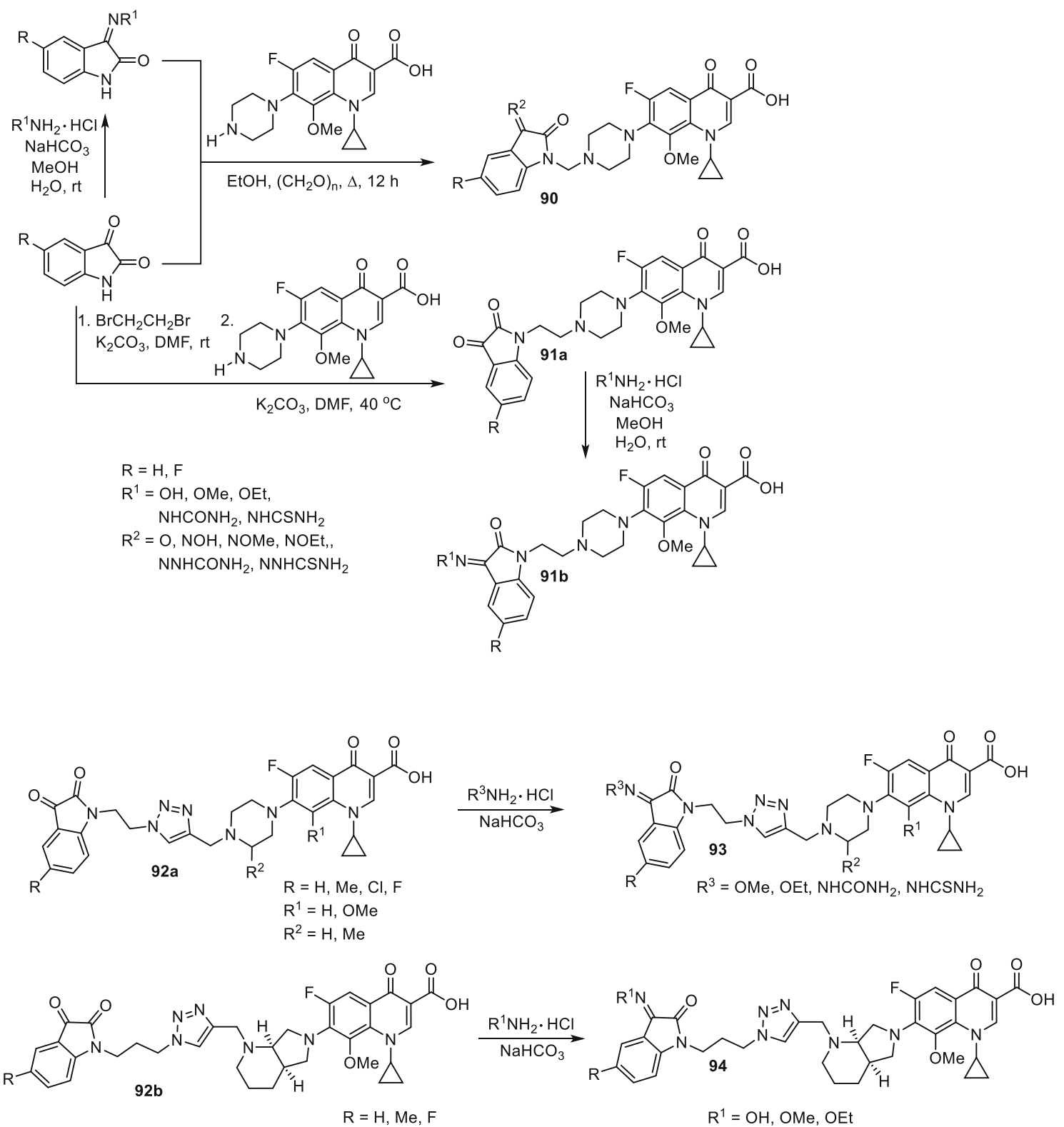

or gatifloxacin with $\alpha$-bromoketones or $\alpha$-bromooximes (Scheme 42). The conjugates were tested in vitro for their antimycobacterial properties against $M$. smegmatis $\mathrm{CMCC}$ 93202 using serial double dilution technique in duplicate and M. tuberculosis H37Rv ATCC 27294 with the use of rapid direct susceptibility tests. The most active compounds were 96b and 96n [167].

Flavonoids constitute a class of phenolic compounds widely found in herbs, seeds, fruits, and vegetables. Some of them, namely, naringenin [168], quercetin, kaempferol [169], chrysin [170], and genistein [171], were identified as effective inhibitors of multidrug transporters. Xiao and coworkers designed and obtained 21 fluoroquinolone-flavonoid hybrids as potential efflux pumps inhibitors by direct coupling of ciprofloxacin, sarafloxacin, norfloxacin, enrofloxacin, or lomefloxacin with naringenin, apigenin, genistin, chrysin, or formononetin with use of ethylene linker. The conjugates were tested against $S$. aureus, B. subtilis, E. coli, and C. albicans. Hybrids incorporating naringenin 97 were found to be the most active. Whole cells accumulation revealed that introduction of naringenin to the fluoroquinolone structure prevents of the hybrid from 


\section{Scheme 41}<smiles>O=C(O)c1cn(C2CC2)c2cc(N3CCNCC3)c(F)cc2c1=O</smiles>

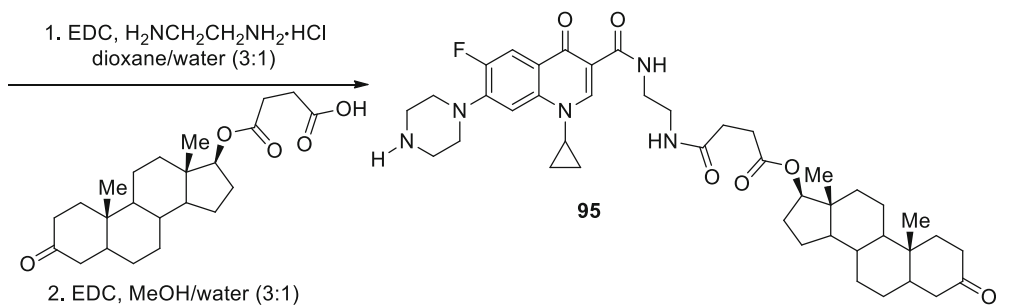

Scheme 42

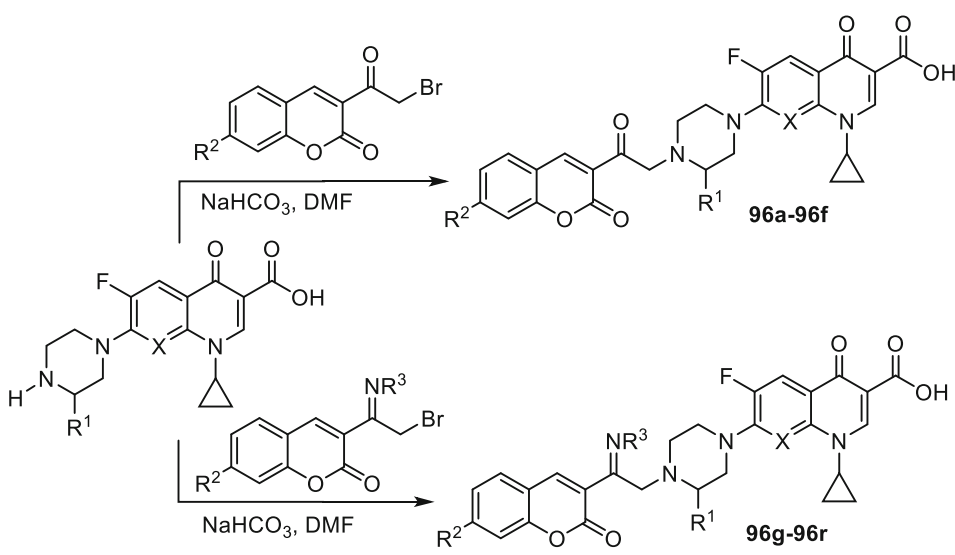

96a: $\mathrm{R}^{1}=\mathrm{H} ; \mathrm{R}^{2}=\mathrm{H} ; \mathrm{X}=\mathrm{C}-\mathrm{OMe}$

96b: $R^{1}=H ; R^{2}=O M e ; X=C-O M e$

96c: $R^{1}=H ; R^{2}=O H ; X=C-O M e$

96d: $R^{1}=\mathrm{Me} ; \mathrm{R}^{2}=\mathrm{OMe} ; \mathrm{X}=\mathrm{C}-\mathrm{OMe}$

96e: $R^{1}=\mathrm{H} ; \mathrm{R}^{2}=\mathrm{OMe} ; \mathrm{X}=\mathrm{CH}$

96f: $R^{1}=H ; R^{2}=O H ; X=C H$

96g: $\mathrm{R}^{1}=\mathrm{H} ; \mathrm{R}^{2}=\mathrm{H} ; \mathrm{R}^{3}=\mathrm{OMe} ; \mathrm{X}=\mathrm{C}-\mathrm{OMe}$

96h: $R^{1}=H ; R^{2}=H ; R^{3}=$ OEt; $X=C-O M e$

96i: $R^{1}=H ; R^{2}=O M e ; R^{3}=$ OMe; $X=C-O M e$

96j: $\mathrm{R}^{1}=\mathrm{H} ; \mathrm{R}^{2}=\mathrm{OMe} ; \mathrm{R}^{3}=\mathrm{OEt} ; \mathrm{X}=\mathrm{C}-\mathrm{OMe}$

96k: $R^{1}=\mathrm{Me} ; \mathrm{R}^{2}=\mathrm{H} ; \mathrm{R}^{3}=\mathrm{OMe} ; \mathrm{X}=\mathrm{C}-\mathrm{OMe}$

96I: $\mathrm{R}^{1}=\mathrm{Me} ; \mathrm{R}^{2}=\mathrm{H} ; \mathrm{R}^{3}=\mathrm{OEt} ; \mathrm{X}=\mathrm{C}$-OMe

$96 \mathrm{~m}: R^{1}=M e ; R^{2}=O M e ; R^{3}=O M e ; X=C-O M e$

96n: $R^{1}=$ Me; $R^{2}=$ OMe; $R^{3}=$ OEt; $X=C-O M e$

960: $R^{1}=H ; R^{2}=H ; R^{3}=O M e ; X=C H$

96p: $\mathrm{R}^{1}=\mathrm{H} ; \mathrm{R}^{2}=\mathrm{H} ; \mathrm{R}^{3}=\mathrm{OEt} ; \mathrm{X}=\mathrm{CH}$

96q: $R^{1}=H ; R^{2}=O M e ; R^{3}=O M e ; X=C H$

96r: $\mathrm{R}^{1}=\mathrm{H} ; \mathrm{R}^{2}=\mathrm{OMe} ; \mathrm{R}^{3}=\mathrm{OEt} ; \mathrm{X}=\mathrm{CH}$

being the substrate for the efflux pumps. Ciprofloxacin $\left(\mathrm{R}^{1}=\right.$ cyclopropyl, $\left.\mathrm{X}=\mathrm{CH}\right)$ and sarafloxacin $\left(\mathrm{R}^{1}=4 \mathrm{~F}\right.$ $\mathrm{C}_{6} \mathrm{H}_{4}, \quad \mathrm{X}=\mathrm{CH}$ ) hybrids of naringenin (97) exhibited greater inhibitory activities than reference ciprofloxacin against the DNA gyrase in DNA supercoiling assay, confirming their strong fluoroquinolone character [172] (Fig. 21).

DNA polymerase III $\mathrm{C}$ is an enzyme essential for bacterial DNA replication. It features an active site of a unique structure that can be selectively inhibited with anilinouracil-type dGTP analogs [173]. Recently a novel hybrid bearing fluoroquinolone and anilinouracil moieties, 251D (99), was prepared and evaluated biologically. 251D was found to be a highly selective potent inhibitor of DNA polymerase III C with little or no effect on Gram-positive and Gram-negative DNA polymerase III E as well as the mammalian polymerases $\alpha$ and $\gamma$. The inhibition effects for both topoisomerase and gyrase were lower than those of the parent fluoroquinolone and ciprofloxacin, but greater than nalidixic acid. This conjugate exhibited potent antibacterial and bactericidal activity against broad range of Gram-positive organisms. It also displayed rapid bactericidality within $2 \mathrm{~h}$ for $S$. aureus strains. Moreover, $251 \mathrm{D}$ exhibited more potency than an equimolar combination of the parent compounds, which indicates that fusion of anilinouracil and fluoroquinolone components into one molecule creates a synergistic effect, which is absent without the covalent linkage. The frequency of resistance development to this hybrid was lower than of the anilinouracil inhibitor and lower or similar to the patent fluoroquinolone after a single passage. Further tests revealed low toxicity on MRC-5 cell line (CC50 not less than $80 \mu \mathrm{g} / \mathrm{cm}^{3}$ ) [174] (Fig. 22).

3-Arylfuran-2(5H)-ones act as inhibitors of tyrosynyl tRNA synthetase (TyrRS), another bacterial enzyme [175] essential for bacterial protein synthesis. This enzyme is one of the aminoacyl-tRNA synthetases which ligates specific amino acids to their cognate tRNA molecules [176]. Wang and coworkers designed and synthesized 27 structures of 3-arylfuran-2(5H)-ones $\mathbf{1 0 0}$ merged with piperazinyl ring of fluoroquinolones. The hybrids were tested against E. coli, B. subtilis, and S. aureus, most of them were found to be more active than the reference drug, ciprofloxacin. The most potent compound $100\left(\mathrm{R}^{1}=\right.$ cyclopropyl, $\mathrm{R}^{2-}$ $=\mathrm{R}^{3}=\mathrm{H}, \mathrm{R}^{4}=\mathrm{F}, \mathrm{X}=\mathrm{CH}$ ) showed MIC values in the range of $0.09-0.19 \mu \mathrm{g} / \mathrm{cm}^{3}$. The inhibitory activities were measured against both possible target enzymes DNA gyrase and TyrRS to determine the possibility of a dual mode 

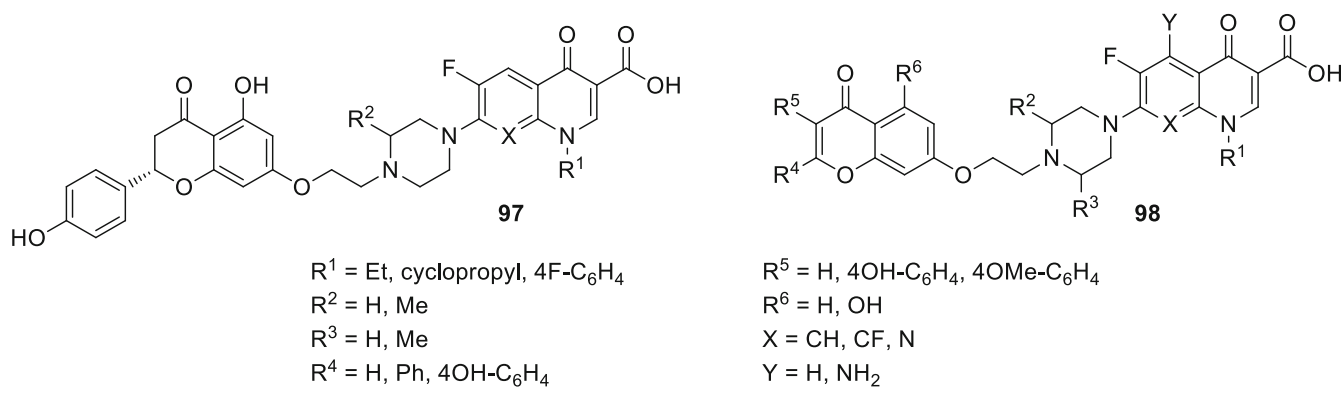

Fig. 21 Structures of flavonoid-fluoroquinolone hybrids $\mathbf{9 7 - 9 8}$<smiles>CCc1cc(Nc2cc(=O)n(CCCCN3CCN(c4c(F)cc5c(=O)c(C(=O)O)cn(C6CC6)c5c4F)CC3C)c(=O)[nH]2)ccc1C</smiles>

Fig. 22 Structure of fluoroquinolone and anilinouracil hybrid 99 (251D)

of action. The selected hybrids displayed similar or better effects against DNA gyrase than ciprofloxacin and significant inhibition effects against TyrRS. The best compound $100\left(\mathrm{R}^{1}=\right.$ cyclopropyl, $\left.\mathrm{R}^{2}=\mathrm{R}^{3}=\mathrm{H}, \mathrm{R}^{4}=\mathrm{F}, \mathrm{X}=\mathrm{CH}\right)$ was selected for docking studies at the active sites of TyrRS and DNA gyrase. In both cases it was proved to be tightly held in the binding pockets by several hydrogenbonding interactions and hydrophobic contacts [177] (Fig. 23).

Chalcones had been reported to inhibit cancer cell proliferation and induce apoptosis in various cell types [178]. Abdel-Aziz and coworkers prepared $N$-4-piperazinyl linked fluoroquinolone-chalcone hybrids $\mathbf{1 0 1}$ as potential cytotoxic agents in cancer therapy. They obtained novel conjugates by alkylation of ciprofloxacin with acylated chalcones in acetonitrile using trimethylamine as a base. The partition coefficient values for all the obtained hybrids were above the parent ciprofloxacin which may affect the cell permeability $\left(\log P_{\exp }\right.$ from -0.0812 to 1.4684 vs. - 0.1432). Most of the obtained conjugates showed significant topoisomerase I and II inhibitory activity. Compounds 101a, 101d, 101e, 101g, 101j were selected for in vitro anticancer screening performed by the National Cancer Institute against 60 cell lines from 9 tumor subpanels, including leukemia, melanoma, lung, colon, CNS, ovarian, renal, prostate, and breast cell lines. Hybrid 101a exhibited the highest broad-spectrum antitumor activity, while $\mathbf{1 0 1 g}$ revealed selectivity towards the leukemia subpanel [179] (Fig. 24).

Vavrikova and coworkers prepared ciprofloxacin and norfloxacin conjugates of fluorine-containing hydrazones 102. Substituted carbohydrazones are known for their good antitubercular activity [180]. Therefore, fluoroquinolone molecules bearing $N$-nucleophile moiety were combined with ethyl benzoylhydrazonoformates to afford the desired conjugated products (Scheme 43). The later were tested on mycobacterial strains. MIC values of ciprofloxacin conjugates were lower than both parent drugs. One of ciprofloxacin hybrids $\mathbf{1 0 2}$ bearing 4-fluorophenyl aryl substituent $\left(\mathrm{R}=\right.$ cyclopropyl, $\left.\mathrm{Ar}=4 \mathrm{~F}-\mathrm{C}_{6} \mathrm{H}_{4}\right)$ was subjected to stability test in aqueous buffers and rat plasma. The hybrid was stable at $\mathrm{pH} 7.4$ and in an acidic buffer; however, in rat plasma slow decomposition was observed. Cytotoxicity of the obtained compounds was evaluated against human hepatocellular carcinoma cells (HepG2), peripheral blood mononuclear cells (PBMC), and human neuroblastoma cells SH-SY5Y. Selectivity index calculated for ciprofloxacin conjugates was extremely high, which make this type of hybrids promising potential antitubercular agents [181].

2-Aminobenzothiazole is one of the privileged structures in medicinal chemistry that demonstrate a myriad spectrum of biological activities such as anti-microbial, anti-inflammatory, analgesic and anti-tumor activity
Fig. 23 Structure of 3-arylfuran-2(5H)-onefluoroquinolone conjugates $\mathbf{1 0 0}$<smiles></smiles>

$$
\begin{aligned}
& \mathrm{X}=\mathrm{CH}, \mathrm{N} \\
& \mathrm{R}^{1}=\mathrm{Et}, \text { cyclopropyl, } \mathrm{C}_{6} \mathrm{H}_{4} \mathrm{~F} \\
& \mathrm{R}^{2}=\mathrm{H}, \mathrm{Cl}, \mathrm{F}, \mathrm{OBn} \\
& \mathrm{R}^{3}=\mathrm{H}, \mathrm{Cl}, \mathrm{Br} \\
& \mathrm{R}^{4}=\mathrm{H}, \mathrm{Me}, \mathrm{Br}, \mathrm{Cl}, \mathrm{F}, \mathrm{OMe}
\end{aligned}
$$




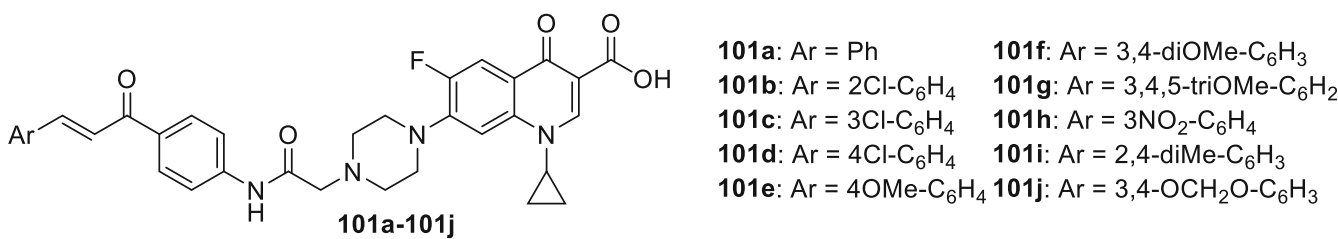

Fig. 24 Structure of fluoroquinolone-chalcone hybrids $\mathbf{1 0 1}$

Scheme 43

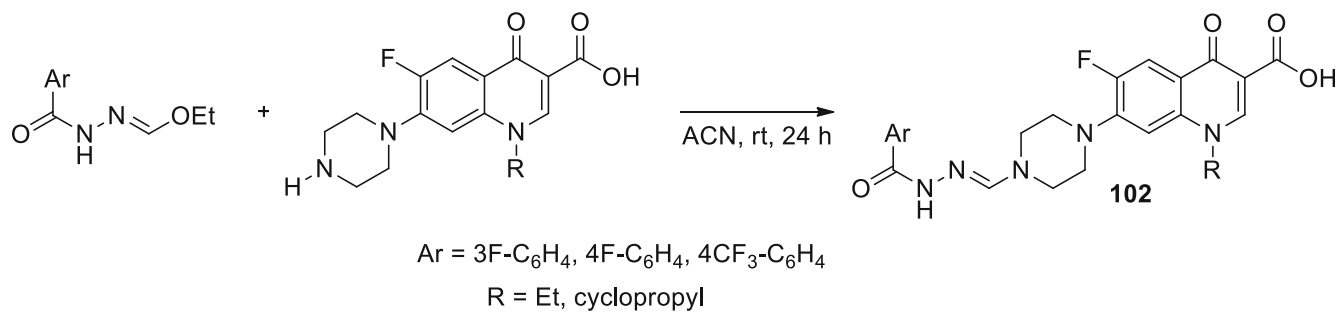

[182-184]. Sharma and coworkers reacted 2-(2chloroacetylamino)-substituted benzothiazoles with ciprofloxacin, gatifloxacin, and norfloxacin, respectively, in DMF with use of sodium bicarbonate as a base (Scheme 44). The conjugates $\mathbf{1 0 3}$ were evaluated for their antibacterial activity by MIC method against $E$. coli, $P$. aeruginosa, B. subtilis, Bacillus polymyxa, and S. aureus. The most potent hybrid was ciprofloxacin conjugate $\mathbf{1 0 3}$ bearing the 6-chlorobenzothiazole substituent $\left(\mathrm{R}^{1}=\mathrm{cy}-\right.$ clopropyl, $\mathrm{R}^{2}=\mathrm{R}^{3}=\mathrm{R}^{4}=\mathrm{R}^{6}=\mathrm{H}, \mathrm{R}^{5}=\mathrm{Cl}$ ). This conjugate exhibited also significant analgesic activity, comparable to the standard drug diclofenac sodium, as tested in Swiss albino mice with the inhibition rates of 55.19 and $67.23 \%$ for the tested compound and the reference drug, respectively. Anthelmintic activity was evaluated against Eisenia foetida. The hybrids $\mathbf{1 0 3}$ showed promising anthelmintic properties at low concentrations as compared to reference drug, piperazine citrate, with mean paralysis time in the range of $22.80-32.60$ vs. $34.4 \mathrm{~min}$ [185].
6-Desfluoroquinolones (6-DFQs) interfere with the Tatmediated transcription (TMT), a step of the HIV replicative cycle that is not targeted by any of the drugs currently in therapy. They are able to interact with the bulge of the HIV-1 TAR RNA element resulting in the Tat-TAR complex formation inhibition [186]. 6-DFQs derivatives 104 bearing benzothiazole or 2-trifluoromethylphenyl substituents were tested for their anti-human immunodeficiency virus (anti-HIV) activity. The novel compounds were found to inhibit HIV-1 replication and transcription in acutely and chronically HIV-1-infected as well as latently infected human primary monocytes/macrophages. The selectivity index for both compounds reached 125 . Compound 104b showed a pronounced suppressive effect on viral reactivation in vivo in SCID mice with no visible signs of drug toxicity [187] (Fig. 25).

Sancineto et al. have reported anti-HIV Designed Multiple Ligands (DMLs) merging the 6-DFQs to reverse transcriptase (RT) inhibitors, with the aim of blocking viral and cellular machineries in two viral cycle events taking

\section{Scheme 44}<smiles>[R]c1c(N2CCNC([R])C2)c(F)cc2c(=O)c(C(=O)O)cn([R])c12</smiles><smiles>[R]c1cc([R])c2nc(NC(=O)CCl)sc2c1[R]</smiles><smiles>[R]c1cc([R])c2nc(NC(=O)CN3CCN(c4c(F)cc5c(=O)c(C(=O)O)cn([R1])c5c4[R])CC3[R])sc2c1[R]</smiles>

$\mathrm{R}^{1}=$ Et, cyclopropyl $\quad \mathrm{R}^{4}=\mathrm{H}, \mathrm{Cl}$

$\mathrm{R}^{2}=\mathrm{H}, \mathrm{OMe}$

$\mathrm{R}^{3}=\mathrm{H}, \mathrm{Me}$

$\mathrm{R}^{5}=\mathrm{H}, \mathrm{Me}, \mathrm{Cl}, \mathrm{F}, \mathrm{NO}_{2}$

$\mathrm{R}^{6}=\mathrm{H}, \mathrm{Me}, \mathrm{Cl}, \mathrm{F}, \mathrm{NO}_{2}$ 
Fig. 25 Structure of desfluoroquinolones 104a, 104b<smiles>Cn1cc(C(=O)O)c(=O)c2ccc(N3CCN(c4cccc(C(F)(F)F)c4)CC3)cc21</smiles><smiles>Cn1cc(C(=O)O)c(=O)c2ccc(N3CCN(c4nc5ccccc5s4)CC3)cc21</smiles>

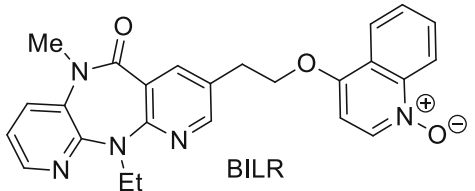

Reverse transcriptase inhibitor<smiles>[R]N1CCN(c2ccc3c(n2)N(CC)c2ncccc2N(C)C3=O)CC1</smiles><smiles>Cn1cc(C(=O)O)c(=O)c2cc(N)c(N3CCN(c4ccccn4)CC3)cc21</smiles><smiles>[R][Y9]c1cc2c(cc1N)c(=O)c(C(=O)O)cn2C</smiles>

Tat-mediated transcription inhibitor

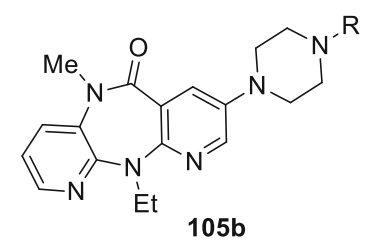<smiles>[R]NCCNc1cnc2c(c1)C(=O)N(C)c1cccnc1N2C</smiles>

Fig. 26 Structures of desfluoroquinolones 105a-105c

place after and before viral integration, respectively. Compounds 105a-105c were able to inhibit the RT, while hybrid 105a showed activity against both targets, TMT and RT. The anti-HIV activity was tested against HIV-1 (IIIB) and HIV-2 (ROD) in acutely infected MT-4 cells, determining their cytotoxicity in parallel. All of the reported compounds were devoid of any antiviral activity. In particular, compound 105a, despite showing inhibitory activity against both the targets, did not show anti-HIV activity in acutely infected cells at concentrations lower than those that were cytotoxic $\left(\mathrm{CC}_{50}=23.5 \mu \mathrm{M}\right)$. However, it proved that 105a is able to selectively inhibit the HIV-1 reactivation from latently infected cells in in latently HIV-1 infected promyelocytic cells (OM-10.1) [188] (Fig. 26).

Pentafluoropyridine derivatives and cyanuric chloride were utilized for the synthesis of new piperazinyl-quinolone derivatives. The reactions were performed in DMF/ water mixture in the presence of potassium carbonate giving rise to the formation of fluoropyridinyl and chloro1,3,5-triazinyl piperazinylquinolone derivatives in good yields (Scheme 45). The synthesized compounds 106-108 were evaluated for their antibacterial activities against Staphylococcus, Enterococcus, Escherichia, Proteus, Shigella, and Klebsiella strains. The hybrids displayed improved antibacterial properties in comparison with ciprofloxacin. Compounds 106a and 108a showed good-toexcellent anti-microbial activity in agar disc diffusion method as well as with the use of broth microdilution technique [189].

Liu and coworkers introduced four-, five-, and sixmembered nitrogen heterocyclic amine moieties to quinolone scaffold by displacement of $\mathrm{C} 7$ halogen atoms of fluoroquinolone derivatives bearing N1 2-fluorocyclopropyl substituent. They synthesized 27 novel fluoroquinolone conjugates. The obtained compounds were evaluated for their in vitro antibacterial activities on panel of Gram-positive and Gram-negative common pathogens. Most the synthesized hybrids exhibited good biological activity. Compounds 109a $(\mathrm{X}=\mathrm{OMe})$ and 109b $(\mathrm{X}=\mathrm{CH})$ were found to be potent antitubercular agents with MIC values for $M$. tuberculosis strains in the range of $0.0625-0.125 \mu \mathrm{g} / \mathrm{cm}^{3}$. In vivo activities of conjugates 109a $(\mathrm{X}=\mathrm{OMe})$ and $\mathbf{1 0 9 b}(\mathrm{X}=\mathrm{N})$ was tested in mice model. The compound 109a was found to be more potent than 109b. However, due to poor solubility both compounds were less active than the parent fluoroquinolone [190] (Fig. 27).

\section{Conclusion}

Quinolones represent an extremely interesting class of synthetic bactericides that can be exploited as precursors and building blocks for the synthesis of a wide range of organic molecules and coordination complexes, active 
Scheme 45<smiles>[R]c1nc([R])nc(Cl)n1</smiles>



Fig. 27 Structure of compounds 109a-109d

pharmaceutical ingredients, and polymers. The huge number of publications which continuously describe novel methods to synthesize and to derivatize quinolones substrates account for their versatility and use in many fields of medicinal chemistry. Most of the methods for the synthesis of quinolone conjugates rely on the catalyzed and uncatalyzed coupling reactions. There are many promising directions in the application of novel quinolone conjugates in fields such as polymer engineering, biomaterials development and the design of novel hybrid bifunctional drugs. It is certain that quinolone modifications will continue to attract the attention of many research groups and that improvements in their biological potency as well as novel transformations of these compounds will be reported in the literature in the near future.

Acknowledgements We are grateful to the National Science Centre, Poland, for financial support (Research Grant 2016/21/N/NZ7/03464).

Open Access This article is distributed under the terms of the Creative Commons Attribution 4.0 International License (http://creative commons.org/licenses/by/4.0/), which permits unrestricted use, distribution, and reproduction in any medium, provided you give appropriate credit to the original author(s) and the source, provide a link to the Creative Commons license, and indicate if changes were made.

\section{References}

1. Lesher GY, Froelich EJ, Gruett MD, Bailey JH, Brundage RP (1962) J Med Chem 5:1063

2. Emmerson AM, Jones AM (2003) J Antimicrob Chemother 51(Suppl S1):13

3. Drlica K (1999) Curr Opin Microbiol 2:504

4. Wohlkonig A, Chan PF, Fosberry AP, Homes P, Huang J, Kranz M, Leydon VR, Miles TJ, Pearson ND, Perera RL, Shillings AJ, Gwynn MN, Bax BD (2010) Nat Struct Mol Biol 17:1152

5. Ma Z, Chu DTW, Cooper CS, Li Q, Fung AKL, Wang S, Shen LL, Flamm RK, Nilius AM, Alder JD, Meulbroek JA, Or YS (1999) J Med Chem 42:4202

6. Aldred KJ, Kerns RJ, Osheroff N (2014) Biochemistry 53:1565

7. Mustaev A, Malik M, Zhao X, Kurepina N, Luan G, Oppegard LM, Hiasa H, Marks KR, Kerns RJ, Berger JM, Drlica K (2014) J Biol Chem 289:12300

8. Malik M, Mustaev A, Schwanz HA, Luan G, Shah N, Oppegard LM, de Souza EC, Hiasa H, Zhao X, Kerns RJ, Drlica K (2016) Nucleic Acids Res 44:3304

9. Pestova E, Millichap JJ, Noskin GA, Peterson LR (2000) J Antimicrob Chemother 45:583

10. Beyer R, Pestova E, Millichap JJ, Noskin GA, Peterson LR (2000) Antimicrob Agents Chemother 44:798

11. Davies TA, Kelly LM, Pankuch GA, Credito KL, Jacobs MR, Applebaum PC (2000) Antimicrob Agents Chemother 44:304

12. Bisi A, Rampa A, Budriesi R, Gobbi S, Belluti F, Ioan P, Valoti E, Chiarini A, Valenti P (2003) Bioorg Med Chem 11:1353

13. Schellenberg D, Abdulla S, Roper C (2006) Curr Mol Med 6:253

14. Sorenson JRJ (1989) Prog Med Chem 26:437 
15. Dendrinou-Samara C, Psomas G, Raptopoulou CP, Kessissoglou CP (2001) J Inorg Biochem 83:7

16. Li L-Z, Zhao C, Xu T, Ji H-W, Yu Y-H, Guo G-Q, Chao H (2005) J Inorg Biochem 99:1076

17. Hernández-Gil J, Perelló L, Ortiz R, Alzuet G, GonzálezÁlvarez M, Liu-González M (2009) Polyhedron 28:138

18. Chalkidou E, Perdih F, Turel I, Kessissoglou D, Psomas G (2012) J Inorg Biochem 113:55

19. Komarnicka UK, Starosta R, Kyzioł A, Jezowska-Bojczuk M (2015) Dalton Trans 44:12688

20. Efthimiadou EK, Katsarou ME, Karaliota A, Psomas G (2008) J Inorg Biochem 102:910

21. Shingnapurkar D, Butcher R, Afrasiabi Z, Sinn E, Ahmed F, Sarkar F, Padhye S (2007) Inorg Chem Commun 10:459

22. Patitungkho S, Adsule S, Dandawate P, Padhye S, Ahmad A, Sarkar FH (2011) Bioorg Med Chem Lett 21:1802

23. Singh R, Jadeja RN, Thounaojam MC, Patel T, Devkar RV, Chakraborty D (2012) Inorg Chem Commun 23:78

24. Alberto R (2010) Top Organomet Chem 32:219

25. Leonidova A, Gasser G (2014) ACS Chem Biol 9:2180

26. Kydonaki TE, Tsoukas E, Mendes F, Hatzidimitriou AG, Paulo A, Papadopoulou LC, Papagiannopoulou D, Psomas G (2016) J Inorg Biochem 160:94

27. Kastner M, Rahm U, Baumann-Wilschke I, Bello A, Stahlmann R (2004) Arch Toxicol 78:61

28. Kratz F (2008) J Control Release 132:171

29. Lee KN, Ye Y, Carr JH, Karem K, D’Souza MJ (2011) J Microencapsul 28:363

30. Marslin G, Revina AM, Khandelwal VKM, Balakumar K, Sheeba CJ, Franklin G (2015) Colloids Surf B 132:62

31. Froehlich E, Mandeville JS, Weinert CM, Kreplak L, TajmirRiahi HA (2011) Biomacromolecules 12:511

32. Johnson BM, Charman WN, Porter CJ (2002) AAPS Pharm Sci 4:E40

33. Merisko-Liversidge EM, Liversidge GG (2008) Toxicol Pathol 36:43

34. Mei J, Leung NL, Kwok RT, Lam JW, Tang BZ (2015) Chem Rev 115:11718

35. Xie S, Manuguri S, Proietti G, Romson J, Fu Y, Inge AK, Wu B, Zhang Y, Igne AK, Wu B, Zhang Y, Häll D, Ramström O, Yan M (2017) Proc Natl Acad Sci USA 114:8464

36. Duncan R, Gac-Breton S, Keane R, Musila R, Sat YN, Satchi R, Searle F (2001) J Control Release 74:135

37. Spellberg B, Powers JH, Brass EP, Miller LG, Edwards JE (2004) Clin Infect Dis 38:1279

38. Schierholz JM, Steinhauser H, Rump AFE, Berkels R, Pulverer G (1997) Biomaterials 18:839

39. Gomez-Guillen MC, Gimenez B, Lopez-Caballero ME, Montero MP (2011) Food Hydrocoll 25:1813

40. Cirillo G, Mauro MV, Spizzirri UG, Cavalcanti P, Puoci F, Giraldi C, Vittorio O, Picci N, Iemma F (2014) J Mater Sci Mater Med 25:67

41. Krumm C, Konieczny S, Dropalla GJ, Milbradt M, Tiller JC (2013) Macromolecules 46:3234

42. Schmidt M, Harmuth S, Barth ER, Wurm E, Fobbe R, Sickmann A, Krumm C, Tiller JC (2015) Bioconjugate Chem 26:1950

43. Allcock HA, Pucher SR (1994) Macromolecules 27:1071

44. Deng M, Kumbar SG, Wan Y, Toti US, Allcock HA, Laurencin CT (2010) Soft Matter 6:3119

45. Tian Z, Zhang Y, Liu X, Xhen C, Guiltinan MJ, Allcock HR (2013) Polym Chem 4:1826

46. Gabrielska J, Sarapuk J, Przestalski S, Wroclaw P (1994) Tenside Surfactants Deterg 31:296

47. Tashiro $T$ (2001) Macromol Mater Eng 286:63

48. He M, Xiao H, Zhou Y, Lu P (2015) J Mater Chem B 18:3704
49. Sobczak M, Witkowska E, Olędzka E, Kołodziejski W (2008) Molecules 13:96

50. Vandamme TF, Lenourry A, Charrueau C, Chaumeil JC (2002) Carbohydr Polym 48:219

51. Abbas NS, Amin M, Hussain MA, Edgar KJ, Takir MN, Tremel W (2016) Carbohydr Polym 136:1297

52. Amin M, Abbas NS, Hussain MA, Edgar KJ, Takir MN, Tremel W, Sher M (2015) Cellulose 22:2011

53. Kumar BS, Ashok V, Kalyani P, Nair GR (2016) Vet World 9:410

54. Kaatz GW, Mcaleese F, Seo SM (2005) Antimicrob Agents Chemother 49:1857

55. Kaatz GW (2005) Curr Opin Investig Drugs 6:191

56. German N, Wei P, Kaatz GW, Kerns RJ (2008) Eur J Med Chem 43:2453

57. Gräslund A, Madani F, Lindberg S, Langel U, Futaki S (2011) J Biophys 2011:414729

58. Ahmed M, Kelley SO (2017) ACS Chem Biol 12:2563

59. Riahifard N, Tavakoli K, Yamaki J, Parang K, Tiwari R (2017) Molecules 22:957

60. Falciani C, Lozzi L, Scali S, Brunetti J, Bracci L, Pini A (2014) Amino Acids 46:1403

61. Ceccherini F, Falciani C, Onori M, Scali S, Pollini S, Rossolini GM, Bracci L, Pini A (2016) MedChemComm 7:258

62. Rodriguez CA, Papanastasiou EA, Juba M, Bishop B (2014) Front Chem 2:71

63. Purkayastha N, Capone S, Beck AK, Seebach D, Leeds J, Thompson K, Moser HE (2015) Chem Biodivers 12:179

64. Barraud N, Storey MV, Moore ZP, Webb JS, Rice SA, Kjelleberg S (2009) Microb Biotechnol 2:370

65. Arora DP, Hossain S, Xu Y (2015) Biochemistry 54:3717

66. Cerecetto H, Porcal W (2005) Mini Rev Med Chem 5:57

67. Chugunova E, Akylbekov N, Bulatova A, Gavrilov N, Voloshina A, Kulik N, Zobov V, Dobrynin A, Syakaev V, Burilov A (2016) Eur J Med Chem 116:165

68. Verderosa AD, Mansour SC, de la Fuebte-Nunez C, Hancock REW, Fairfull-Smith KE (2016) Molecules 21:841

69. Verderosa AD, de la Fuebte-Nunez C, Mansour SC, Cao J, Lu TK, Hancock REW, Fairfull-Smith KE (2017) Eur J Med Chem 138:590

70. Long TE, Keding L, Lewis DD, Anstead MI, Withers TR (2016) Bioorg Med Chem Lett 26:1305

71. Pattus F, Abdallah MAJ (2000) Chin Chem Soc 47:1

72. Braun V, Pramanik A, Gwinner T, Koeberle M, Bohn EE (2009) Biometals 22:3

73. Budzikiewicz H (2011) Curr Top Med Chem 1:73

74. Gautier-Luneau I, Merle C, Phanon D, Lebrun C, Biaso F, Serratrice G, Pierre JL (2005) Chem Eur J 11:2207

75. Wagegg W, Braun V (1981) J Bacteriol 145:156

76. Md-Saleh SR, Chilvers EC, Kerr KG, Milner SJ, Snelling AM, Weber JP, Thomas GH, Duhme-Klair AK, Routledge A (2009) Bioorg Med Chem Lett 19:1496

77. Milner SJ, Seve A, Snelling AM, Thomas GH, Kerr KG, Routledge A, Routledge A, Duhme-Klair A-K (2013) Org Biomol Chem 11:3461

78. Milner SJ, Snelling AM, Kerr KG, Abd-El-Aziz A, Thomas GH, Hubbard RE, Routledge A, Duhme-Klair A-K (2014) Bioorg Med Chem 22:4499

79. Jacques I, Derelle J, Weber M, Vidailhet M (1998) Eur J Pediatr $157: 427$

80. Rivault F, Liébert C, Burger A, Hoegy F, Abdallah MA, Schalk IJ, Mislin GLA (2007) Bioorg Med Chem Lett 17:640

81. Noël S, Gasser V, Pesset B, Hoegy F, Rognan D, Schalk IJ, Mislin GLA (2011) Org Biomol Chem 9:8288

82. Raymond KN, Dertz EA, Kim SS (2003) Proc Natl Acad Sci USA 100:3584 
83. Zheng T, Bullock JL, Nolan EM (2012) J Am Chem Soc 134: 18388

84. Zheng T, Nolan EM (2015) Bioorg Med Chem Lett 25:4987

85. Fardeau S, Dassonville-Klimpt A, Audic N, Sasaki A, Pillon M, Baudrin E, Mullié C, Sonnet P (2014) Bioorg Med Chem 22:4049

86. Wencewicz TA, Miller MJ (2013) J Med Chem 56:4044

87. Muller G, Raymond KNJ (1984) Bacteriol 160:304

88. Wencewicz TA, Long TE, Möllmann U, Miller MJ (2013) Bioconjugate Chem 24:473

89. Juárez-Hernández RE, Miller PA, Miller MJ (2012) ACS Med Chem Lett 3:799

90. Milstien S, Cohen LA (1972) J Am Chem Soc 94:9158

91. Ji C, Miller MJ (2012) Bioorg Med Chem 20:3828

92. Ji C, Miller MJ (2015) Biometals 28:541

93. Miller MJ, Ji C, Miller PA (2015) ACS Med Chem Lett 6:707

94. Lew DP, Waldvogel FA (2004) Lancet 364:369

95. Mandal S, Berendt AR, Peacock SJ (2002) J Infect 44:143

96. Fleisch H (1967) Ann Med 29:55

97. Uludag H (2002) Curr Pharm Des 8:1929

98. Tanaka KSE, Houghton TJ, Kang T, Dietrich E, Delorme D, Ferreira SS, Caron L, Viens F, Arhin FF, Sarmiento I, Lehoux D, Fadhil I, Laquerre K, Liu J, Ostiguy V, Poirier H, Moeck G, Parr TR Jr, Far AR (2008) Bioorg Med Chem 16:9217

99. Houghton TJ, Tanaka KSE, Kang T, Dietrich E, Lafontaine Y, Delorme D, Ferreira SS, Viens F, Arhin FF, Sarmiento I, Lehoux D, Fadhil I, Laquerre K, Liu J, Ostiguy V, Poirier H, Moeck G, Parr TR Jr, Far AR (2008) J Med Chem 51:6955

100. McPherson JC III, Runner R, Buxton TB, Hartmann JF, Farcasiu D, Bereczki I, Roth E, Tollas S, Ostorházi E, Rozgonyi F, Herczegh P (2012) Eur J Med Chem 47:615

101. Dubar F, Anquetin G, Pradines B, Dive D, Khalife J, Biot C (2009) J Med Chem 52:7954

102. Dubar F, Wintjens R, Martins-Duarte ÉS, Vommaro RC, De Souza W, Dive D, Pierrot C, Pradines B, Wohlkonig A, Khalife J, Biot C (2011) Med Chem Commun 2:430

103. Chu DTW, Fernandes PB (1991) Adv Drug Res 21:41

104. Dhaneshwar S, Tewari K, Joshi S, Godbole D, Ghosh P (2011) Chem Phys Lipids 164:307

105. Velema WA, Szymanski W, Feringa BL (2014) J Am Chem Soc 136:2178

106. Velema WA, Hansen MJ, Lerch MM, Driessen AJM, Szymanski W, Feringa BL (2015) Bioconjugate Chem 26:2592

107. Obata M, Hirohara S, Sharyo K, Alitomo H, Kajiwara K, Ogata S, Tanihara M, Ohtsuki C, Yano S (2007) Biochim Biophys Acta 1770:1204

108. Santos FC, Cunha AC, de Souza MCBV, Tomé AC, Neves MGPMS, Ferreira VF, Cavaleiro JAS (2008) Tetrahedron 49:7268

109. Gomes ATPC, Cunha AC, Domingues MDRM, Neves MGPMS, Tomé AC, Silva AMS, Santos FdC, Souza MCBV, Ferreira VF, Cavaleiro JAS (2011) Tetrahedron 67:7336

110. Batalha PN, Gomes ATPC, Forezi LSM, Costa L, De Souza MCBV, Boechat FDCS, Ferreira VF, Almeida A, Faustino MAF, Neves MGPMS, Cavaleiro JAS (2015) RSC Adv 5:71228

111. Wainwright M (1998) J Antimicrob Chemother 42:13

112. Wainwright M, Shah A, Meegan K, Loughran C, Smith A, Valli N, Dempster N (2010) Int J Antimicrob Agents 35:405

113. Suzuki I, Takahashi M, Takeda K (2011) Heterocycles 83:125

114. Banerjee S, Veale EB, Phelan CM, Murphy SA, Tocci GM, Gillespie LJ, Frimannsson DO, Kelly JM, Gunnlaugsson T (2013) Chem Soc Rev 42:1601

115. Kumar S, Kumar G, Tripathi AK, Seena S, Koh J (2018) J Mol Struct 1157:292

116. Plech T, Wujec M, Siwek A, Kosikowska U, Malm A (2011) Eur J Med Chem 46:241
117. Gonzalez-Calderon D, Mejía-Dionicio MG, Morales-Reza MA, Ramírez-Villalva A, Morales-Rodríguez M, Jauregui-Rodríguez B, Díaz-Torres E, Gonzalez-Romero C, Fuentes-Benítes A (2016) Eur J Med Chem 112:60

118. Basoglu Ozdemir S, Uygun Cebeci Y, Bayrak H, Mermer A, Ceylan S, Demirbas A, Alpay Karaoglu S, Demirbas N (2017) Heterocycl Commun 23:43

119. Dixit SK, Mishra N, Sharma M, Singh S, Agarwal A, Awasthi SK, Bhasin VK (2012) Eur J Med Chem 51:52

120. Faidallah HM, Girgis AS, Tiwari AD, Honkanadavar HH, Thomas SJ, Samir A, Kalmouch A, Alamry KA, Khan KA, Ibrahim TS, AL-Mahmoudy AMM, Asiri AM, Panda SS (2018) Eur J Med Chem 143:1524

121. Plech T, Wujec M, Kosikowska U, Malm A, Rajtar B, PolzDacewicz M (2013) Eur J Med Chem 60:128

122. Plech T, Kapron B, Paneth A, Kosikowska U, Malm A, Strzelczyk A, Staczek P, Swiatek L, Rajtar B, Polz-Dacewicz M (2015) Eur J Med Chem 97:94

123. Plech T, Kaproń B, Paneth A, Kosikowska U, Malm A, Strzelczyk A, Stączek P, Świątek Ł, Rajtar B, Polz-Dacewicz M (2015) Molecules 20:6254

124. Kant R, Singh V, Nath G, Awasthi SK, Agarwal A (2016) Eur J Med Chem 124:218

125. Liau SY, Read DC, Pugh WJ, Furr JR, Russell AD (1997) Lett Appl Microbiol 25:279

126. Zhang L, Kumar KV, Rasheed S, Zhang S-L, Geng R-X, Zhou C-H (2015) MedChemComm 6:1303

127. Acocella G (1983) Rev Infect Dis 5:S428

128. Zheng Z, Stewart PS (2002) Antimicrob Agents Chemother 46:900

129. Robertson GT, Bonventre EJ, Doyle TB, Du Q, Duncan L, Morris TW, Roche ED, Yan D, Lynch AS (2008) Antimicrob Agents Chemother 52:2324

130. Robertson GT, Bonventre EJ, Doyle TB, Du Q, Duncan L, Morris TW, Roche ED, Yan D, Lynch AS (2008) Antimicrob Agents Chemother 52:2313

131. Locher HH, Seiler P, Chen X, Schroeder S, Pfaff P, Enderlin M, Klenk A, Fournier E, Hubschwerlen C, Ritz D, Kelly CP, Keck W (2014) Antimicrob Agents Chemother 58:892

132. Locher HH, Caspers $\mathrm{P}$, Bruyère $\mathrm{T}$, Schroeder $\mathrm{S}$, Pfaff $\mathrm{P}$, Knezevic A, Keck W, Ritz D (2014) Antimicrob Agents Chemother 58:90

133. Chilton CH, Crowther GS, Baines SD, Todhunter SL, Freeman J, Locher HH, Athanasiou A, Wilcox MH (2014) J Antimicrob Chemother 69:697

134. Baldoni D, Gutierrez M, Timmer W, Dingemanse J (2014) J Antimicrob Chemother 69:706

135. Louie T, Nord CE, Talbot GH, Wilcox M, Gerding DN, Buitrago M, Kracker H, Charef P, Cornely OA (2015) Antimicrob Agents Chemother 59:6266

136. Gerding DN, Hecht DW, Louie T, Nord CE, Talbot GH, Cornely OA, Buitrago M, Best E, Sambol S, Osmolski JR, Kracker H, Locker HH, Charef P, Wilcox M (2016) J Antimicrob Chemother 71:213

137. Darehkordi A, Javanmiri M, Ghazi S, Assar S (2011) J Fluorine Chem 132:263

138. Pavlović D, Mutak S (2011) ACS Med Chem Lett 2:331

139. Bulitta JB, Ly NS, Landersdorfer CB, Wanigaratne NA, Velkov T, Yadav R, Oliver A, Martin L, Shin BS, Forrest A, Tsuji BT (2015) Antimicrob Agents Chemother 59:2315

140. Gorityala BK, Guchhait G, Fernando DM, Deo S, McKenna SA, Zhanel GG, Kumar A, Schweizer F (2016) Angew Chem Int Ed 55:555

141. Gorityala BK, Guchhait G, Goswami S, Fernando DM, Kumar A, Zhanel GG, Schweizer F (2016) J Med Chem 59:8441 
142. Pokrovskaya V, Belakhov V, Hainrichson M, Yaron S, Baasov T (2009) J Med Chem 52:2243

143. Panda SS, Bajaj K, Meyers MJ, Sverdrup FM, Katritzky AR (2012) Org Biomol Chem 10:8985

144. Servusová B, Vobicková J, Paterová P, Kubiček V, Kuneš J, Doležal M, Zitko J (2013) Bioorg Med Chem Lett 23:3589

145. Panda SS, Detisov OS, Girgis AS, Mohapatra PP, Samir A, Katritzky AR (2016) Bioorg Med Chem Lett 26:2198

146. Markad SD, Kaur P, Kishore Reddy BK, Chinnapattu M, Raichurkar A, Nandishaiah R, Panda M, Iyer PS (2015) Med Chem Res 24:2986

147. Lai HC, Singh NP, Sasaki T (2013) Investig New Drugs 31:230

148. Zhou F-W, Lei H-S, Fan L, Jiang L, Liu J, Peng X-M, Xu X-R, Chen L, Zhou C-H, Zou Y-Y, Liu C-P, He Z-Q, Yang D-C (2014) Bioorg Med Chem Lett 24:1912

149. Sriram D, Yogeeswari P, Senchani G, Banerjee D (2007) Bioorg Med Chem Lett 17:2372

150. Sutherland HS, Blaser A, Kmentova I, Franzblau SG, Wan B, Wang Y, Ma Z, Palmer BD, Denny WA, Thompson AM (2010) J Med Chem 53:855

151. Tukulula M, Sharma RK, Meurillon M, Mahajan A, Naran K, Warner D, Huang JX, Mekonnen B, Chibale K (2013) ACS Med Chem Lett 4:128

152. Cui S-F, Peng L-P, Zhang H-Z, Rasheed S, Vijaya Kumar K, Zhou C-H (2014) Eur J Med Chem 86:318

153. Henry MJ, Sisler HD (1984) Pestic Biochem Physiol 22:262

154. Gu X-L, Liu H-B, Jia Q-H, Li J-F, Liu Y-L (2015) Monatsh Chem 146:713

155. Wang Y, Damu GLV, Lv J-S, Geng R-X, Yang D-C, Zhou C-H (2012) Bioorg Med Chem Lett 22:5363

156. Panda SS, Liaqat S, Girgis AS, Samir A, Hall CD, Katritzky AR (2016) Bioorg Med Chem Lett 25:3816

157. Ross AG, Benton BM, Chin D, De Pascale G, Fuller J, Leeds JA, Reck F, Richie DL, Vo J, LaMarche MJ (2015) Bioorg Med Chem Lett 25:3468

158. Azéma J, Guidetti B, Korolyov A, Kiss R, Roques C, Constant P, Daffé M, Malet-Martino M (2011) Eur J Med Chem 46:602

159. Hu G-Q, Yang Y, Yi L, Wang G-Q, Duan N-N, Wen X-Y, Cao T-Y, Xie S-Q, Huang W-L (2011) Acta Pharm Sin B 1:172

160. Feng L-S, Liu M-L, Zhang S, Lv K, Guan Y, Guo H-Y, Xiao C-L (2011) Eur J Med Chem 46:341

161. Hu Y-Q, Meng L-D, Qiang M, Song X-F (2017) J Heterocycl Chem 54:3725

162. Xu Z, Zhang S, Song X, Qiang M, Lv Z (2017) Bioorg Med Chem Lett 27:3643

163. Xu Z, Song X-F, Hu Y-Q, Qiang M, Lv Z-S (2017) Eur J Med Chem 138:66

164. Yan X, Lv Z, Wen J, Zhao S, Xu Z (2018) Eur J Med Chem 143:899

165. Figueroa-Valverde L, Díaz-Cedillo F, López-Ramos M, Díaz$\mathrm{Ku}$ E (2009) Asian J Chem 21:6209

166. Figueroa-Valverde L, Díaz-Cedillo F, Camacho-Luis A, López Ramos M, Garcia Cervera E (2010) Monatsh Chem 141:373

167. Guo Q, Liu M-L, Feng L-S, Lv K, Guan Y, Guo H-Y, Xiao C-L (2011) Arch Pharm Chem Life Sci 344:802
168. Wong ILK, Chan K-F, Tsang KH, Lam CY, Zhao Y, Chan TH, Chow LM (2009) J Med Chem 52:5311

169. Han YQ, Cao LJ, Wu J, Hao HJ, Shi YJ, Xu GB, Ren HY (2011) Afr J Biotechnol 10:13399

170. Tran VH, Marks D, Duke RK, Bebawy M, Duke CC, Roufogalis BD (2011) Nutr Cancer 63:435

171. Jaganathan SK (2011) Med Hypotheses 76:535

172. Xiao Z-P, Wang X-D, Wang P-F, Zhou Y, Zhang J-W, Zhang L, Zhou J, Zhou S-S, Hui O, Lin X-Y, Mustapa M, Reyinbaike A, Zhu H-L (2014) Eur J Med Chem 80:92

173. Brown NC, Dudycz LW, Wright GE (1986) Drugs Exp Clin Res 12:555

174. Butler MM, LaMarr WA, Foster KA, Barnes MH, Skow DJ, Lyden PT, Kustigian LM, Zhi C, Brown NC, Wright GE, Bowlin TL (2007) Antimicrob Agents Chemother 51:119

175. Xiao ZP, Ma TW, Liao ML, Feng YT, Peng XC, Li JL, Li ZP, Wu Y, Luo Q, Deng Y, Liang X, Zhu HL (2011) Eur J Med Chem 46:4904

176. Guo M, Yang XL, Schimmel P (2010) Nat Rev Mol Cell Biol 11:668

177. Wang XD, Wei W, Wang PF, Tang YT, Deng RC, Li B, Zhou S-S, Zhang J-W, Zhang L, Xiao Z-P, Ouyang H, Zhu H-L (2014) Bioorg Med Chem 22:3620

178. Shigemura K, Tanaka K, Yamamichi F, Shirakawa T, Miyake H, Fujisawa M (2012) Int J Antimicrob Agents 40:516

179. Abdel-Aziz M, Park S-E, Abuo-Rahma GE-DAA, Sayed MA, Kwon Y (2013) Eur J Med Chem 66:427

180. Eswaran S, Adhikari AV, Pal NK, Chowdhury IH (2010) Bioorg Med Chem Lett 20:1040

181. Vavř́íková E, Polanc S, Kočevar M, Horváti K, Bsze S, Stolaříková J, Vávrová K, Vinšová J (2011) Eur J Med Chem 46:4937

182. Huang S, Collony PJ (2004) Tetrahedron Lett 45:9373

183. Baell JB, Duggan PJ, Forsyth SA, Lewis RJ, Lok YP, Schroeder CI (2004) Bioorg Med Chem 12:4025

184. Sharma PC, Jain A, ShaharYar M, Pahwa R, Singh J, Goel S (2011) Arab J Chem 8:971

185. Sharma PC, Kumar R, Chaudhary M, Sharma A, Rajak H (2013) J Enzyme Inhib Med 28:1

186. Richter S, Parolin C, Gatto B, Del Vecchio C, Brocca-Cofano E, Fravolini A, Palu G, Palumbo M (2004) Antimicrob Agents Chemother 48:1895

187. Stevens M, Pollicita M, Pannecouque C, Verbeken E, Tabarrini O, Cecchetti V, Aquaro S, Perno CF, Fravolini A, De Clercq E, Schols D, Balzarini J (2007) Antimicrob Agents Chemother 51:1407

188. Sancineto L, Iraci N, Barreca ML, Massari S, Manfroni G, Corazza G, Cecchetti V, Marcello A, Daelemans D, Pannecouque C, Tabarrini O (2014) Bioorg Med Chem 22:4658

189. Darehkordi A, Ramezani M, Rahmani F, Ramezani M (2016) J Heterocycl Chem 53:89

190. Liu H, Huang J, Wang J, Wang M, Liu M, Wang B, Guo H, Lu Y (2014) Eur J Med Chem 86:628 